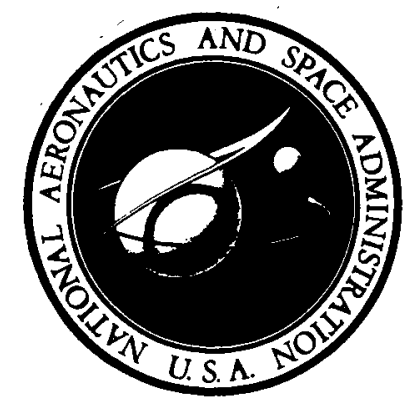

\title{
QUANTITATIVE LEAK TEST DESIGN GUIDE
}

\author{
by \\ J. L. Manganaro \\ D. L. Hollinger
}

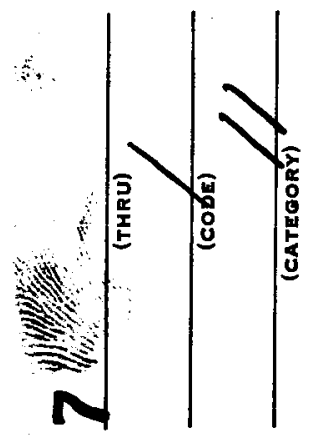

August 1967

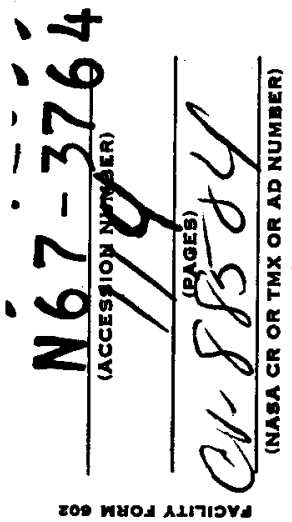

Design Guide Prepared under Contract No. 951763

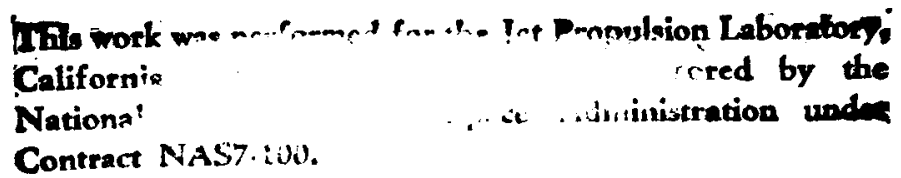

GENERAL STECTRIC

RESEARCH

AND

DEVELOPMENT

CENTER

S-67-1135

SCHENECTADY, NEW YORK 
RE-ORdER No. $67-479$

\title{
QUANTITATIVE LEAK TEST DESIGN GUIDE
}

\author{
by \\ J. L. Manganaro \\ D. L. Hollinger
}

August 1967

Design Guide Prepared under Contract No. 951763

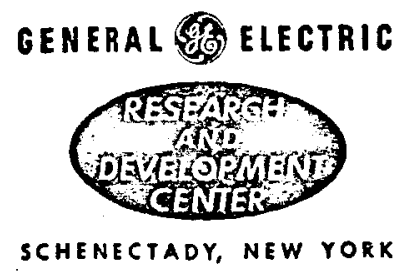




\title{
QUANTITATIVE LEAK TEST DESIGN GUIDE
}

August 1967

Prepared for

JET PROPULSION LABORATORY

CALIFORNIA INSTITUTE OF TECHNOLOGY 4900 OAK GROVE DRIVE

PASADENA, CALIFORNIA 91103

This work was performed for the Jet Propulsion Laboratory, California Institute of Technology, sponsored by the National Aeronautics and Space Administration under Contract NAS7.100.

\author{
Prepared by \\ J. L. Manganaro \\ D. L. Hollinger \\ Research and Development Center \\ General Electric Company \\ Schenectady, New York 12305
}

JPL Technical Representative: Edgar Koch 


\section{FOREWORD}

This "Quantitative Leak Test Design Guide, " was prepared for the Jet Propulsion Laboratory, California Institute of Technology, Pasadena, California. The theoretical work was performed by J. L. Manganaro of the Electrochemical Systems Branch of the Chemical Systems and Processes Laboratory of the General Electric Research and Development Center, Schenectady, New York, and D. L. Hollinger of the Plastics Process Development Operation of the Manufacturing Engineering Service of the General Electric Company, Schenectady, New York. The experimentel work was performed by $\mathrm{K}$. Herbert Malmstrom, o - ie Thermal Branch of the Mechanical Technology Laboratory, General Electric Research and Development Center, Schenectady, New York, to whom the authors owe thanks for mariy helpful suggestions.

Thanks are due Walter G. Kanetzky for his efforts in constructing the enclosure. The authors wish to express their appreciation to J. A. Consiglio, Edgar F. Koch, JPL Technical Representative for the program, and J. W. Marr for their beneficial discussions and suggestions.

The work was done between 8 December 1966 and 7 August 1967 under Contract No. 951763. 
DERIVATION OF THE GOVERNING ECUATIONS FOR LEAK RATE TESTING

Leak Rate, Enclosure Volume, and Time to Partial Pressure Rise . . . . . .

Effect of Permeation . . . . . . . . . 12

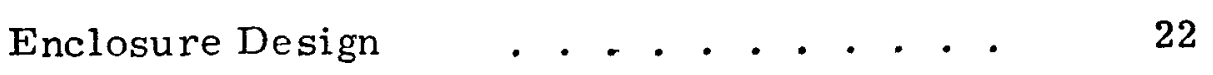

Configuration of Enclosure $. . \quad . . . . .22$

Materials Selection . . . . . . . . 23

Detailed Design and Fabrication . . . 25

Helium Mass Spectrometer Leak Detector . 31

Steady Leak Flow Calibrator . . . . . . 37

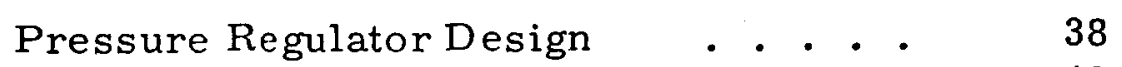

Ballast Tank Design . . . . . . 40

Leak Construction and Data . . . . . . 46

Construction of Leaks . . . . . . . 46

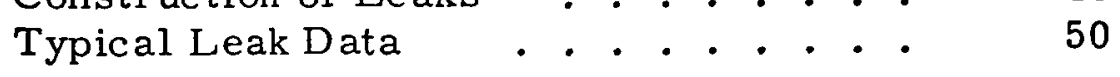

6 EXPERIMENTAL PROCEDURE AND SAMPLE

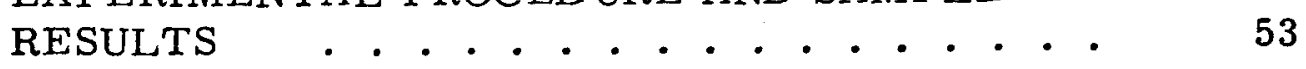

Comparison Testing Method . . . . . . 53

Pressurizing the Test System . . . 54

Preparing the Enclosure . . . . . 54

Selecting Helium Mass Spectrometer Leak

Detector Settings . . . . . .

Detecting Helium Trace Gas Leaks from Test System . . . . . . . . 58

Comparison of Test Leak with Known Leak . . . . . . . . . 58

Superposition Testing Method . . . . . . 62

Pressurizing the Test System . . . . 62 


\section{TABLE OF CONTENTS (Cont'd)}

Section

$\underline{\text { Page }}$

6

Preparing the Enclosure ......

Selecting Helium Mass Spectrometer

Leak Detector Settings . . . .

62

Detecting Helium Trace Gas Leaks from Test System . . . . . . . .

Superpositioning the Calibrated Leaks and Test Leak

Injection Testing Method . . . . . 65

Pressurizing the Test System _. . 65

Preparing the Enclosure ..... 65

Selecting Helium Mass Spectrometer

Leak Detector Settings . . . . 65

Detecting Helium Trace Gas Leaks from Test System _. . . . . . . 65

Injecting a Known Quantity of Helium . $\quad 65$

Suggestion for Increasing Accuracy $\quad$. . $\quad 69$

\section{Appendix}

ERROR ANALYSIS

Error Due to Pressure Slope . . . . .

Error Due to Leak Rate . . . . . . 71

Error Due to Volume . . . . . . 72

Error Due to Permeation _. . . . . 72

II

EXTRAPOLATION OF LEAK DATA FROM LOW

TO HIGH PRESSURE

Flow Regime . . . . . . . . 79

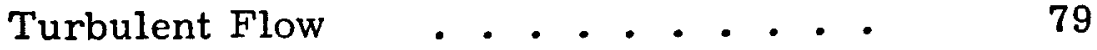

Molecular and Viscous Flow . . . 80

Extrapolation of Leak Data for Viscous Flow. $\quad 80$

Extrapolation of Leak Data for Molecular

Flow

Recommendation for Extrapolation ...

PREDICTING THE LEAK RATE OF THE SYSTEM GAS FROM THE LEAK RATE OF HELIUM OR A MIXTURE OF HELIUM AND ANOTHER GAS •

Viscous Flows

Molecular Flows 
TABLE OF CONTENTS (Cont'd)

Áppendix

IV

LEAK RATE AS A FUNCTION OF LEAK

STRUCTURE

Check Valve Leak

Self-cleaning Leak

Porosity Leak

95

Summary

95

V

OPERATION OF A TESTED STEADY LEAK

FLOW BALLAST TANK CALIBRATOR

Instructions for Start-up from Total Shutdown

Instructions for Partial Shutdown $\cdot \dot{*}^{\circ} \cdot$.

Instructions for Start-up from Partial Shutdown

Instructions for Total Shutdown . . . .

VI

CHARACTERISTICS AND SOURCES OF COMMERCIALLY AVAILABLE LEAK DETECTORS

List of Manufacturers and Addresses . . 101

Available in the United States . . . 101

Arailable in Europe . . . . . . 102

Characteristics of Leak Detectors Available

in United States.

102

VII

REFERENCES

113 
Test Setup . . . . . . . . . . . . . .

Time Required to Achieve an Increase of $10^{-6}$ atmosphere in the Trace Gas Partial Pressure with No Permeation . . . . . . . . . . .

Time Required to Achieve a Given Trace Gas

; Partial Pressure Rise Versus $\left(\mathrm{p}-\mathrm{p}_{\mathrm{o}}\right) \mathrm{V}_{\mathrm{b}} / \mathrm{TQ}$.

Permeation Correction Factor Versus $\mathrm{K} / \boldsymbol{\ell}$.

Trace Gas Pressure Rise in Enclosure

Versus Time . . . . . . . . . . . . .

Enclosure Parts . . . . . . . . . . . . .

LEXAN Enclosure Cylinder Assembled with

First Reinforcing Ring . . . : . . . . . . .

Positioning Second Enclosure Reinforcing Ring •

$9 \quad$ Enclosure Frame Erected and Flexible Bag

Ready to be Drawn Over . . . . . . . . . 27

Drawing Enclosure Bag Over Frame . . . . •

Nylon Enclosure Harness in Position for Lifting .

Schematic of General Electric LC-20 Helium

Mass Spectrometer Leak Detector . . . . .

14 Mass Spectrometer Reading Versus Tube

Pressure at Given Manifold Pressure . . . . .

15 Mass Spectrometer Reading Versus Manifold Pressure at Given Tube Pressure . . . . . . .

Detector Sensitivity Versus Tube Pressure . . .

Schematic of Pressure Regulator Calibrator . .

20 Functional Flow Rate Decline Versus Parameter $\Delta p v_{b} / v_{B T}$..........

21 Flow Rate Change Versus Initial Ballast Tank Pressure .. . . . . . . 


\section{LIST OF ILLUSTRATIONS (Cont'd)}

Figure

Page

23

Leak Rate Versus Trace Gas Partial

Pressure Drop . . . . . . . . . . . . . . .

51

24

Enclosure Connectors . . . . . . . . . 56

25

Test Setup

59

26

Comparison Testing Method Data . . . . .

61

27

Superposition Testing Method Data . . . . . .

63

28

Injection Testing Method Data.

66

29

Leak Rate Versus $\mathrm{P}_{2}^{2}-1$. . . . . . . . . .

83

30

31

Viscosity of an $\mathrm{He}-\mathrm{N}_{2}$ Mixture Versus

Mole Fraction of Helium at $25^{\circ} \mathrm{C}$

and 1 atmosphere: . . . . . . . . . . . . .

89

$\mu \mathrm{mix} / \mathrm{xHe} \mu \mathrm{N}_{2}$ Versus Mole Fraction

of Helium $\quad \because$. . . . . . . . . . . . . . . 90

32

Check Valve Effect in Hardware Leak . . . .

94

\section{LIST OF TABLES}

$\underline{\text { Table }}$

Page

1

Permeability of Polymeric

Materials to Helium . . . . . . . . 16

2

Permeation Criteria . . . . . . . . . .

17

3 Suggested Mass Spectrometer Settings . . . .

Injection Data . . . . . . . . . . . . 68

Error Coefficients

Tabulation of Leak Slopes . . . . . . . . 
Section 1

SUMMARY ,

Rapid and accurate procedures for determining leak rates using a calibrated enclosure technique have been developed. In the calibrated enclosure technique, the object to be tested is pressurized with helium and the helium leak rate determined. A mixture of helium and another gas may also be used. The governing equations for this technique are derived.

The major steps of this test procedure are:

1. Pressurizing the test object with pure helium or a mixture of helium and another gas (preferably the former).

2. Enclosing the object in a bag or tent.

3. Sensing the helium content in the enclosure and determining the rate of current increase in a mass spectrometer tube.

4. Calibrating the current increase in the mass spectrometer in terms of a helium rate by either 1) comparing to know $n$ helium leaks or 2) injecting a known quantity of helium.

Three different methods for estimating leak rates with this system are outlined and the resilts of experimental tests run by these methods are reported. The method re:

1. Comparison Testing Method, in which the test leak is directly compared with a calibrated leàk.

2. Supe rposition Testing Method, in which the ratio of the rate of increase for the test leak and the combined calibrated and test leaks is an indication of the test leak rate.

3. Injection Testing Method, in which the rate of helium increase in the enclosure is determined, and then the system calibrated by injecting a known amount of helium.

The relative merits and disadvantages of the testing methods a re compared. The Comparison Testing Method is the most generally applicable since it is valid even for cases of relatively large helium tracer gas permeation through the enclosure. However, this method is the lengthiest of those considered. The Injection Testing Method was found the most rapid and convenient. The Injection Testing Method is recommended for general use. It is suggested that improved accuracy could be obtained by taking an average for the results obtained from several runs.

Once the helium or helium-mixture leak rate is known, the leak rates of other gases, such as nitrogen, can be estimated. The estimation process is described. The effect of leak structure on leak rate is discussed. Although 
it is recommended that they be avoided when possible, the procedures for extrapolating to high pressure are provided. 'An error analysis is also included.

The major equipments needed for this procedure are described and their design criteria considered. The equipments are:

- Enclosure

- Helium Mass Spectrometer Leak Detector

- Steady Leak Flow Calibrator for the Testing-by-Comparison Methods. When the fourth step of the procedure, the calibration of the current increase in the mass spectrometer in terms of helium rate, is done by comparison with the current increase caused by known helium leaks, a steady leak"flow calibrator system is needed for generating trace gas at a known, steady leak rate. This system includes:

Steady Leak Flow Calibrator

Calibrated Leaks

- Syringe for the InjectionTesting Method. When the fourth step of the procedure is performed by injecting a known quantity of helium and comparing the resulting current inc rease with that caused by the unknown leak, a common laboratory syringe is used for injection. A steady leak flow calibrator is not used. The sizing of the syringe is discussed.

Attention is given to the practical aspects of enclosure and calibrator design, leak construction, and factors of importance in the operation of a leak detector. Operating techniques required in use of this procedure are discussed. The theoretical aspects of the enclosure volume-time relation and permeation are also treated. The test setup is shown in Figure 1.

The accuracy of the results obtainable using the calibrated enclosure technique vary with enclosure volume, test leak rate, and leak detector sensitivity and stability. The speed of the test will also vary with these parameters. Data obtained in sample experiments demonstrate the technique! s promise for accuracy (an error factor of less than ten percent) and testing time. For example, a test leak rate of approximately 16 cubic centimeters per hour was predicted with two percent error in a period of six hours by the Injection Testing Method. 


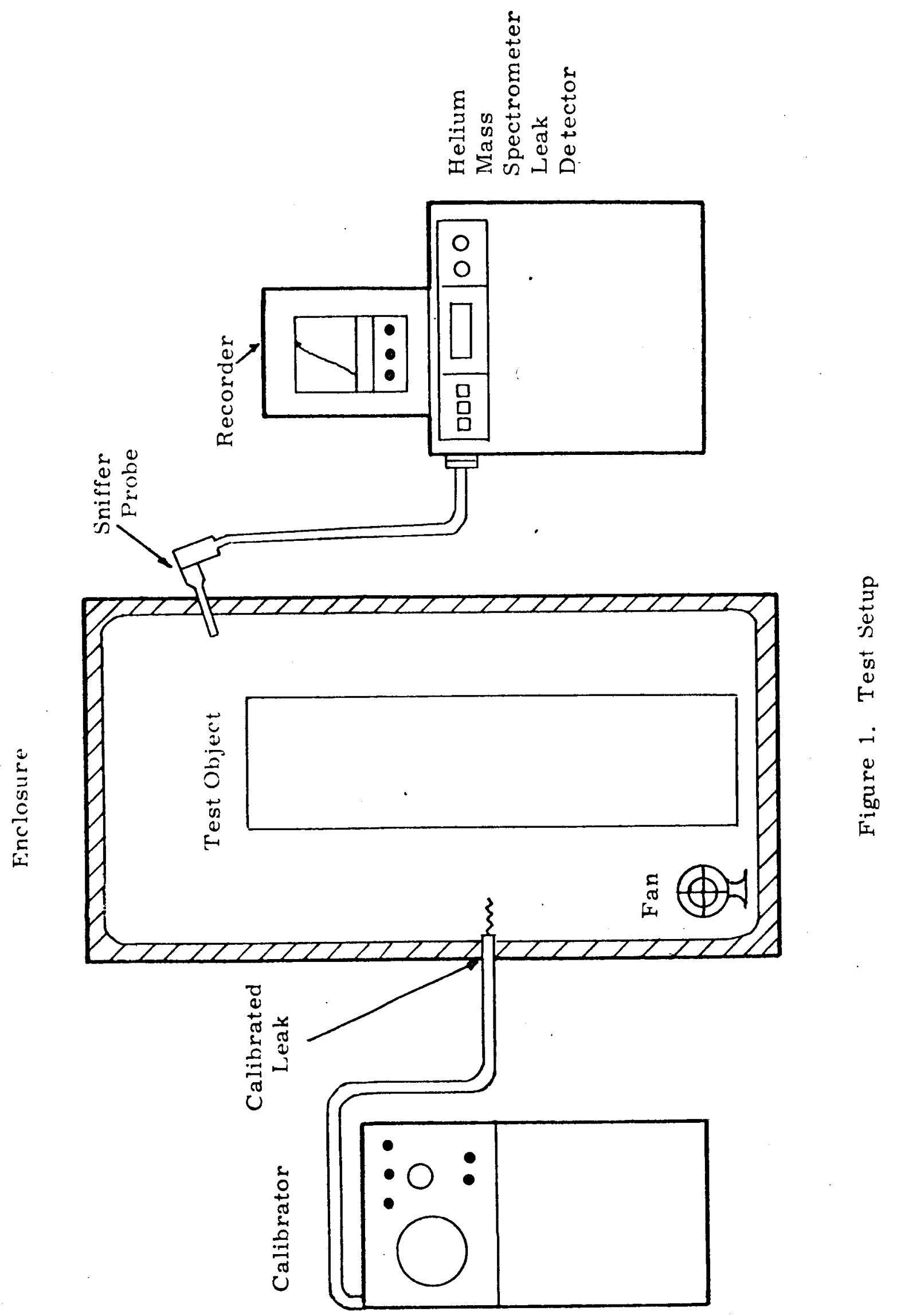


INTRODUCTION

In the leak testing of large systems, both speed and accuracy are of major concern. For example, satellite and spacecraft pressure systems are now tested at Cape Kennedy by a differential pressure method which, although yielding highly accurate results, requires two or three days to perform. In such situations, the test system is in high demand and time is a critical factor. The same problem arises in the leak testing of a large quantity of items, or of large industrial components.

Rapid and accurate procedures for determining leak rates using a calibrated enclosure technique have been developed. The object to be tested is pressurized with helium and the helium leak rate determined. Once the helium leak rate is known, the leak rates of other gases, such as nitrogen, can be estimated.

Three different methods of using this technique are discussed in this Design Guide, and sample experiments are reported. The basic procedure common to these three methods is:

1. Pressurizing the test object with pure helium.

2. Enclosing the ject in a bag or tent.

3. Sensing the helium content in the enclosure and determining the rate of current increase in a mass spectrometer tube.

4. Calibrating the current increase in the mass spectrometer in terms or a helium rate by either 1) comparing to known helium leaks or 2) injecting a known quantity of helium.

The basic equipments required and their design criteria are discussed. Theoretical aspects of the procedure and of leak types and characteristics are also discussed. 


\section{Section 3}

\section{SYMBOLS}

A area, square centimeters

a leak radius, centimeters

$\mathrm{K}_{\mathrm{n}} \quad$ Knudsen number, dimensionless

k perméability coefficient, cubic centimeter (stand ard temperature and pressure) millimeter per square centimeter second atmosphere

L leak length, centimeters

$L_{e} \quad$ entrance length, centimeters

film thickness, millimeters

$P_{1} \quad$ pressure downstream of leak, pounds per square inch gage

$\mathrm{P}_{2} \quad$ pressure upstream of leak, pounds per square inch gage

$\mathrm{P}_{2 f} \quad$ final pressure in ballast tank, atmospheres .

$\mathrm{P}_{\mathrm{zi}} \quad$ initial pressure in ballast tank, atmospheres

$P_{m} \quad$ manifold pressure, microns

$\mathrm{P}_{\mathrm{t}} \quad$ tube pressure, torr

p pressure, atmospheres

Q leak rate, cubic centimeter-atmospheres per second (at standard temperature and pressure, i.e., $\mathrm{P}=1$ atmosphere $\mathrm{T}=273^{\circ} \mathrm{K}$ )

R gas constant

Re Reynolds number

$\mathrm{T}$ temperature, ${ }^{\circ} \mathrm{K}$

u velocity

$\mathrm{V}_{\mathrm{b}} \quad$ enclosure volume, liters

$\mathrm{V}_{\text {bt }} \quad$ volume of ballast tank, liters 
$\Delta \mathrm{n} \quad$ moles of gas lost from ballast tank

$\Delta \mathrm{p} \quad$ partial pressure rise of leak gas in enclosure, atmospheres

$\theta \quad$ time, minutes

$\lambda \quad$ mean free path, centimeters

$\mu \quad$ viscosity

$\rho$ density 


\section{DERIVATION OF THE GOV ERNING EQUATIONS \\ FOR LEAK RATE TESTING}

Rapid and accurate procedures for determining leak rates using a calibrated enclosure technique have been developed. The object to be tested is pressurized with helium and the helium leak rate determined. Once the helium leak rate is known, the leak rates of other gases, such as nitrogen, can be estimated.

Three different methods of using this technique are discussed in Section 6, "Experimental Procedures and Sample Results." The basic procedure common to these three methods is:

1. Pressurizing the test object with pure helium.

2. Enclosing the object in a bag or tent.

3. Sensing the helium content in the enclosure and determining the rate of current increase in a mass spectrometer tube.

4. Calibrating the current increase in the mass spectrometer in terms of a helium rate by either 1) comparing the current increase to that caused by known helium leaks or 2) injecting a known quantity of helium and comparing the resulting current increase, with that caused by the inknown leak.

The major equipments needed for this procedure are: an enclosure and a helium mass spectrometer leak detector. In addition, when the fourth step of the procedure, the calibration of the current increase in the mass spectrometer in terms of a helium rate, is done by comparison with the current increase caused by known helium leaks, a steadyleak flow calibrator system is needed for generating trace gas at a known, steady leak rate. The test setup is shown in Figure 1. This equipment is discussed fully in Section 5, "Test Equipment."

The governing equations for leak $r$ ate testing are derived from a material balance of the trace gas, helium, in the enclosure. Helium is allowed to leak into the enclosure at a rate of $Q$ cubic centimeter-atmosphere per second. * For simplicity the leak gas is assumed to be pure helium. In Appendix III, "Predicting the Leak Rate of the System Gas From the Leak Rate of Helium or a Mixture of Helium or Aıother Gas," the use of a mixture of helium and an inert gas is discussed.

- The molar flow rate of helium into the enclosure is:

$$
\mathbf{M}_{\text {in }}=\frac{\mathrm{Q} \times 10^{-3}}{22.4} \frac{\mathrm{mol}}{\mathrm{sec}}
$$

*Symbols used in this "Quantitative Leak Test Design Guide" are defined and their units given in Section 3, "Symbols." 
The helium may leave the enclosure by flowing through the seals or seams and by permeating through the enclosure material. Great care should be taken in making the seals and seams. The molar rate of helium permeation through the enclosure is obtained from the permeation equation which, when converted into molar quantities, becomes:

$$
M_{\text {out }}=\frac{k\left(p-p_{\ell}\right) A \times 10^{-3}}{22.4 l} \frac{\mathrm{mol}}{\mathrm{sec}}
$$

Helium is accumulated in the enclosure at a rate expressed by:

$$
M_{\text {acc }}=\frac{60 \mathrm{~V}_{\mathrm{b}}}{\mathrm{RT}} \frac{\mathrm{dp}}{\mathrm{d} \theta}
$$

A material balance of the helium in the bag is now written:

$$
M_{\text {acc }}=M_{\text {in }}-M_{\text {out }}
$$

When Equations 1, 2, and 3 are substituted into Equation 4, the following first order differential equation results:

$$
\frac{\mathrm{Q} \times 10^{-3}}{22.4}-\frac{\mathrm{k}\left(\mathrm{p}-\mathrm{p}_{0}\right) \mathrm{A} \times 10^{-3}}{22.4 \mathrm{l}}=\frac{60 \mathrm{~V}_{\mathrm{b}}}{\mathrm{RT}} \cdot \frac{\mathrm{dp}}{\mathrm{d} \theta}
$$

with the initial condition $\mathrm{p}=\mathrm{p}_{\mathrm{o}}$ when $\dot{\theta}=0$.

Equation 5 is solved to yield the exponential expression:

$$
\mathrm{p}=\mathrm{p}_{\mathrm{o}}+\frac{\mathrm{Q} \ell}{\mathrm{kA}}\left[1-\mathrm{e} \frac{-2.19 \times 10^{-4} \mathrm{kAT}^{\prime} \theta}{\ell \mathrm{v}_{\mathrm{b}}}\right]
$$

where $\theta$ is time in minutes.

The exponential of Equation 6 may be expanded for small values of its argument to give:

$$
\mathrm{p}=\mathrm{p}_{\mathrm{o}}+\frac{2.19 \times 10^{-4} \mathrm{TQ \theta}}{\mathrm{V}_{\mathrm{b}}}-2.41 \times 10^{-8} \frac{\mathrm{kA} \theta}{\ell} \frac{\mathrm{T}^{2} \theta^{2}}{\mathrm{~V}_{\mathrm{b}}{ }^{3}}
$$

in which the third and succeeding terms have been deleted in order to achieve a simple expression.

For values of

$$
\frac{2.19 \times 10^{-4} \mathrm{kAT} \theta}{2 \mathrm{~V}_{\mathrm{b}}}<\frac{1}{3}
$$


the approximation, Equation 7, differs from the exact value by less than 1.8 percent. For reasonable values of the parameters this criterion will almost certainly be true.

A more detailed treatment of the values nor mally assumed for the parameters and the contribution due to higher order terms is presented in the discussion of permeation in this section. Equation 7 may be put in a somewhat more convenient form by rearranging and solving for the trace gas partial pressure rise:

$$
\Delta \mathrm{p}=\mathrm{p}-\mathrm{p}_{\mathrm{o}}=\frac{2.19 \times 10^{-4} \mathrm{TQ \theta}}{\mathrm{V}_{\mathrm{b}}}\left(1-1.098 \times 10^{-4}\left(\frac{\mathrm{kA}}{\ell}\right)\left(\frac{\mathrm{T} \theta}{\mathrm{V}_{\mathrm{b}}}\right)\right]
$$

A formula for the leak rate in terms of the rate of helium partial pressure rise in the enclosure can be drived from Equation 8 whose last term is assumed small but not: negligible:

$$
\mathrm{Q}=\frac{4.55 \times 10^{3} \Delta \mathrm{pV}_{\mathrm{b}}}{\mathrm{T} \theta} 1+1.098 \times 10^{-4}\left(\frac{\mathrm{kA}}{\mathrm{V}_{\mathrm{b}}}\right)\left(\frac{\mathrm{T}_{\theta}}{\mathrm{V}_{\mathrm{b}}}\right)
$$

LEAK RATE, ENCLOSURE VOLUME, AND TIME TO PARTIAL PRESSURE RISE

Both leak rate and enclosure volume affect the time required to achieve a given helium partial pressure rise. The calculations which describe these effects are made with the assumption that the system runs without loss of gas by means of permeation; that is $\mathrm{kA} / \ell=0$. This is the most favorable case, requiring the least testing time.

An explicit relation for the time required to achieve a given helium partial pressure rise is readily obtained from Equations 8 or 9:

$$
\theta=\frac{4.65 \times 10^{3} \Delta \mathrm{pV}_{\mathrm{b}}}{\mathrm{TQ}}
$$

where the permeation term has been dropped and the time is in minutes.

A helium partial pressure rise within the enclosure of about $10^{-6}$ atmospheres is required so that a reading can be taken. The normal value of helium in the atmosphere is $5.24 \times 10^{-6}$ atmospheres.

Using Equation 10, the time required to achieve a $10^{-6}$ atmospher $\epsilon$ partial pressure rise versus enclosure volume is plotted in Figure 2.

For a sample calculation consider the following system values:

$$
V_{b}=100 \mathrm{ft}^{3}=2.83 \times 103 \text { liter }
$$




$$
\begin{aligned}
& \mathrm{Q}=10^{-3} \mathrm{cc}-\mathrm{atm} / \mathrm{sec} \\
& \mathrm{T}=298^{\circ} \mathrm{K}
\end{aligned}
$$

From Figure 2 or Equation 10, the time required to achieve a 10-6 atmosphere rise in the partial pressure of helium is 43 minutes.

The reading of the mass spectrometer leak detector used for the tests described in this "Quantitative Leak Test Design Guide" would increase approximately 5 to 15 microamperes for a helium partial pressure rise of $10^{-6}$ atmospheres.

Doubling the volume, in the absence of permeation, causes the time required to double, since the time expression is linear. Similarly, a doubling of the leak rate will halve the required time. A more general plot of the time required to achieve a given helium partial pressure rise versus $\left(\mathrm{p}-\mathrm{p}_{\mathrm{o}}\right) \mathrm{V}_{\mathrm{b}} / \mathrm{TQ}$ is shown in Figure 3 .

\section{EFFECT OF PERMEATION}

In order to maintain the highest possible le vel of testing sensitivity and reliability, it is necessary to minimize permeation of the trace gas, helium, through the enclosure as well as to minimize leakage through seals or seams. The effect of permeation on the helium partial pressure enters through the last terms of Equations 8 and 9.

A permeation par - eter $\varphi$ is now defined:

$$
\varphi=1.098 \times 10^{-4}\left(\frac{\mathrm{kA}}{\ell}\right)\left(\frac{\mathrm{T}_{\ell}}{\mathrm{V}_{\mathrm{b}}}\right) \text {. }
$$

This is a dimensionless quantity since implicit in the coefficient $1.098 \times 10^{-4}$, among other conversion factors, are the units of the gas constant, $R$, divided by the number of cubic centimeters per mole of gas.

The permeation correction term is plotted in Figure 4 for various values of the parameter $\mathrm{kA} / \ell$. For convenience, a tabulation of various plastics and their permeabilities at $25^{\circ} \mathrm{C}$ to helium is shown in Table 1. Polyvinylidene chloride (Sara 517) has the lowest permeability coefficient of all the gases considered. The permeability of polyvinylidene chloride to helium is a factor of 67 times lower than that of the next lowest polymer, polyethylene glycol terephthalate (Mylar A).

- Consider the following system values:

$$
\begin{aligned}
& V_{b}=100 \mathrm{ft}^{3}=2.83 \times 10^{3} \mathrm{l} . \\
& A=10^{5} \mathrm{~cm}^{2}
\end{aligned}
$$




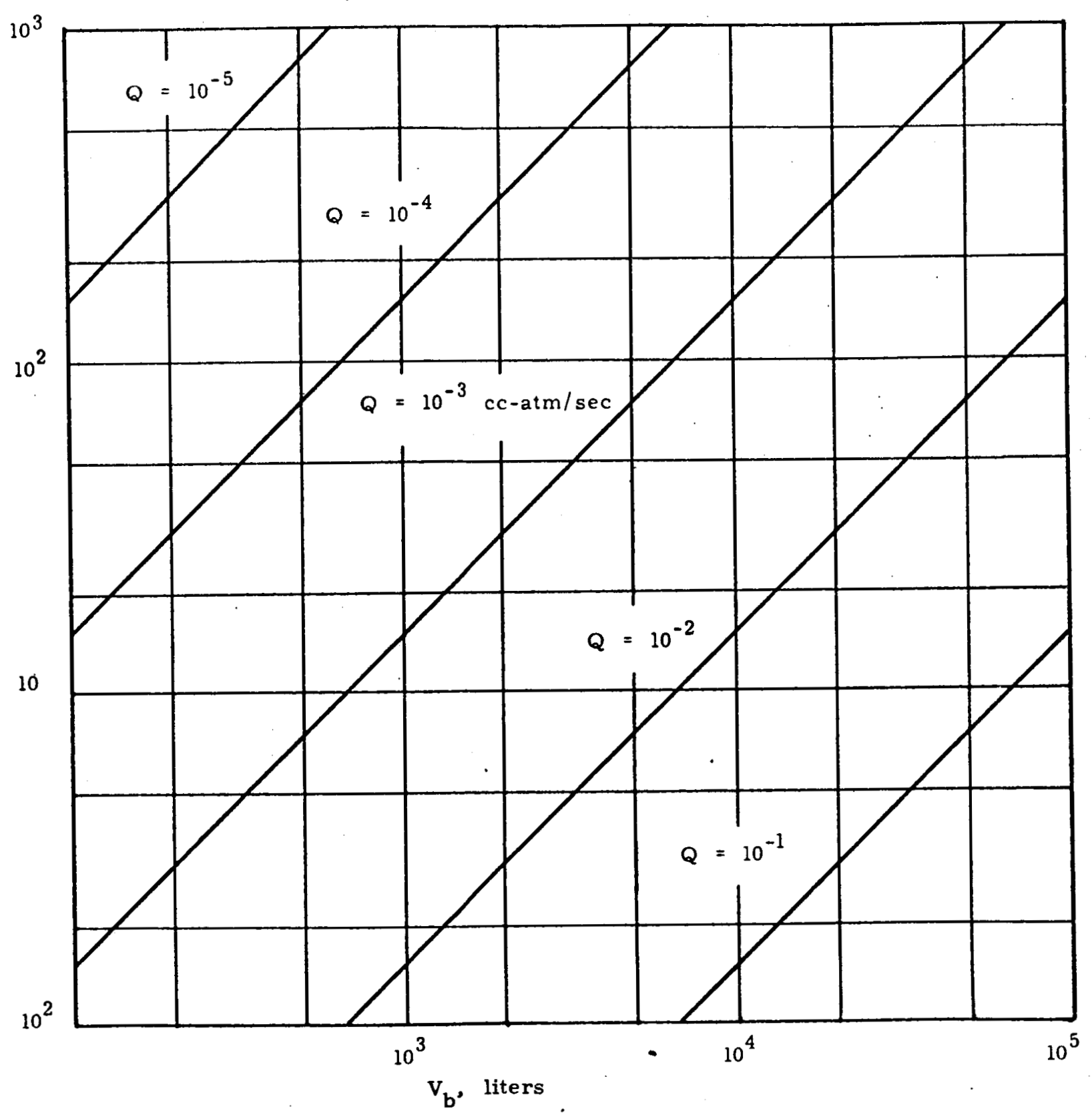

Figure 2. Time Required to Achieve an Increase of $10^{-6}$ atmosphere in Trace Gas Partial Pressure with No Permeation. 


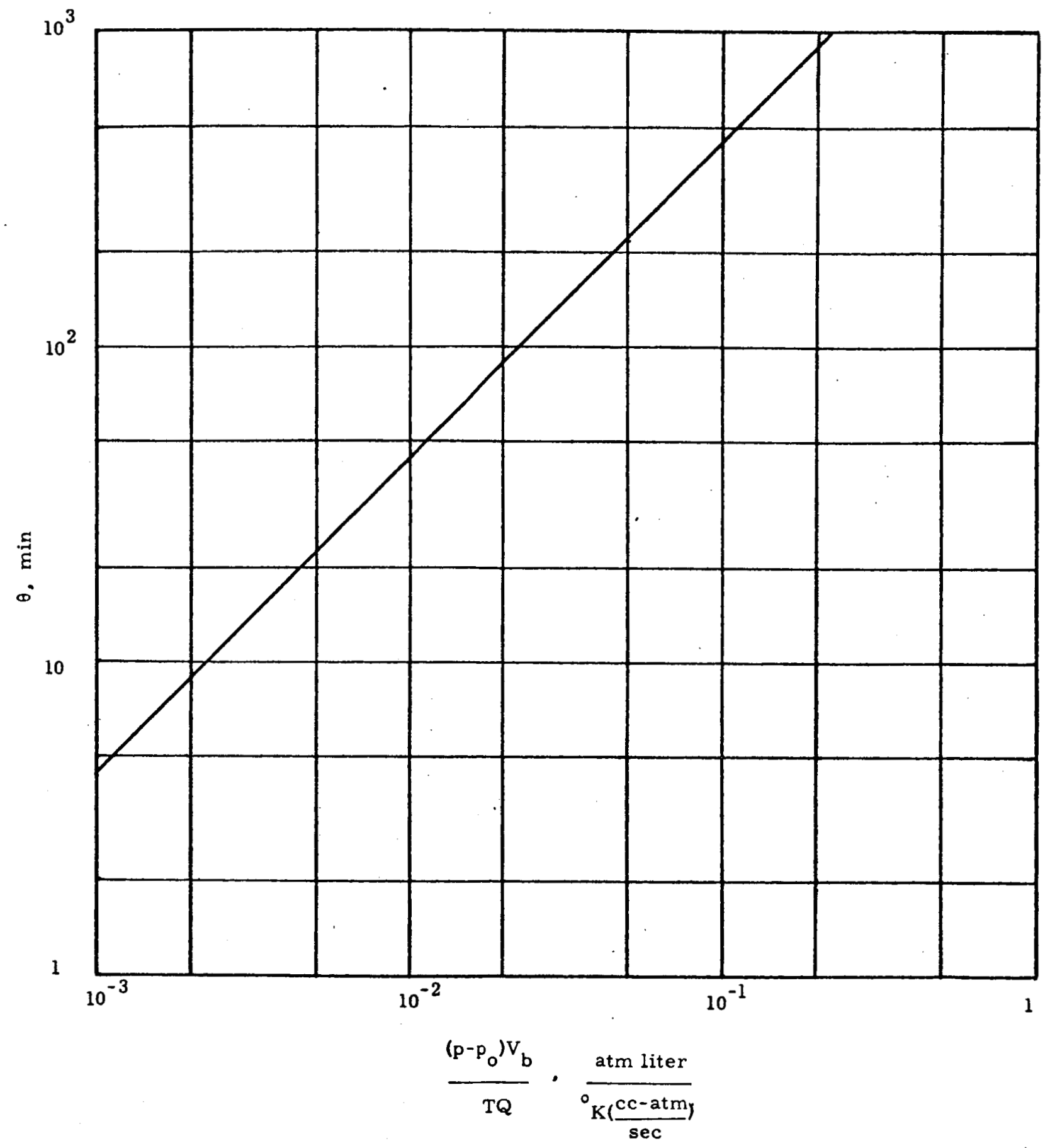

Figure 3. Time Required to Achieve a Given Trace Gas Partial Pressure Rise Versus $\left(p-p_{o}\right) V_{b} / T Q$. 


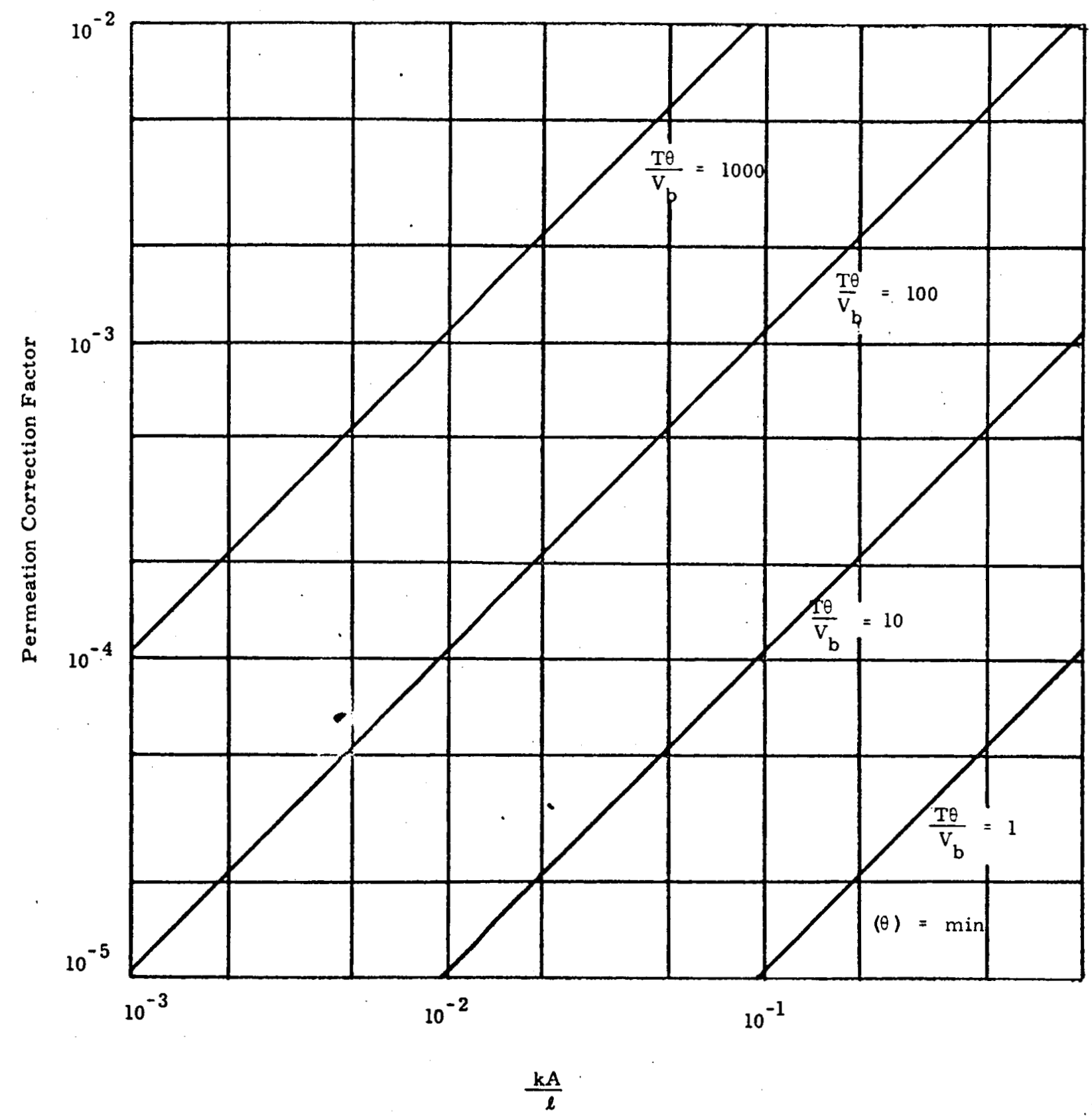

Figure 4. Permeation Correction Factor Versus kA/l. 
Table 1

\section{PERMEABILITY OF POLYMERIC MATERIALS TO HELIUM}

$\mathrm{k}$ in cc(STP) $-\mathrm{mm} / \mathrm{cm}^{2}-\mathrm{sec}$-atm, at $25^{\circ} \mathrm{C}$

MATERIAL

TRADE NAME

OR CODE

$\mathrm{k} \times 10^{7}$

Natural Rubber

Rubber Hydrochloride

Poly (butadiene)

hydrogenated

Poly (dimethyl butadiene)

Poly (isobutylene)

Poly(butadieneacrylonitrile)

Poly (butadiene-styrene)

Poly(chloroprene)

Polyethylene (density 0.914)

(density 0.964)

Poly (ethylene glycol terephthalate)

Polyvinylidene chloride

Poly (t etrafluo roethylene)

Poly (chlorotrifluoroethylene)

plasticized

Cellulose acetate-butyrate

Cellulose nitrate
Pliofilm 140-Nz

23

Hydropol

12. 0

Methyl rubber

11

Oppanol B-200

5. 6

(butyl rubber)

Perbunan (German)

8. 7

Perbunan 18

12. 9

Hycar OR 15

5. 2

Hycar OR 25

7. 5

Buna S, GR-S

17. 5

Neoprene G

3. 4

DE2400

3. 75

Alathon 14

Grex

0.87

Mylar A

0. 74

Saran 517

0.011

Teflon

530

Kel-F

10. 7

Kodapak II

10. 9

5. 2 


$$
\begin{aligned}
& \ell=0.5 \mathrm{~mm} \\
& \mathrm{k}=4.8 \times 10^{-7} \quad \begin{array}{l}
\mathrm{cc}(\mathrm{STP})-\mathrm{mm} / \mathrm{sec}-\mathrm{cm}^{2}-\text { atm, (which is the permeabil- } \\
\text { ity of helium through polyvinyl chloride) }
\end{array} \\
& \mathrm{T}=298^{\circ} \mathrm{K} \\
& \theta=240 \mathrm{~min} .
\end{aligned}
$$

Thus,

$$
\frac{\mathrm{kA}}{\ell}=9.6 \times 10^{-\mathrm{a}} \quad \frac{\operatorname{cc}(\mathrm{STP})}{\sec \text { atm }}
$$

and,

$$
\frac{\mathrm{T}_{\theta}}{\mathrm{V}_{\mathrm{b}}}=25.3 \quad \frac{\mathrm{o} \mathrm{K} \min }{\text { liter }}
$$

From Figure 4 or Equation 11 we obtain $\varphi=2.66 \times 10^{-4}$. Therefore, the correction due to permeation for this rather reasonable set of values is only about one part in 10,000. Note that the effect of permeation becomes more pronounced for longer runs. This is due, of course, to the greater time period over which permeation may occur. Decreasing the volume of the enclosure also increases the contribution of permeation because of the more rapid accumulation of helium in the enclosure. Decreasing the enclosure surface area will naturally aid in the reduction of permeation.

A somewhat more convenient method of determining the relative significance of permeation is to set $\varphi$ (Equation 11) to the limits given in Table 2. The definitions in Table 2 are arbitrary and can be changed for particular applications.

Table 2

PERMEATION CRITERIA

Permeation

1. Unimportant

(less than 1\%)

2. Somewhat Important (between $1 \%$ and 10\%)

3. Important (above 10\%) $\varphi$

$\varphi \leq 0.01$

$0.01<\varphi \leq 0.1$

$\varphi>0.1$
$\frac{\mathrm{kAT} \theta}{\ell \mathrm{V}_{\mathrm{b}}}$

$\frac{\mathrm{kAT}_{\varphi}}{\ell \mathrm{V}_{\mathrm{b}}} \leq 91.1$

$91.1<\frac{\mathrm{kAT}_{\theta}}{\ell \mathrm{V}_{\mathrm{b}}} \leq 911$

$\frac{\mathrm{kAT} \theta}{\ell \mathrm{V}_{\mathrm{b}}}>911$ 
If room temperature is taken as $298^{\circ} \mathrm{K}$ a single criterion for negligible contributions due to permeation can be obtained from the following expression:

$$
\frac{k A_{\theta}}{\ell V_{b}} \leq 0.3
$$

When this condition is satisfied permeation is less thean 1 percent. Inserting the values of the previous example yields:

$$
\frac{\mathrm{k} A_{\theta}}{l V_{b}}=8.13 \times 10^{-3}
$$

which is well within the desired limits.

These calculations indicate that permeation through the plastic film of the enclosure for most system values will be of little or no consequence. Special care should still be taken when sealing the bag. .

The influence of permeability may be further examined by plotting the helium partial pressure as a function of time for several different permeability coefficients at a given enclosure thickness. Consider the following set of values.

$$
\begin{aligned}
& \mathrm{Q}=10^{-3} \frac{\mathrm{cc}-\mathrm{atm}}{\mathrm{se}} \\
& \mathrm{V}_{\mathrm{b}}=100 \mathrm{ft}^{3}=2.83 \times 10^{3} \text { liters } \\
& l=0.5 \mathrm{~mm} \\
& \mathrm{~A}=10^{5} \mathrm{~cm}^{2} \\
& \mathrm{~T}=298^{\circ} \mathrm{K}
\end{aligned}
$$

Upon substituting these values Equation 7 becomes:

$$
\mathrm{p}=\mathrm{p}_{0}+1.35 \times 10^{-6} \theta-1.74 \times 10^{-5} \mathrm{k} \theta^{3}
$$

with time in hours. A graph of Equation 12 is shown in Figure 5. Permeability coefficients of $10^{-5}$ or less result in a very nearly linear plot of the pressure rise versus time at least for running times on the order of 30 hours or less. The partial pressure rise in this sytem is strongly affected by increasing the permeation coefficient beyond $10^{-4}$. Such coefficients, however, are extremely large. Gross leaks in the system might result in an effective permeation coefficient which is rather large and consequently cause the change in pressure versus time curve to tail off. 


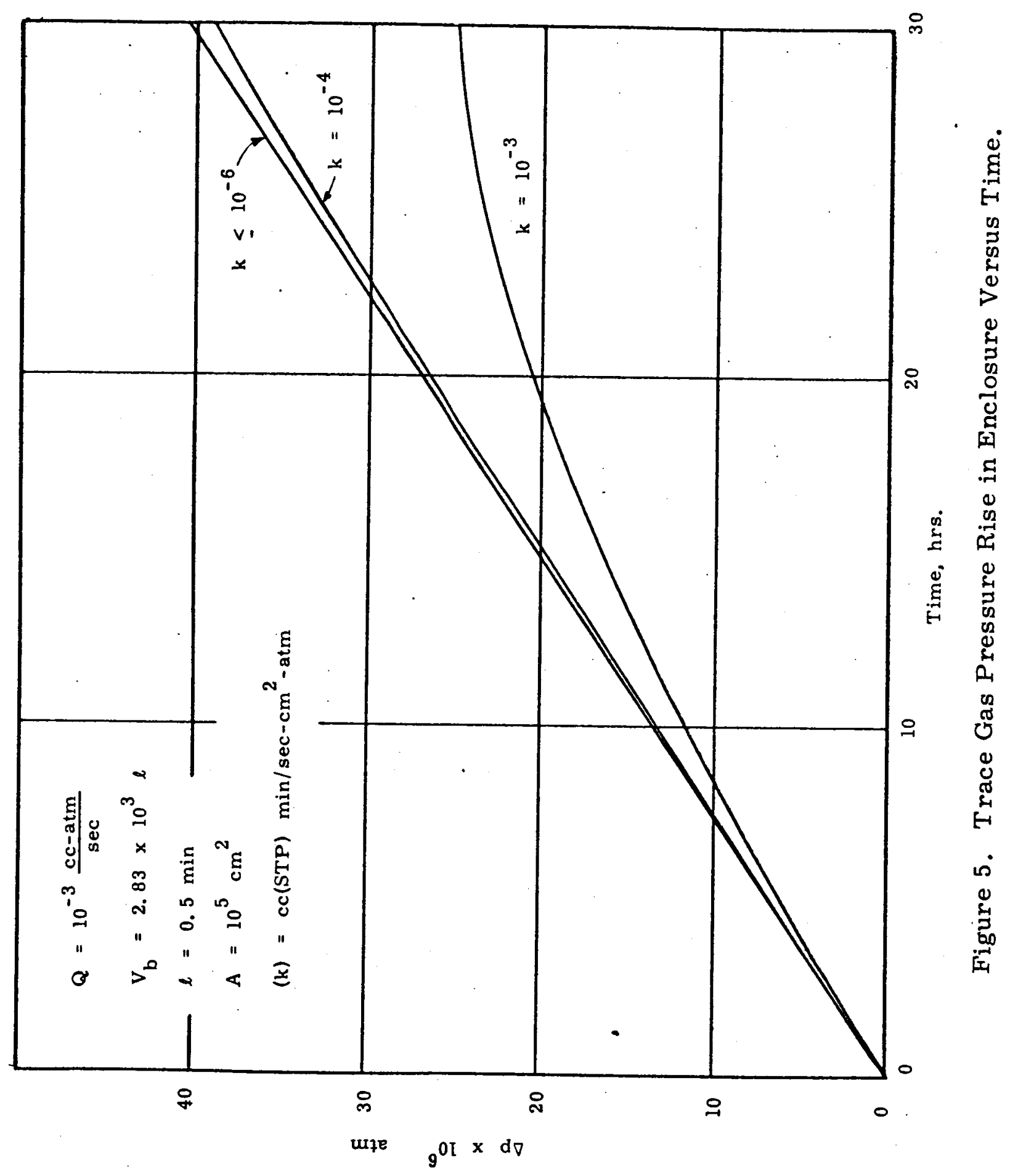




\section{Section 5}

\section{TEST EQUIPIMENT}

This section contains a discussion of the test equipments used to leak test a system by means of a calibrated enclosure technique. This discussion includes both theoretical and practical considerations.

In the calibrated enclosure technique the object to be tested is pressurized with helium and the helium leak rate determined. Once the helium leak rate is known, the leak rates of other gases, such as nitrogen, can be estimated. The test setup is shown in Figure 1.

Three different methods of using the technique are discussed in Section 6. "Experimental Procedures and Sample Results." The basic procedure common to these three methods is:

1. Pressurizing the test object with pure helium.

2. Enclosing the object in a bag or tent.

3. Sensing the helium content in the enclosure and determining rate of current increase in a mass spectrometer tube.

4. Calibrating the current increase in the mass spectrometer in terms of a helium rate by either 1) comparing the current increase to that caused by known helium leaks or 2) injecting a known quantity of helium and comparing the resulting current increase with that caused by the unknown leak.

The major equipments needed for this procedure are:

- Enclosure

- Helium Mass Spectrometer Leak Detector

- Steady Leak Flow Calibrator Ior the Testing-by-Comparison Methods. When the fourth step of the procedure, the calibration of the current increase in the mass spectrometer in terms of helium rate, is done by comparison with the current increase caused by known helium leaks, a steady leak flow calibrator system is needed for generating trace gas at a known, steady leak rate. This system includes:

\section{Steady Leak Flow Calibrator \\ Calibrated Leaks}

- Syringe for the Injection Testing Method. When the fourth step of the procedure is done by injecting a known quantity of helium and comparing the resulting current increase with that caused by 
the unknown leak, a common laboratory syringe is used for injection. A steady leak flow calibrator is not used. The sizing of the syringe is discussed in the description of the Injection Testing Method in Section 6.

\section{ENCLOSURE DESIGN}

\section{Configuration of Enclosure}

The goals toward which the enclosure design is aimed may be placed in four main categories:

1. minimum gas leakage

2. volume constancy

3. ease of assembly, handling, and shipping

4. low-cost manufacturing

Each of these goals introduces particular considerations, some of which may be of prime importance in establishing the final design, while others can be compromised for practical reasons.

\section{Designing for Minimum Leakage}

In designing for minimum leakage, the shape of the enclosure should be chosen to have maximl. values for enclosed volume per surface ratio and enclosed volume per seal length ratio, consistent with the shape of the tested vehicle. Of course, the materials which have the lowest specific permeability to gases of interest. and which fabricate with maximum thickness of materials should be employed. Reliable methods for sealing the necessary joints or openings must be found.

\section{Designing for Volume Constancy}

In order to obtain accurate relationships between the leak rate and the measured partial pressure rise, or instrument response, it is necessary to maintain a constant enclosure volume throughout the test period. For 99 percent accuracy in partial pressure measurements, the volume must remain constant within 1 percent. This shows the need ior a rigid framework which will completely define the volume enclosed.

\section{Designing for Ease of Assembly, Handling and Shipping}

Assembly, handling, and shipping characteristics are practical considerations which can make large differences in the usefulness of the equipment and test method. First, of course, the materials must be durable. Because of equipment size alone, it is impractical to expect fragile materials to serve satisfactorily. For repeated assembly and disassembly, packaging, 
and shipping, it is highly desirable to use the smallest possible number of individual parts and to require only common, readily available tools. When completely assembled, the enclosure must have good form stability and reasonably light weight, since it will be handled as a unit when put into position around a test vehicle. For shipping from place to place, packaging should be simple and perhaps reusable.

\section{Designing for Low-Cost Manufacturing}

This is, perhaps, a less important design area where the quantities needed are quite low. Nevertheless, cost does influence choices when alternatives are otherwise equally desirable. Cost considerations include: the basic materials cost; the cost of fabricating the materials in a form which is usable in the design concept, particularly as reflected by their ready availability commercially; the parts and manufacturing cost, including tooling and labor; and, the ease of adaptability of the product design to the range of sizes needed for various testing situations.

$\underline{\text { Materials Selection }}$

Frame

Material. Requirements of strength, rigidity, toughness, dimensional stability, fire resistance, and ease of fabrication, together with size availability, dictate the use of extruded polycarbonate: (LEXAN) or rigid polyvinyl chloride sheets. Polycarbonate is preferable because it has significantly greater toughness and dimensional stability, particularly at elevated temperatures.

Sheet Thickness. Sheet thickness is selected to provide a balance between the rigidity required for structural support and the flexibility needed to allow rolling sheets into a tubular package shape. With plastic materials having flexural moduli between 300,000 and 400,000 pounds per square inch, a thickness in the range 0.080-0.100 inch is satisfactory.

Critical compressive (buckling) load for a cylindrical frame is approximated as follows:

$$
\mathbf{s}^{\prime}=0.12 \frac{\mathrm{Et}}{\mathrm{R}}=\frac{\mathrm{P}}{\mathrm{A}}
$$

where:

$$
\begin{aligned}
& \mathbf{s}^{\prime}=\text { critical stress, psi } \\
& \mathbf{E}=\text { Young's modulus } \\
& \mathbf{t}=\text { cylinder thickness, in } . \\
& \mathbf{R}=\text { cylinder radius, in. } \\
& \mathrm{P}=\text { total compressive load, psi } \\
& \mathrm{A}=\text { cross-sectional area, in } 2
\end{aligned}
$$




$$
\begin{aligned}
\mathrm{A} & \cong 2 \pi \mathrm{Rt} \\
0.12 \frac{\mathrm{Et}}{\mathrm{R}} & =\frac{\mathrm{P}}{2 \pi \mathrm{Rt}} \\
P & =0.755 \mathrm{Et}^{2}
\end{aligned}
$$

letting $E$ for LEXAN equal 375,000 pounds per square inch and $t$ equal 0.090 inch,

$$
\begin{aligned}
& \mathbf{P}=0.755 \times 3.75 \times 10^{5} \times\left(9.0 \times 10^{-3}\right)^{3} \\
& \mathbf{P}=2290 \mathrm{lbs}
\end{aligned}
$$

Critical transverse bending moment for buckling is estimated thus:

$$
M^{\prime}=\frac{0.72 \text { ERt }^{2}}{\left(1-v^{2}\right)}
$$

where:

$$
\begin{aligned}
\mathbf{M}^{\prime} & =\text { critical } \text { bending moment } \\
\mathbf{v} & =\text { Poisson's ratio }
\end{aligned}
$$

Assuming:

$$
\begin{aligned}
E & =375,000 \mathrm{psi} \\
\mathbf{R} & =33 \text { in. } \\
\mathbf{t} & =0.090 \mathrm{in} . \\
\mathbf{V} & =0.25 \\
\mathbf{M}^{\prime} & =\frac{0.72 \times 3.75 \times 10^{5} \times 33 \times\left(9.0 \times 10^{-3}\right)^{2}}{1-(0.25)^{3}} \\
M & =76,600 \text { inch-lbs }
\end{aligned}
$$

Reinforcing Rings. The reinforcing rings at each end of the cylindrical frame may be of any material which can provide the necessary rigidity. Considerations of weight and ease of fabrication would narrow the choice to fiberglass reinforced plastic (FRP), aluminum alloys or magnesium alloys. Steel parts could also be used here if the design were simplified somewhat to lessen fabrication costs. The principal design requirement is for a reinforcing member with an EI product (Young's modulus times the moment of inertia of the cross section) of perhaps $1 \times 10^{-6}$ pounds-square inches.

Flexible Bag Gas Barrier

For limited production, the overriding considerations for choosing material for the flexible bag when there will be limited production are 
durability, availability in wide stock, and adaptability to suitable methods of fabricating large bags. Although some upper limit on the tolerable specific permeability must exist, in practice the degree to which the seals are porous or leaky is more critical.

Plasticized polyvinyl chloride has a specific permeability to helium gas of about $5 \times 10^{-7}$ cubic centimeters (standard temperature and pressure) millimeters per square centimeters - second - atmosphere, Although other films, notably those incorporating a lamination or coating of polyvinylidene chloride (Saran), have lower permeabilities by factors of perhaps 100 to 1,000, such films are not available in forms which have the necessary durability for this application. In most cases, maximum thickness produced commercially is 2-4 mils, since such films find application almost exclusively in food and drug packaging.

Laminated films made with aluminum foils and polyethylene for heat sealability, and, sometimes, a woven fabric for strength are also available. Some of these have quite high strength, but lack the elasticity required in the present design concept.

\section{Detailed Design and Fabrication}

An experimental enclosure was fabricated. The volume within the bag, it was decided, would be controlled almost entirely by means of a rigid frame. A conforming flexible plastic bag drawn over this frame would provide the impermeable gas barrier. The complete enclosure would be comprised of four major components:

Semirigid, plastic, cylindrical frame

Rigid reinforcing rings for the cylindrical frame ends

Flexible plastic bag

Lifting harness

Figures 6 through 12 show the enclosure in several stages of fabrication.

Semirigid Plastic Cylindrical Frame

The enclosure frame is a cylinder of LEXAN plastic sheet, 66 inches in diameter and 117 inches high, with a wall thickness of 0.090 inch. LEXAN was chosen as the frame material because it is tough enough to resist damage from repeated handling, because it has dimensional stability including lack of creep at service temperatures, and because it is self-extinguishing.

The cylinder is assembled from five smaller, flat sheets of LEXAN, four measuring 48 inches by 117 inches and a fifth measuring 31 inches by 117 inches. Since the largest size sheet available in small quantities was 48 by 96 inches, the 117 -inch long panels.were made up by bonding on 


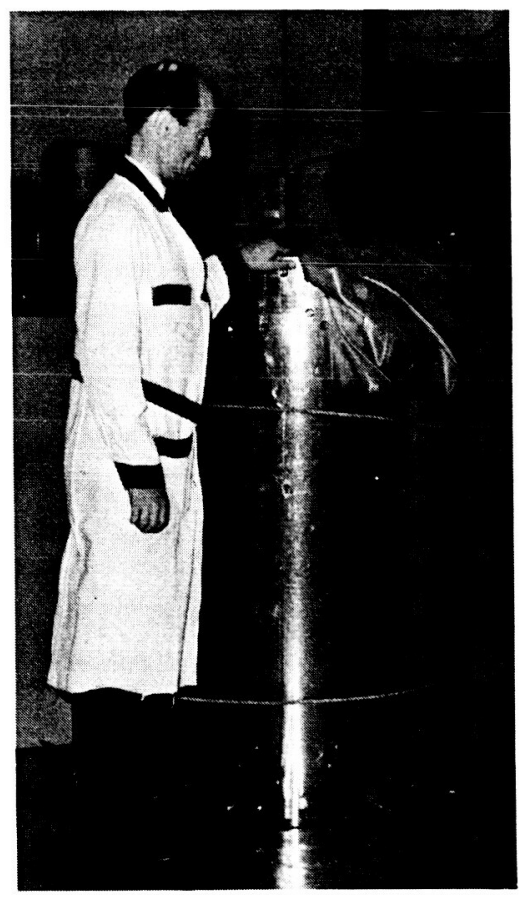

Figure 6. Enclosure Parts.

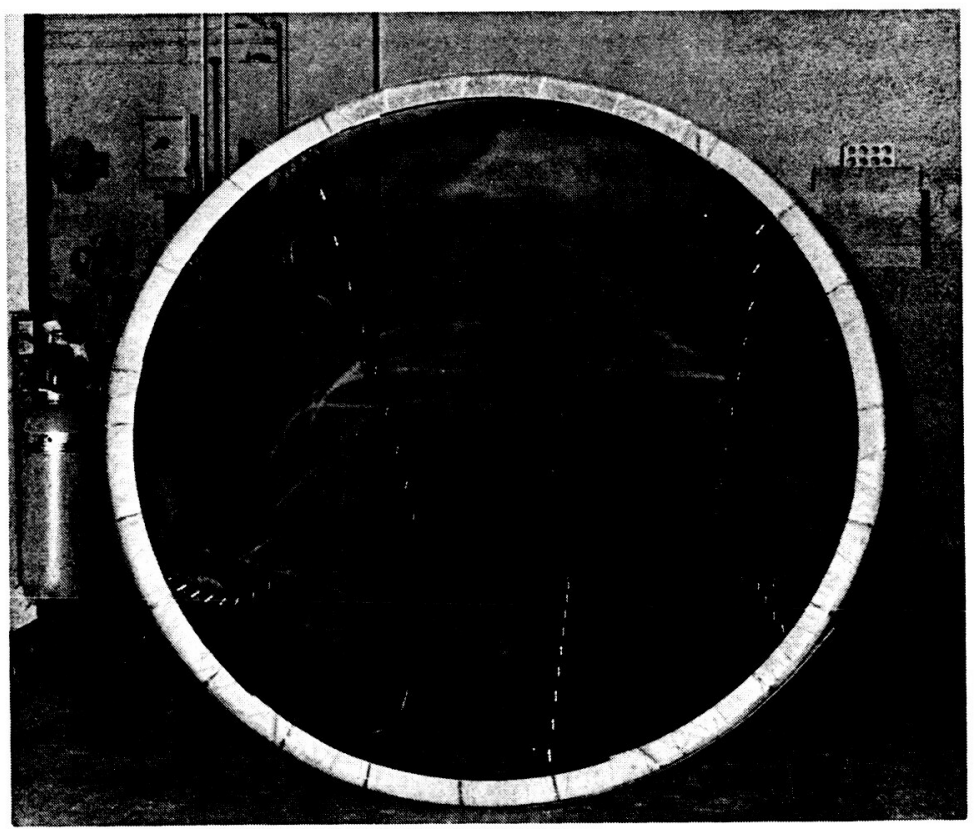

Figure 7. LEXAN Enclosure Cylinder Assembled with First Reinforcing Ring. 


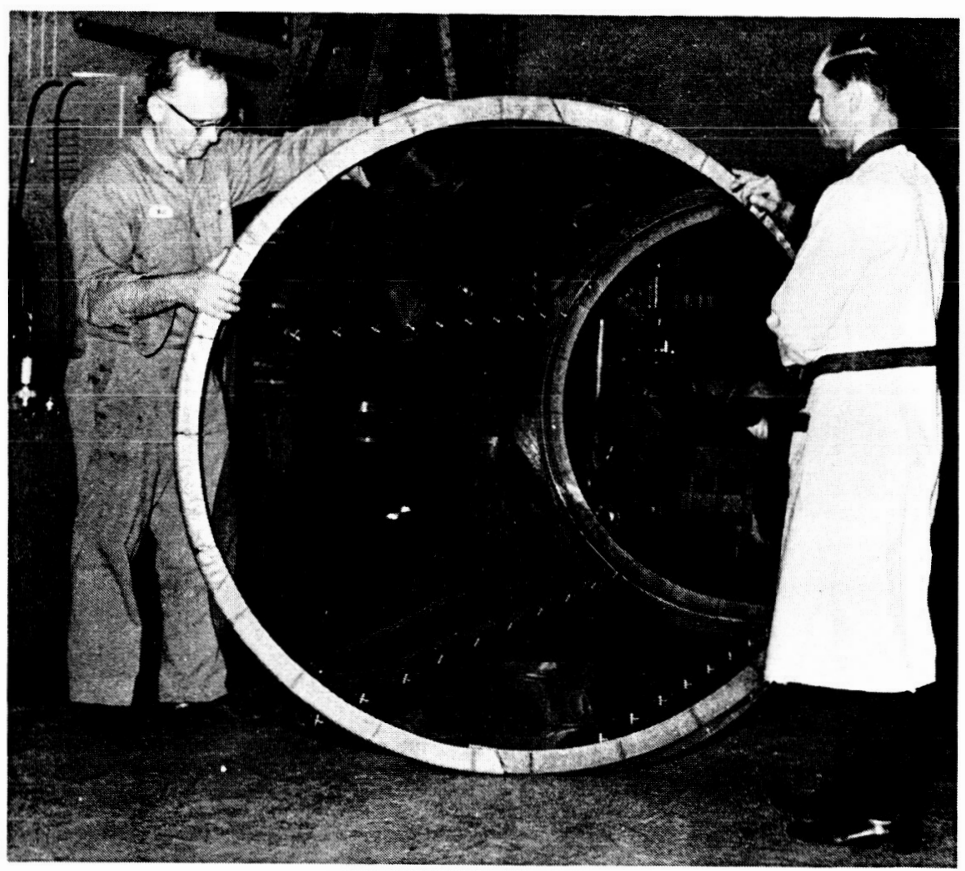

Figure 8. Positioning Second Enclosure Reinforcing Ring.

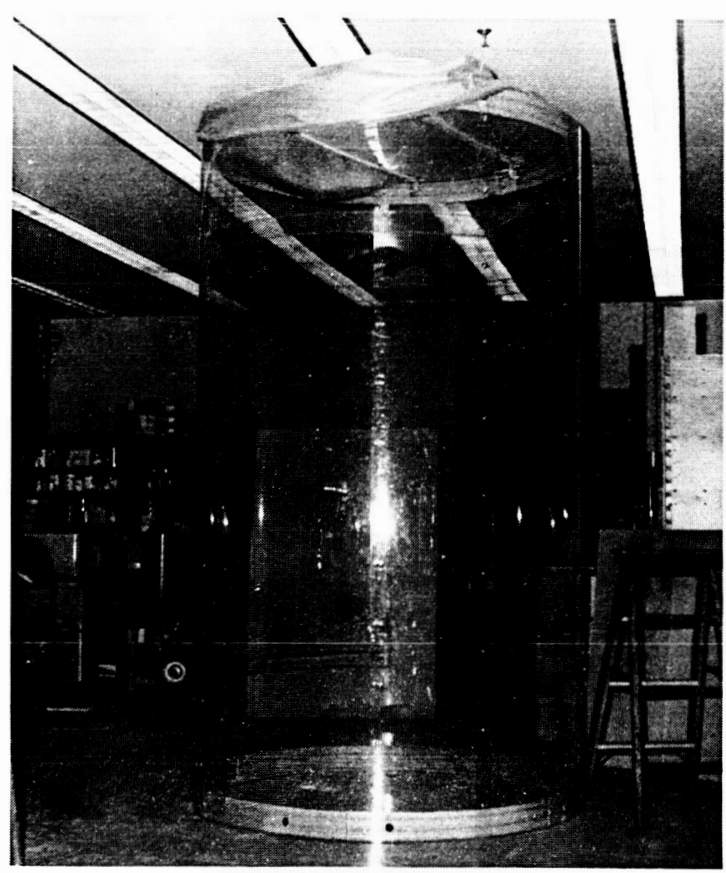

Figure 9. Enclosure Frame Erected and Flexible Bag Ready to be Drawn Over. 


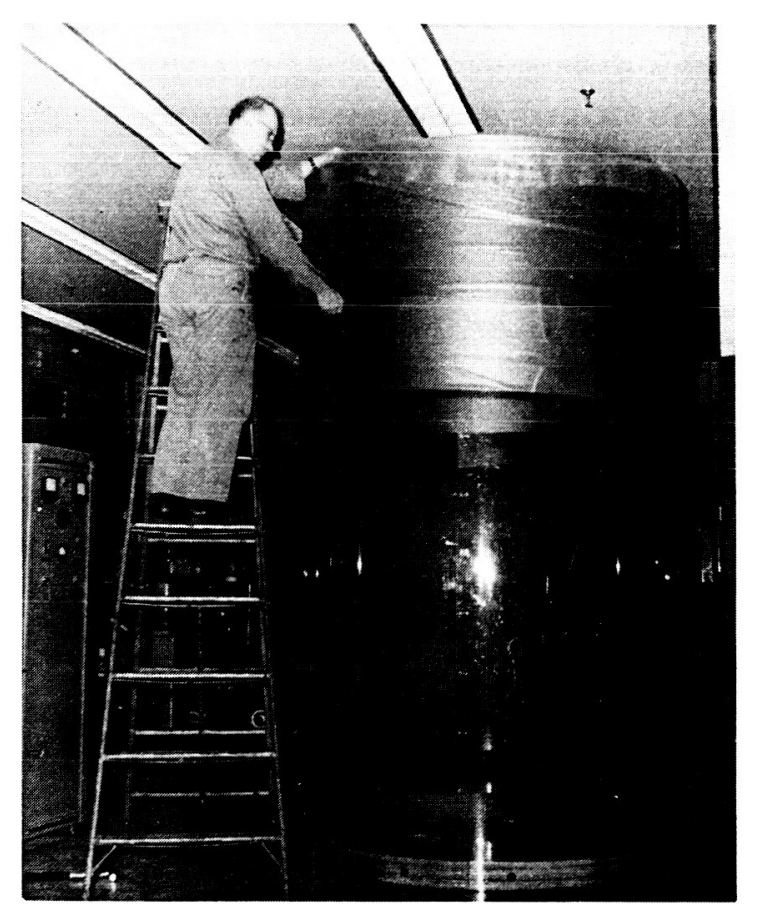

Figure 10. Drawing Enclosure Bag Over Frame.

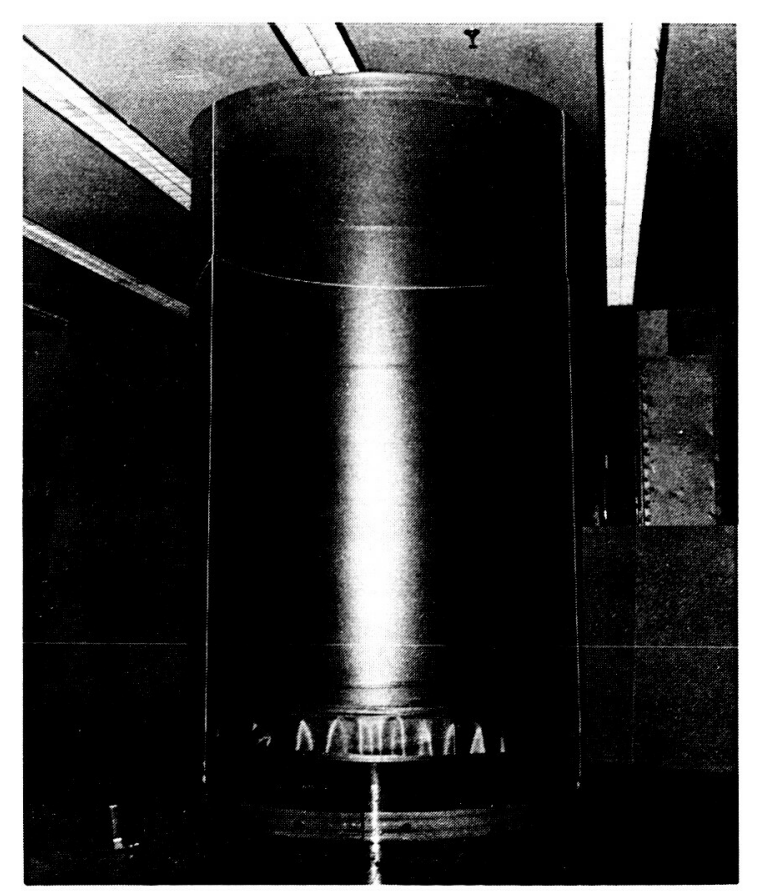

Figure 11. Nylon Enclosure Harness in Position for Lifting. 


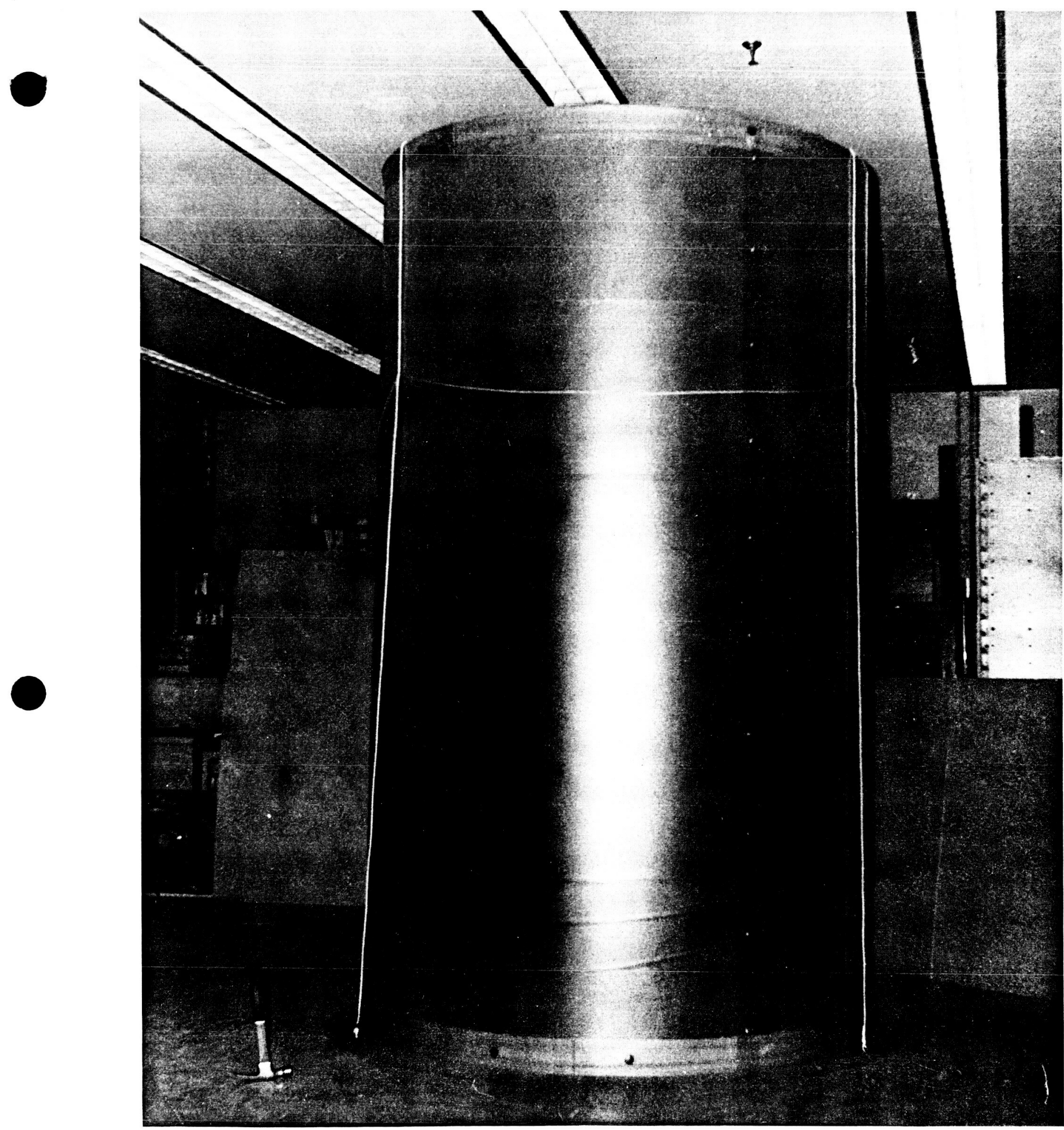

Figure 12. Enclosure Bag Ready for Sealing to Floor. 
extensions with a polyurethane adhesive, Adiprene L-100 by DuPont, cured with 11 parts by weight of methylenebis (orthochloroaniline). Each sheet, or panel, has a series of Quick-Lock fasteners attached permanently along the two long edges. These bind the panels together to form the complete cylinder and are operated by a one-quarter turn with a common screwdriver.

\section{Rigid Reinforcing Rings}

To maintain the cylinder in an accurately round shape, reinforcing rings of fiberglass laminate are bolted inside to its top and bottom. These rings are composed of six overlapping segments, bolted together, and have an essentially L-shaped cross section. Fiberglass is used primarily because the desired shape could be obtained with low tooling cost. The reinforcing rings could also be aluminum.

Polyvinyl Chloride Bag

A tailored plastic bag made of polyvinyl chloride film, 0.020 inch thick, is placed over the frame. The bag has reasonably low gas permeability, has good strength and toughness, can be readily obtained in heavy gases and large sheet widths, is self-extinguishing, lends itself well to fabrication by heat sealing, and has a useful degree of elasticity and flexibility.

A separate sheet 0 the same polyvinyl chloride material is supplied for use as a floor covering. It is to be placed beneath the test vehicle in locations where the existing floor does not lend itself to forming a seal with the bag. In the test work done at General Electric, the bag was taped directly to the asphalt tile floor, using black vinyl plastic tape.

\section{Lifting Harness}

A nylon rope lifting harness was supplied to facilitate the positioning of the enclosure over a space vehicle. The harness is placed over the enclosure and the three hooks of the harness are inserted into the holes in the LEXAN frame and the bottom reinforcing ring. The steel ring at the top of this harness may then be picked up by a crane and the complete enclosure lifted into position. The three hooks are released from the structure when the bottom seal is made, but the harness remains in position on the outside.

The only hardware which is not permanently attached to the major pieces of this equipment are some 5/16 - $18 \times 3 / 4$ inch long pan head machine screws and matching nuts. They are used to fasten the reinforcing ring segments together and to fasten the rings to the LEXAN panels.

Since the polyvinyl chloride bag fits rather tightly over the LEXAN frame, it is not feasible to align the same small holes made through these 
two hardwares for instrument penetrations in subsequent runs. It is recommended that, when the instrumentation is withdrawn at the end of a run, the holes in the polyvinyl chloride bag be sealed with either polyvinyl chloride pressure sensitive tape or small patches of the floor piece material applied with vinyl plastic cement, for example, VC-2 by Schwartz Chemical Company, Inc., Long Island City, New York. When the next run is to be made, new holes can easily be made in the polyvinyl chloride bag to coincide with the existing holes in the LEXAN frame.

\section{Enclosure Ventilation}

The contents of the enclosure may be exhausted by lifting the structure from the floor or plastic sheet and ventilating by means of fans or blowers. Ventilation may also be accomplished by raising the polyvinyl chloride bag material to a height of about four feet from the floor. This enables the smallest LEXAN panel to be opened at the bottom by releasing about four disconnect screws along a side. Leaving the panel partially open while the fans inside the enclosure are operating will ventilate the system in 15 to 30 minutes. Blowers may be used to speed ventilation.

HELIUM MASS SPECTROMETER LEAK DETECTOR

A helium mass spectrometer leak detector is used to determine the partial pressure of helium in the enclosure. In order to minimize testing time and maximize accuracy, it is critical that the leak detector possess good stability and sensitivity. Modifications of conventional leak detectors have been made to increase sensitivity. For instance, the two-stage mass spectrometer by Peters ${ }^{1}$ is capable of easily detecting a leak of $10^{-13}$ centimeters - atmosphere per second. Daly 2 also describes a means of reducing background noise. A General Electric LC-20 Helium Mass Spectrometer Leak Detector was used in the experiments described in Section 6, "Experimental Procedures and Sample Results." It is discussed in this subsection.

\section{Types Available}

Turnbul1 ${ }^{3,4}$ has outlined the general principles of leak detectors and has commented on the performance and specifications of several which are commercially available. A report on leak detectors was made recently by A. J. Bialous ${ }^{5}$ for the General Electric Company. The information in Appendix VI, "Manufacturers and Operating Characteristics of Helium Mass Spectrometer Leak Detectors," is extracted from Mr. Bialous's report.

Behavior of Tested Mass Spectrometer Leak Detector

A General Electric LC-20 Helium IVlass Spectrometer Leak Detector was employed in the work described in Section 6, "Experimental Procedures and Test Results." Figure 13 is a diagrammatic sketch of the LC $-20^{6}$. 


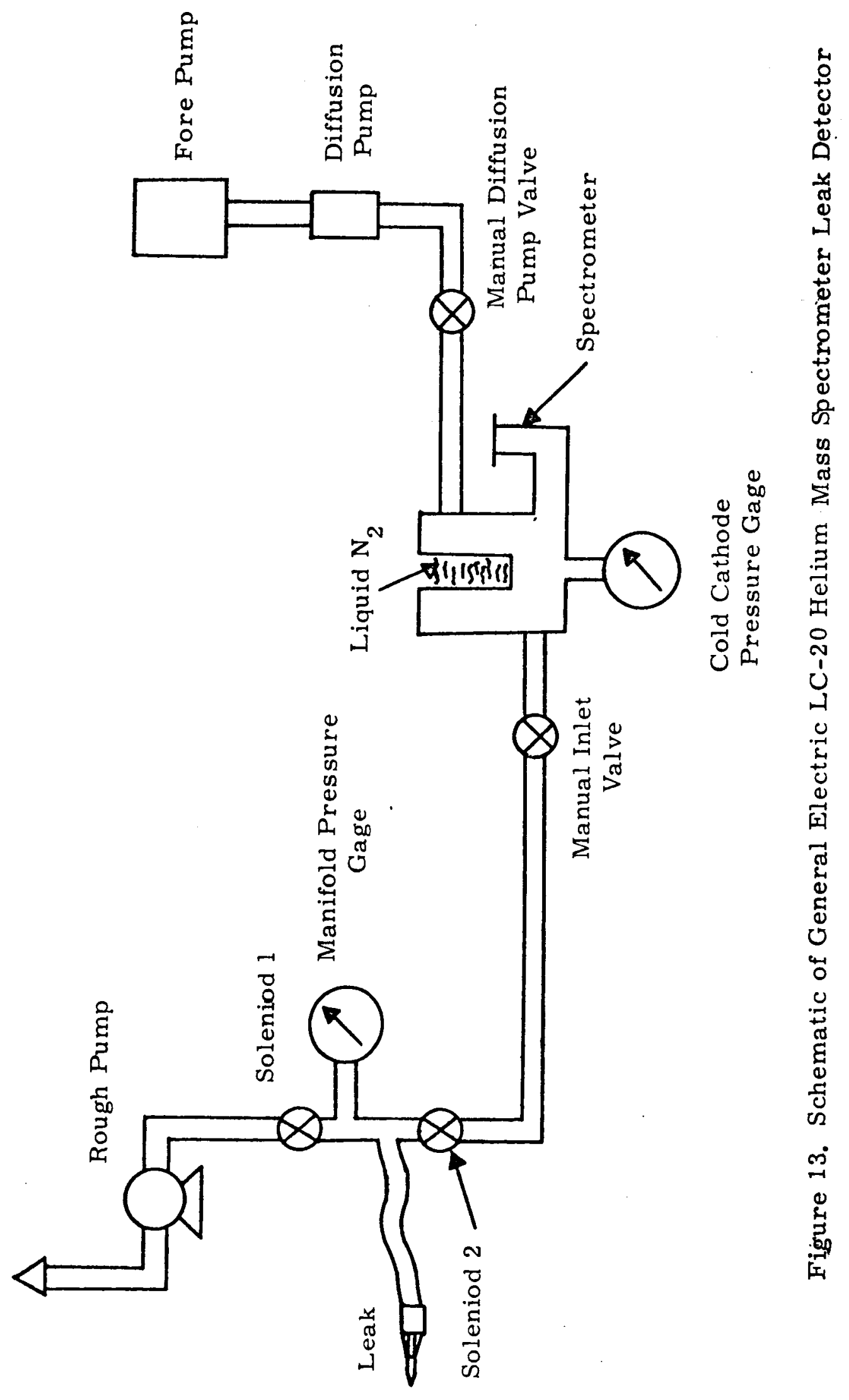


Startup begins with the valves in the following positions:

\begin{tabular}{ll}
\multicolumn{1}{c}{ Valves } & $\begin{array}{l}\text { Positien } \\
\text { Solenoid 1 }\end{array}$ \\
Solenoid 2 & Open \\
Manual Inlet & Closed \\
Manual Diffusion Pump & $\begin{array}{l}\text { Closed } \\
\text { Open }\end{array}$
\end{tabular}

When the manifold pressure is in the range of $1<\mathrm{p}<30 \mu$ soleniod 2 would be opened and the manual inlet valve cracked to allow tie sample gas to enter the mass spectrometer tube. The cold cathode gage can register between $10^{-5}$ and $10^{-3}$ torr.

Good control of the pressure in the spectrometer tube, indicated by the cold cathode gage, was difficult to obtain. Control was improved by lengthening the channel for the valve seating. A Consolidated Electrodynamics Corporation sampling probe was used and it gave good control of the manifold pressure. Figure 13 shows that a certain portion of the flow through the probe will go to the rough pump; the remainder being directed tow ard the spectrometer tube.

Figures 14 and 15 illustrate the influence of tube and manifold pressures on the reading for atmospheric helium. Figure 14 shows that the sensitivity of the instrument rapidly increases for tube pressures greater than $7 \times 10^{-8}$ torr, exhibiting a monotonic dependence of sensitivity on tube pressure. Figure 15 shows only $\varepsilon_{\text {. }}$ ild effect of manifold pressure on sensitivity. The effect, however, becomes more pronounced with increasing tube pressure.

For example, consider the following values:

$$
\begin{aligned}
& \stackrel{\mathrm{P}}{\mathrm{m}}=30 \mu \\
& \mathrm{P}_{\mathrm{t}}=2 \times 10^{-5} \text { torr }
\end{aligned}
$$

The ammeter reading is 47 microamperes. . Hence, since the partial pressure of helium in the atmosphere is $5.24 \times 10^{-6}$ atmospheres, $10^{-7}$ atmospheres of helium should give a reading with these settings of appoximately 1 microampere. . Considering noise, the General Electric LC-20. Helium Mass $\$$ pectrometer. Leak Detector should be able to detect a helium pressure rise of $5 \times 10^{-7}$ atmospheres. at these settings.

Figure 16 shows a plot of leak detector sensitivity (microamperes per microatmosphere of helium) versus tube pressure at a manifold pressure of 15 microns. A microatmosphere is defined as $10^{-6}$ atmospheres. 'This figure can be useful in estimating the leak detector sensitivity at a given setting. 


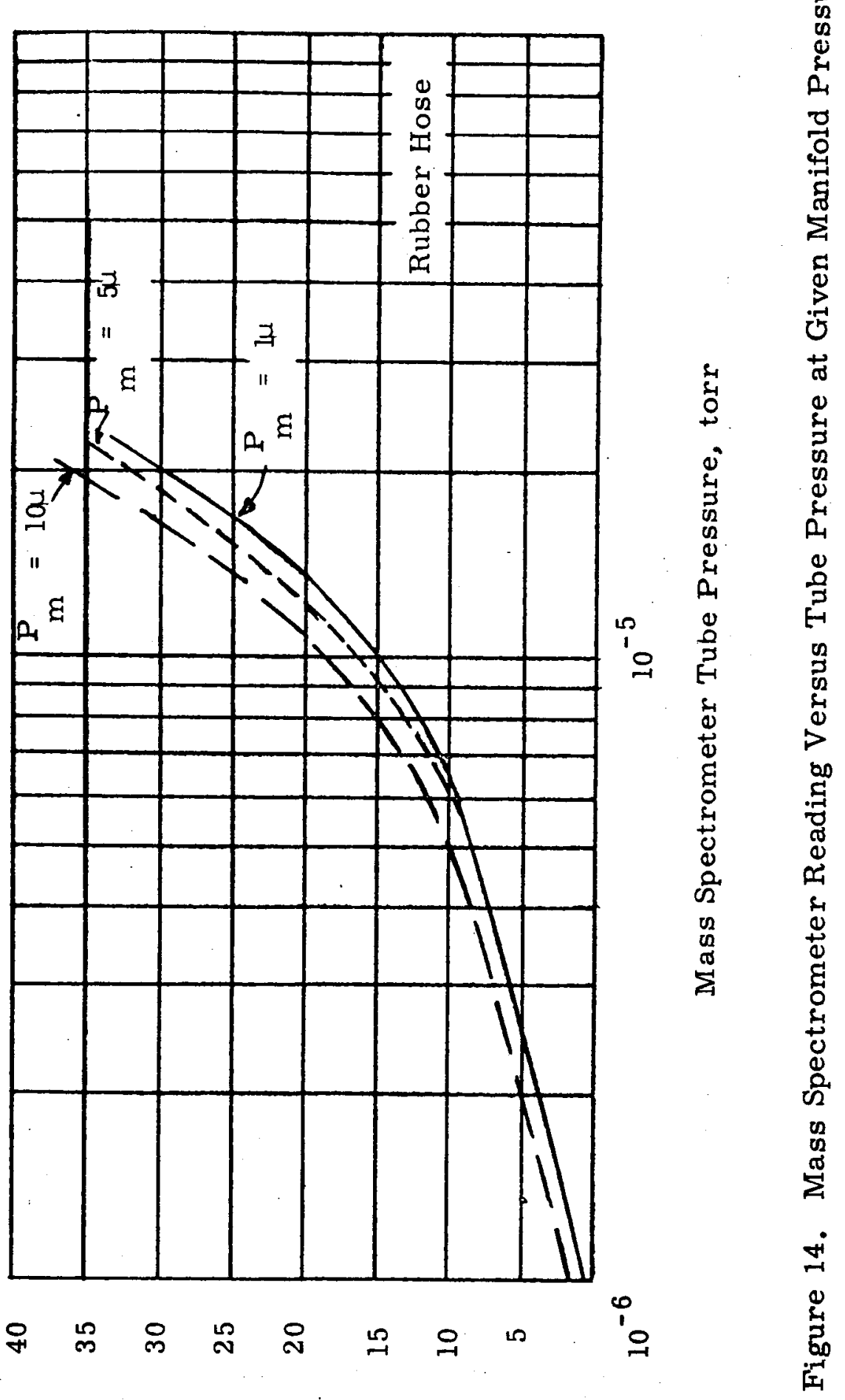

en sutpeəy 


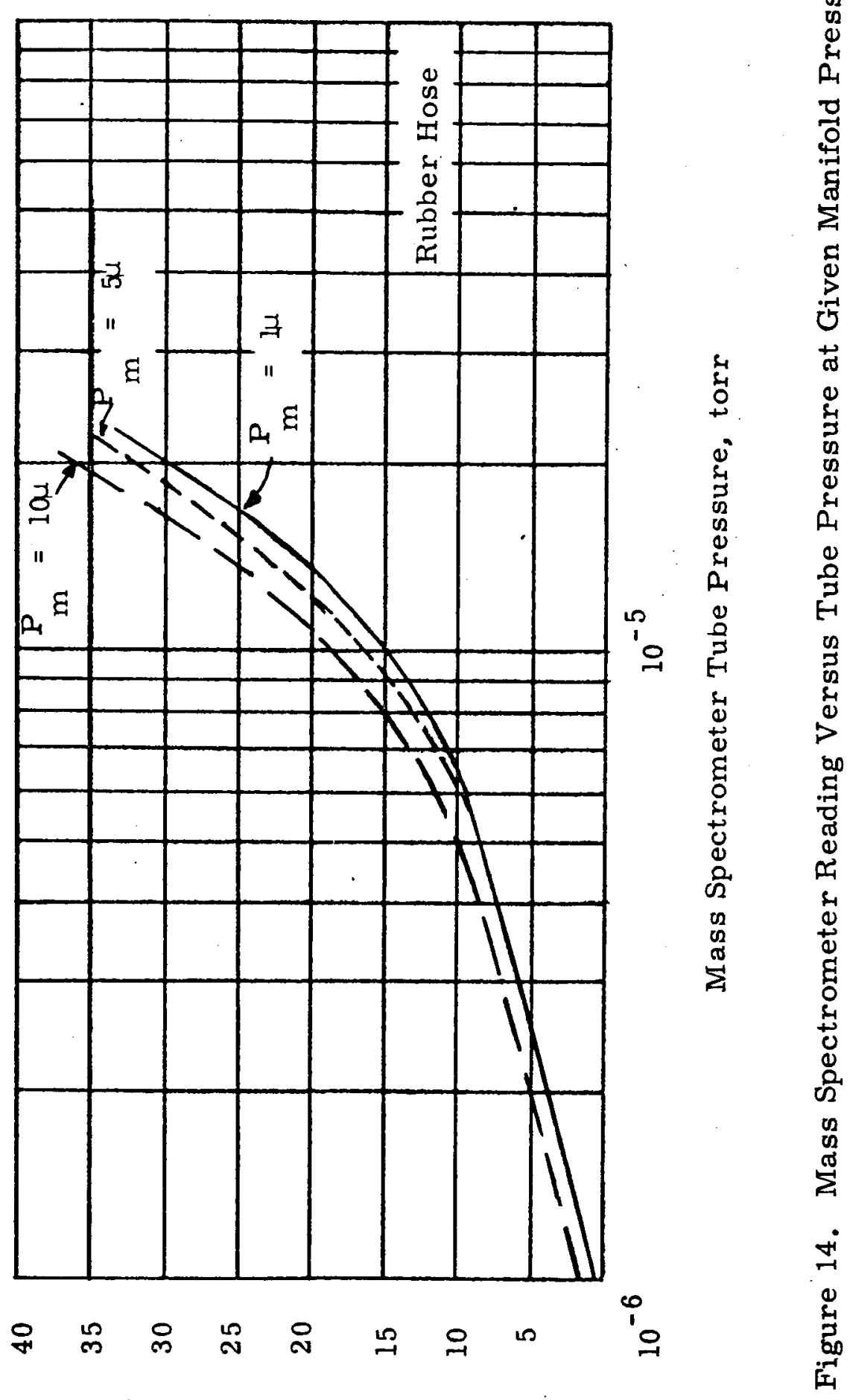

e 


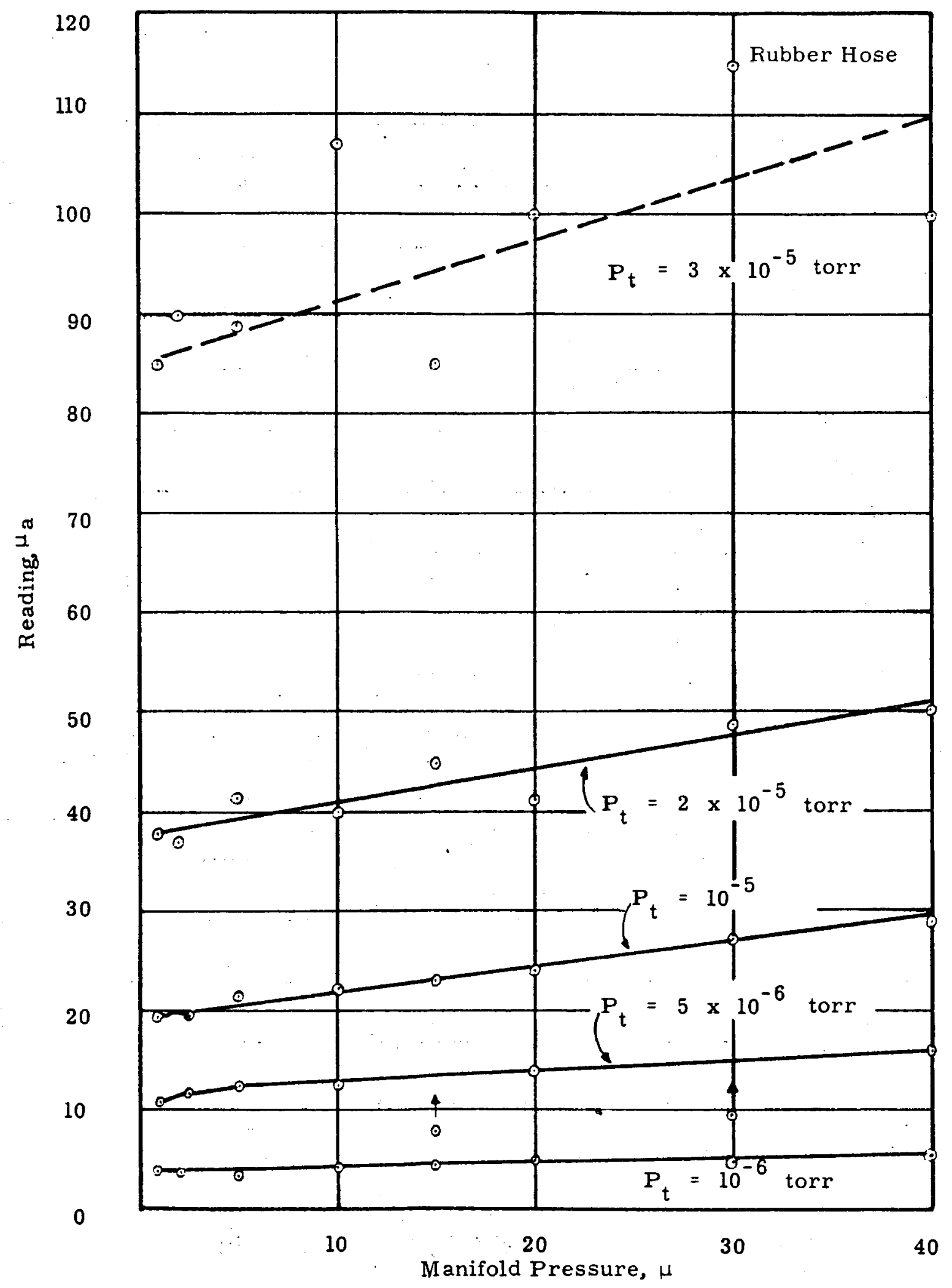

Figure 15. Mass Spectrometer Reading Versus Manifold Pressure at Given Tube Pressure. 


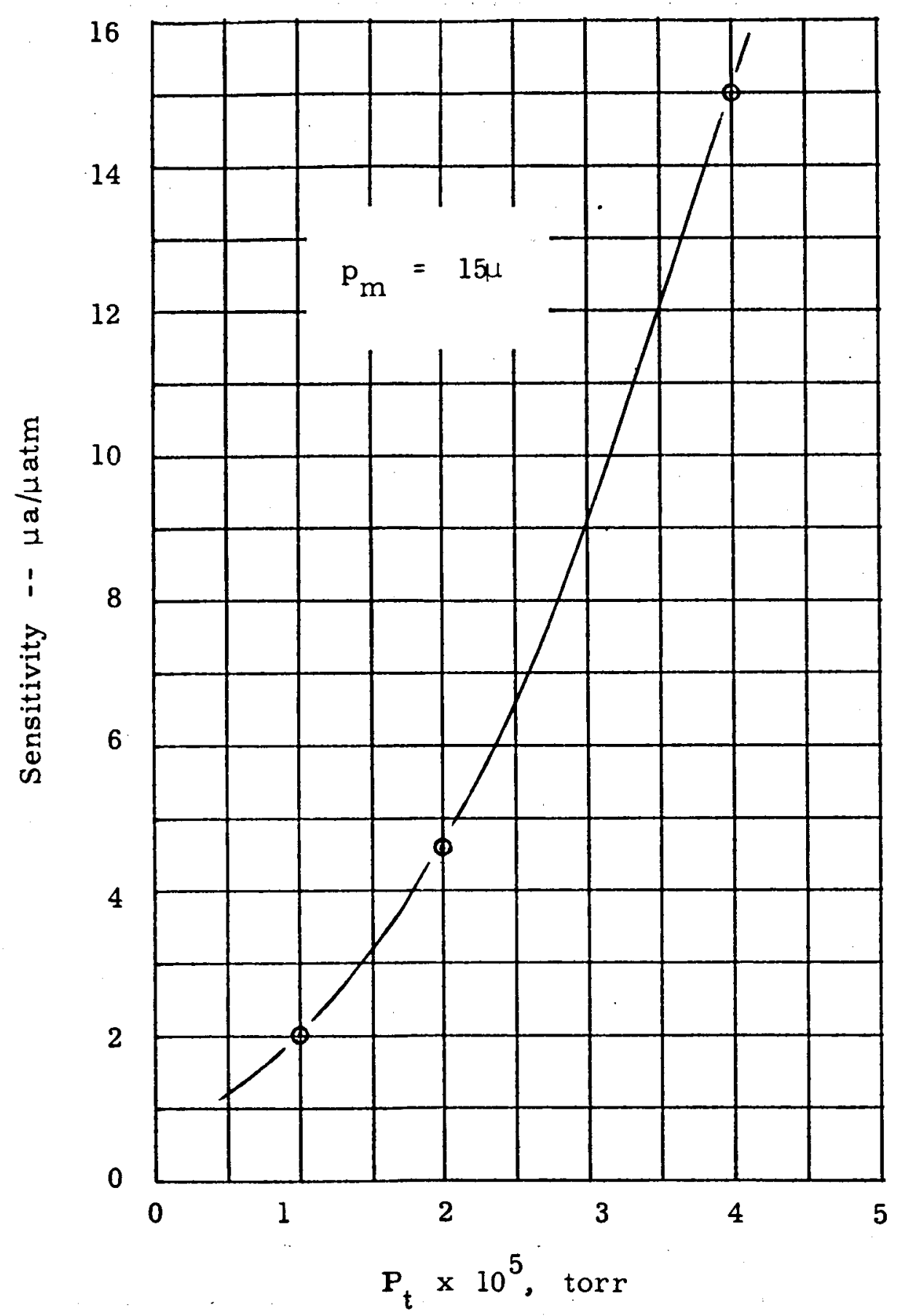

Figure 16. Detector Sensitivity Versus Tube Pressure. 


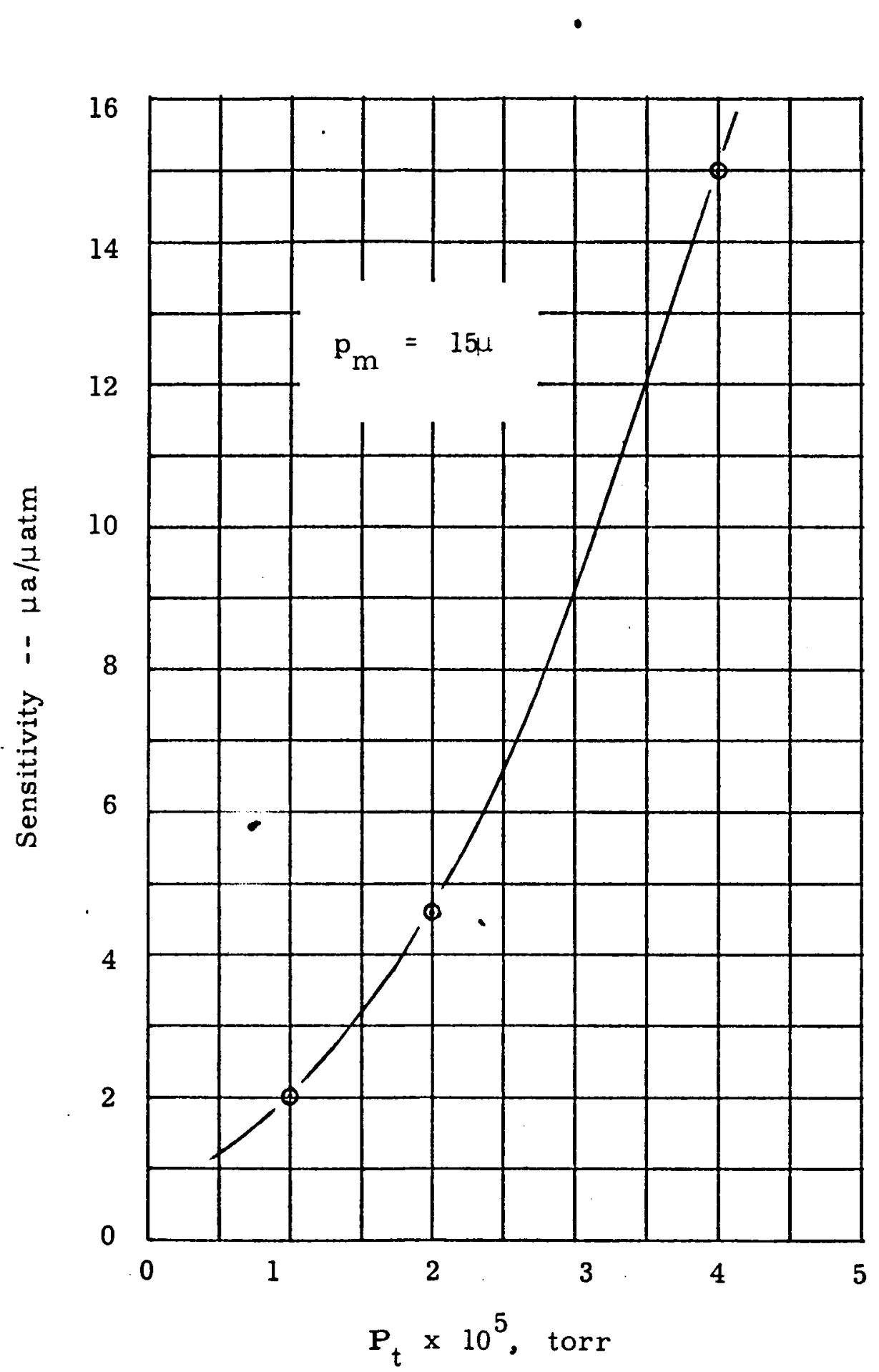

Figure 16. Detector Sensitivity Versus Tube Pressure. 


\section{STEADY LEAK FLOW CALIBRATOR}

The purpose of the Steady Leak Flow Calibrator is to supply a known and constant leak of helium trace gas into the enclosure. Comparison can then be made of the calibrated leak with the leak to be tested. The calibrator is used for two of the three methods of estimating leak flows which

are described in Section 6, "Experimental Procedures and Sample Results." They are:

1. Comparison Testing Method, in which the test leak is directly compared with a calibrated leak.

2. Superposition Method, in which the ratio of the rate of increase for the test leak and the combined calibrated and test leaks is used to determine the test leak rate.

3. The third method, the Injection Testing Method, uses a common laboratory syringe rather than a steady leak flow calibrator. This method is fully discussed in Section 6.

In effect, the calibrator acts as a reference or zero point which enables the user to determine the overall performance of the system. The use of a calibrating device is required primarily because of limited knowledge of the free volume in the enclosure and the possibility of permeation of trace gas through the enclosure. Although the volume of the enclosure remains constant, each system to be tested displaces a different amount of free space. In addition the enclosure volume may not be known at all.

Since the calibrator will supply a standard reference for the system, care should be exercised in its design. It is particularly important that the calibrator

1. include leaks accurately calibrated against standard leaks

2. maintain a constant rate of leak for the entire test period.

Naturally, simplicity and ease of use are to be considered.

Two alternative designs incorporating the above delineated characteristics were suggested. These designs were based on

1. the use of a pressure regulating device, or

2. the use of a ballast tank.

Both methods of construction are aimed at achieving a constant leak rate by maintaining a constant pressure difference across the calibrated leak. In the first design constant pressure is maintained through the use of a regulator, and in the second design it is maintained by means of a large quantity of helium trace gas which suffers a small fractional depletion during the run. 
The leak rate is a function of the pressure drop across the leak. The functionality of the pressure drop depends upon the flow regime, that is, whether the flow is laminar and/or molecular. These aspects are discussed in greater depth in Appendix II, "Extrapolation of Leak Data from Low to High Pressure." In laminar or viscous flow, the leak rate is related to the pressure through Poiseuille's equation:

$$
Q=\frac{\pi a^{4}}{16 \mu L}\left(P_{2}^{2}-P_{1}^{2}\right)
$$

That is, the leak rate depends on the difference of the squares of the pressures.

In molecular flow (Ref. 7) the leak rate is proportional to the pressure drop, thus::*

$$
Q=30.48 \times 10^{3} \frac{a^{3}}{L}\left(\frac{T}{M}\right)^{1 / 2}\left(P_{3}-P_{1}\right) \frac{c c-a t m}{s e c}
$$

Equations 13 and 14 illustrate the importance of a relatively steady pressure in maintaining a constant leak rate, especially for flow which is predominantly laminar.

Safety aspects in calibrator design should not be overlooked. Provision should be made for at least 3 or 4 times the maximum expected pressure.

Pressure Regulator Design

A schematic of a possible system employing a pressure regulator is shown in Figure 17. A number of mechanical and electronic pressure control devices are available and a list of these devices with the manufacturers is given below. The first two listed are electronic and cost between 600 and 2000 dollars. The last two cost between 50 and 200 dollars

1. Electronic Process Regulator

Manufactured by: Physics for Industry, Inc.

Rochester 17, New York

Many pressure ranges available: e.g., 0-200, 0-300, .. 0-1000 psig

Control to within $\pm 0.4 \%$

2. Pressure Controller (Type PSC-2)

Manufactured by: Hass Instrument Corporation

6173 Branch Avenue

Washington 23, D.C.

Has a maximum pressure limit of 52 psia

*Symbols used in this "Quantitative Leak Test Design Guide" are defined and their units given in Section 3, "Symbols." 


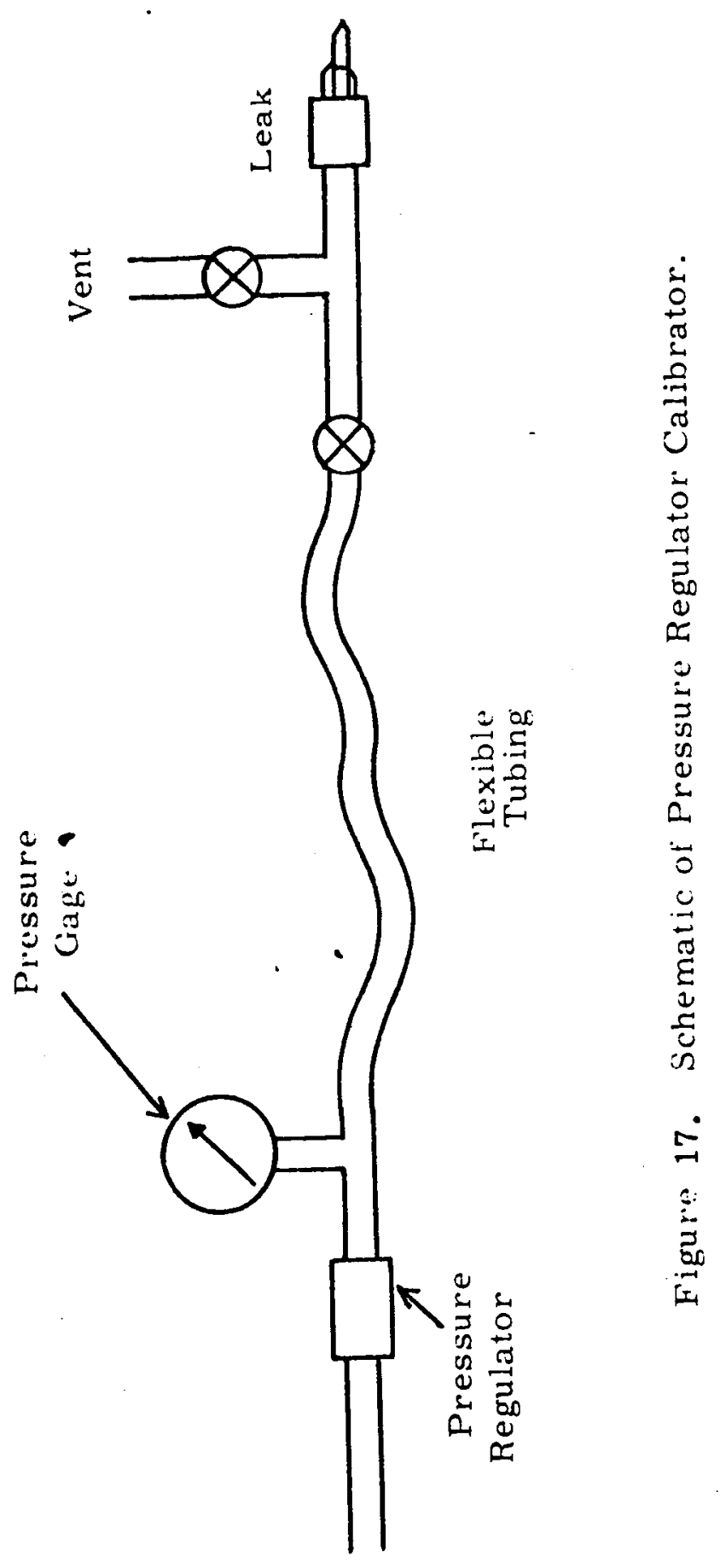


3. Cartesian Manostat (\#6A or 8)

Manufactured by: The Emil Grenier Company

20-26 N. Moore Street

New York 13, New York

Good accuracy: $0.05 \%$ of setting or $1 \mathrm{mmHg}$ whichever is larger

4. Cartesian Manostat

Manostat Corporation

New York 13, New York

\section{Ballast Tank Design}

Another simple means of achieving a constant flow rate is through use of a large capacity reservoir of helium trace gas in a ballast tank. Such a scheme possesses a minimum of complicated components. A schematic of a calibrator employing a ballast tank is shown in Figure 18. A photograph of a steady leak flow calibrator constructed on the ballast tank principle is shown in Figure 19. Details for operating the calibrator shown in Figure 18 are given in Appendix V "Operation of A Steady Leak Flow Ballast Tank Calibrator."

Starting up the calibrator from time zero requires that the system be pumped down. Vacuum is indicated by the coarse pressure gage, which is a combination gage. The vacuum valve is then closed and leak gas admitted through the appropriate valve until the desired pressure is obtained. The valve before the fine pressure gage acts as a protection. This, however, might have been obviated through the use of an actual protection valve or relief valve. The vent is also used in adiusting the pressure and venting the system.

System valves should be able to withstand both vacuum and pressure. Bellow seal valves are well suited for the purpose. Hoke Company and Nuclear Products Company, among others, manufacture this type of valve in a variety of materials and for various operational conditions.

1. Sizing of the Ballast Tank for the Desired Leak Rate Control

For accurate testing, the variation in the leak rate should be minimal. The system recommended for a steady leak flow calibrator employs a ballast tank to maintain a constant or nearly constant pressure drop across the leak. During operation the ballast tank will lose trace gas and therefore pressure. Consequently, the gas leak rate will decline with operating time.

The variation of the flow rate is dependent on several quantities:

Helium pressure rise in the enclosure

Enclosure volume

Ballast tank volume 


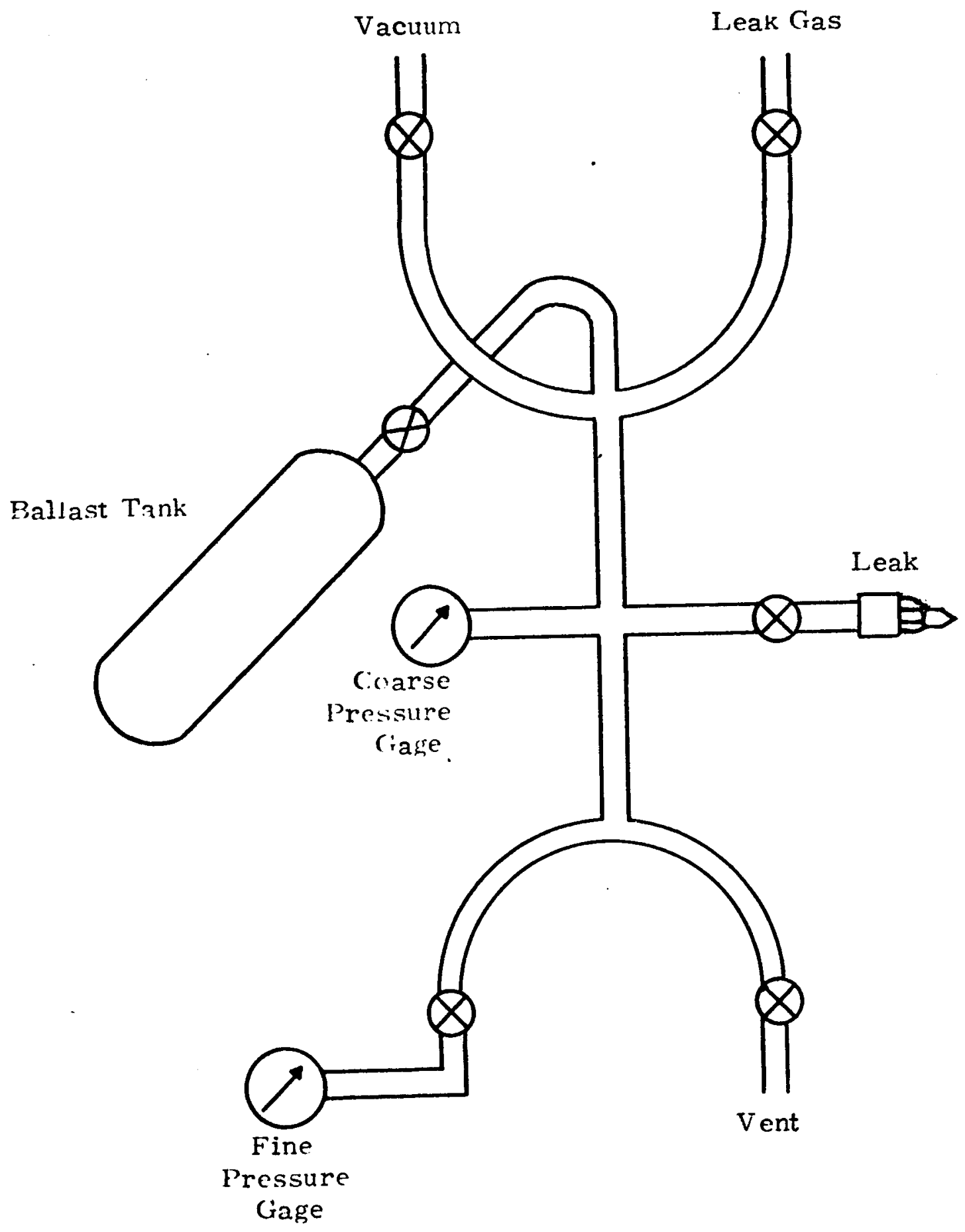

Figure 18. Schematic of Ballast Tank Calibrator. 


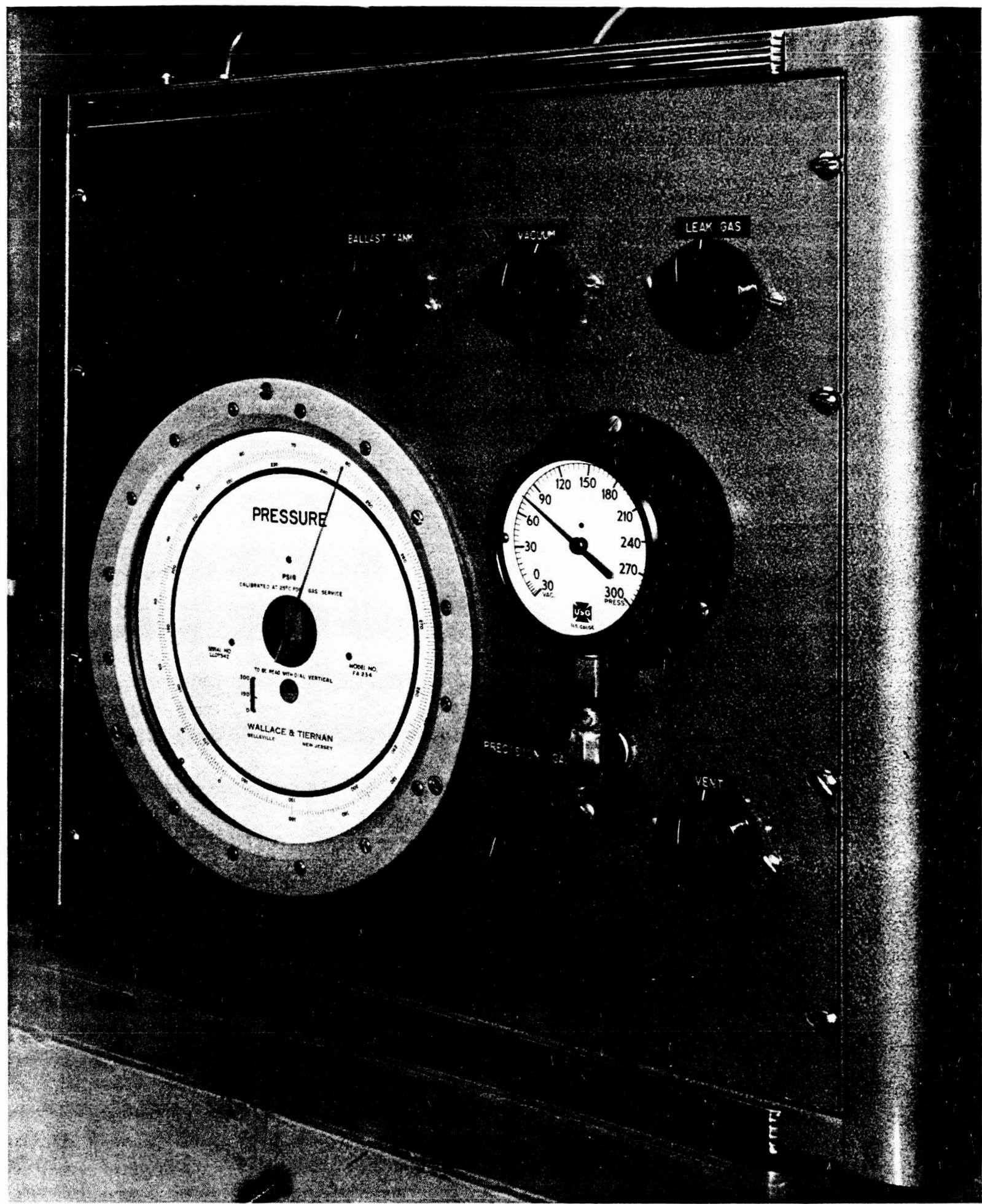

Figure 19. A Ballast Tank Calibrator. 
Initial pressure of helium in the ballast tank

Pressure at the downstream side of the leak

This subsection explains the method for choosing the volume of the ballast tank for a given percent change in the leak rate. Theory is presented first, followed by the recommended curves and an example.

Theory. Pressure decline in the ballast tank is computed from the ideal gas law:

$$
\Delta_{p}=P_{a i}-P_{a f}=\frac{4 n R T}{V_{B T}}
$$

Neglecting permeation, the product $Q \theta$, the cubic centimeters of leak gas may be expressed as:

$$
\dot{\mathrm{Q} \theta}=2.73 \times 10^{5} \frac{\Delta \mathrm{p}_{\mathrm{b}}}{\mathrm{T}}
$$

The moles of leak gas lost from the ballast tank is readily computed from Equation 16:

$$
\Delta \mathrm{n}=\frac{\mathrm{Q} \theta}{22.4 \times 10^{3}}=12.2 \frac{\Delta \mathrm{p} \mathrm{V}_{\mathrm{b}}}{\mathrm{T}}
$$

Equation 17 next substit d into Equation 15 to give the pressure decline:

$$
\Delta_{\mathrm{p}}=\mathrm{P}_{\mathrm{zi}}=\mathrm{P}_{\mathrm{zf}}=\frac{12.2 \mathrm{R} \Delta \mathrm{p} \mathrm{V}_{\mathrm{b}}}{\mathrm{V}_{\mathrm{BT}} .}
$$

The contents of the ballast tank and enclosure have been assumed to be at identical temperatures.

Assuming laminar flow through the leak, the flow rate is a function of the difference of squares of the upstream and downstream pressures:

$$
Q=K\left(P_{3}^{2}-P_{1}^{2}\right)
$$

Thus, the fractional change in leak rate is calculated from Equation 19:

$$
\frac{Q_{i}-Q_{f}}{Q_{i}}=\frac{P_{2 i}^{2}-P_{2 f}^{2}}{P_{z_{i}}^{2}-P_{1}^{2}}
$$

where $P_{1}$ is the pressure downstream of leak, expressed in atmospheres, and the subscripts $i$ and $f$ denote initial and final conditions respectively. 
Upon rearranging, Equation 20 becomes:

$$
\frac{Q_{i}-Q_{f}}{Q_{i}}=\frac{2 \frac{\Delta P}{P_{2 i}}-\frac{\Delta P^{2}}{P_{z i}^{2}}}{1-\frac{P_{i}^{2}}{P_{2 i}^{2}}}
$$

where,

$$
\Delta P=P_{2 i}-P_{2 f}, \text { atm }
$$

The last term in the numerator of Equation 21 is neglected as being small in comparison to the first term. This approximation, if anything, would tend to increase the estimation of the leak rate variation. When Equation 18 is substituted into Equation 21 and the gas constant taken into account, the working equation for selecting the ballast tank volume given the desired fractional flow decrease is obtained:

$$
\frac{Q_{i}-Q_{f}}{Q_{i}}=\frac{1.99 \Delta_{p} V_{b}}{V_{B T} P_{2 i}\left(1-\frac{P_{i}^{2}}{P_{2 i}^{2}}\right)}
$$

Practice. Figure 20 shows a plot of Equation 22 for various initial ballast tank pressures and the most typical downstream pressure, one atmos phere.

As an example, the ballast tank volume required for a fractional flow change of one percent with an initial ballast tank pressure of ten atmospheres is computed. The pressure rise is assumed to be $10 \times 10^{-6}$ atmosphere. The enclosure volume is assumed to be 1000 cubic feet or $2.83 \times 10^{4}$ liters. Then:

$$
\frac{1 \mathrm{pV} V_{\mathrm{b}}}{\mathrm{V}_{\mathrm{BT}}}=\frac{0.283}{\mathrm{~V}_{\mathrm{BT}}}
$$

and:

$$
\frac{Q_{i}-Q_{f}}{Q_{i}}=10^{-2}
$$

From Figure 15 the solution is obtained:

$$
\frac{\mathrm{CpV}_{\mathrm{b}}}{\mathrm{V}_{\mathrm{BT}}}=\frac{0.283}{\mathrm{~V}_{\mathrm{BT}}}=4.9 \times 10^{-2}
$$

or:

$$
\mathrm{V}_{\mathrm{BT}}=5.78 \text { liters. }
$$




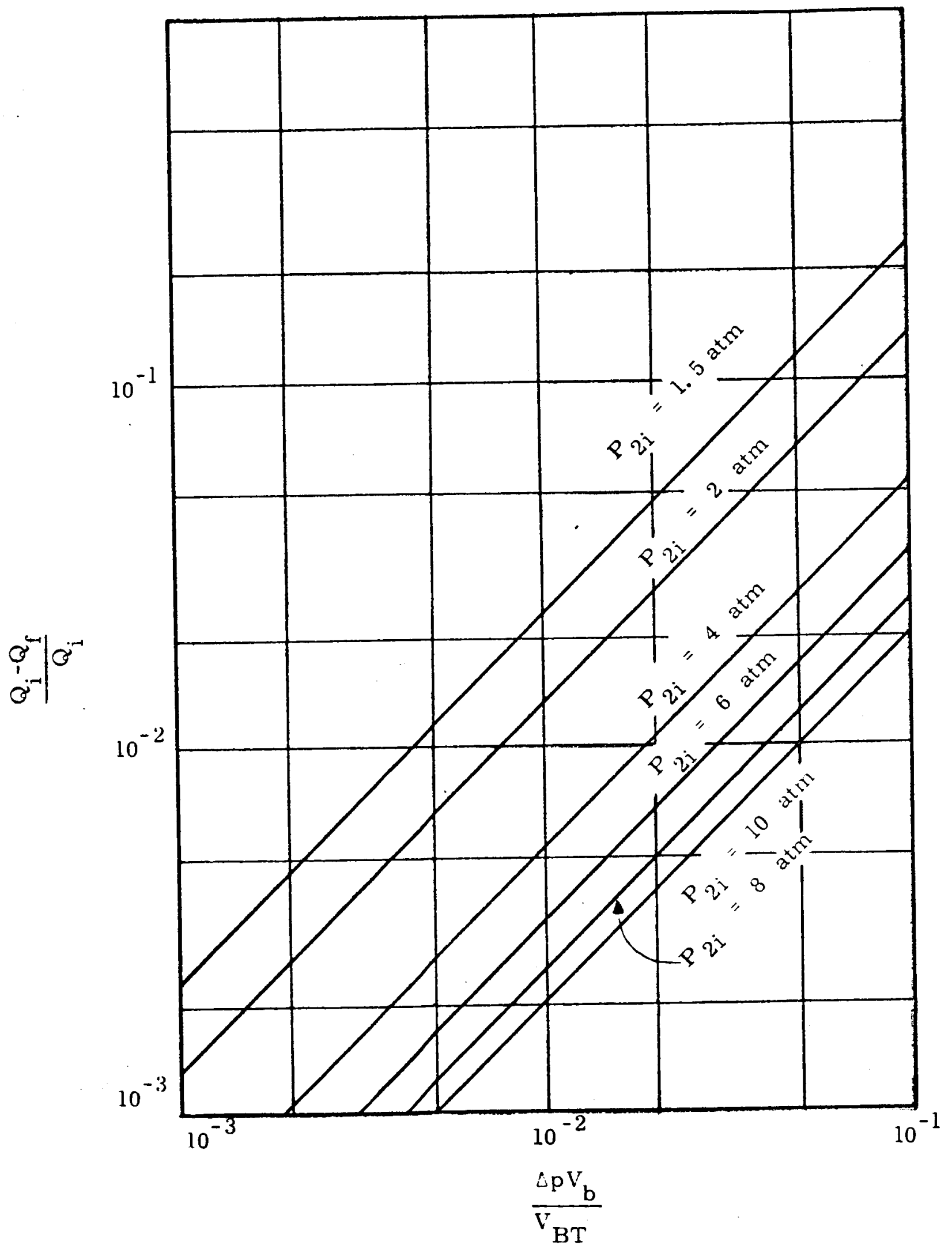

Figure 20. Functional Flow Rate Decline Versus Parameter $\Delta \mathrm{pV}_{\mathrm{b}} / \mathrm{V}_{\mathrm{BT}}$. 
For a second example, the following values are assumed:

$$
\begin{aligned}
& \Delta \mathrm{p}=10 \times 10^{-6} \mathrm{~atm} \\
& \mathrm{~V}_{\mathrm{b}}=100 \mathrm{ft}^{3}=2.83 \times 10^{3} \text { liters } \\
& \mathrm{V}_{\mathrm{BT}}=4 \text { liters } \\
& \mathrm{P}_{\mathrm{2}_{\mathrm{I}}}=3 \mathrm{~atm} \\
& \mathrm{P}_{1}=1 \mathrm{~atm}
\end{aligned}
$$

From Equation 22:

$$
\begin{aligned}
\frac{Q_{i}-Q_{f}}{Q_{i}} & =\frac{1.99\left(10^{-5}\right)\left(2.83 \times 10^{3}\right)}{(4)(3)(1-1 / 9)} \\
& =0.528 \times 10^{-2}
\end{aligned}
$$

In other words, for these conditions, a leak variation of about 0.5 percent can be expected.

Values for the Tested Calibrator. The calibrator supplied to the Jet Propulsion Laboratory was equipped with a one gallon (3.785 liters) ballast tank. The enclosure $w: 231$ cubic feet. Calculations were made based on these figures for the $p$ entage flow rate change as a function of ballast charging pressure. The resulting graph is shown in Figure 21 . In the light of these calculations, it was decided to, fix the minimum charging pressure of the ballast tank at four atmospheres. Therefore, calibrated leaks for this particular application must be constructed such that the leak rate for a pressure drop of four atmospheres into one atmosphere must be sufficiently small to satisfy the lower limit of the leak rate range.

\section{LEAK CONSTRUCTION AND DATA}

Leaks whose flow rate versus pressure drop is known are required for the fabrication of the calibrator. This subsection describes the construction of leaks and their calibration. Representative data are also included.

Construction of Leaks

Leaks can be fashioned in a variety of ways. The method used by the General Electric Company will be outlined, in hopes that it will serve as a useful example.

The leaks are formed from nickle tubing. Nickel is preferred to copper which is more temperature sensitive. A diagram of a typical leak is shown 


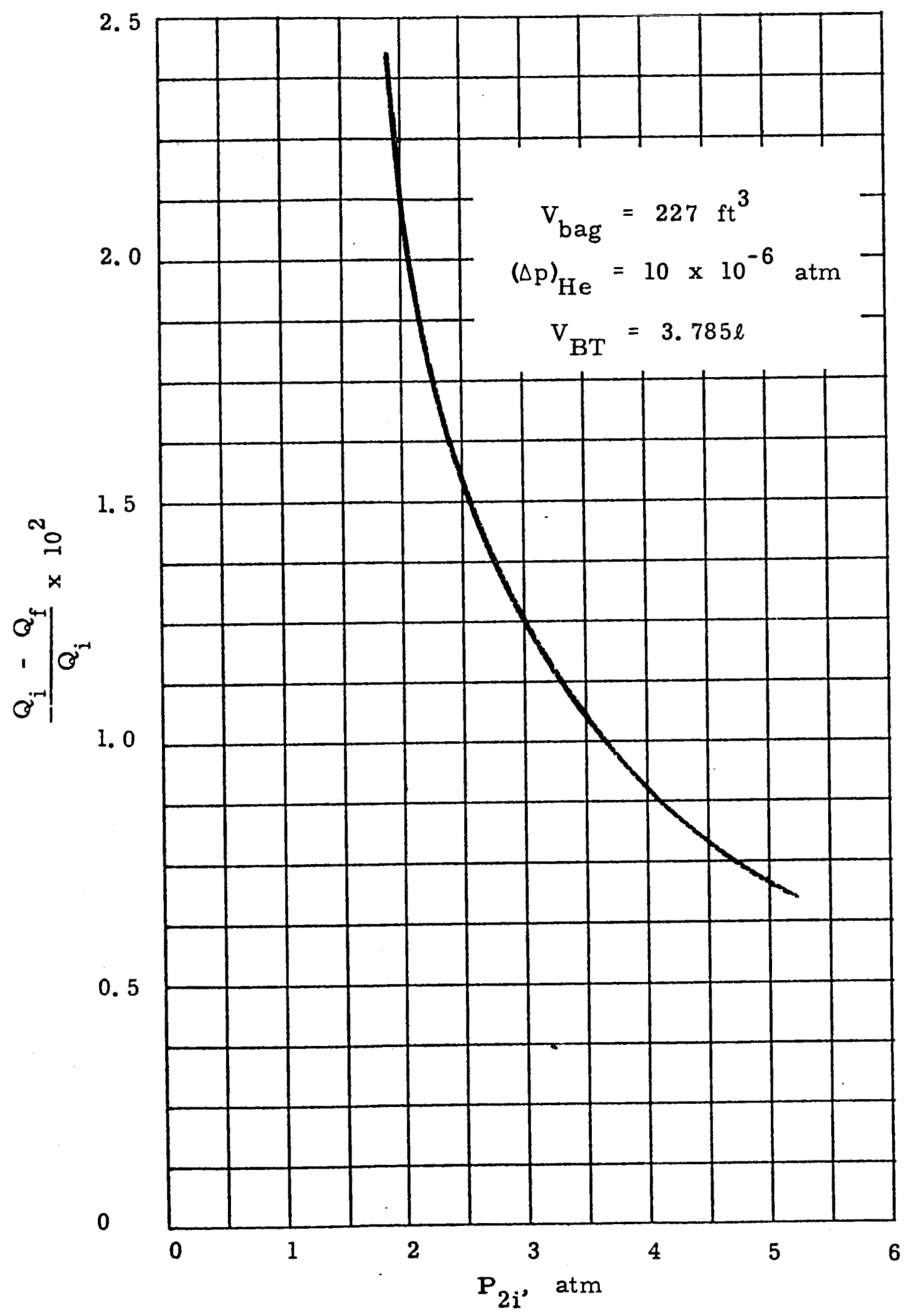

Figure 21. Flow Rate Change Versus Initial Ballast Tank Pressure. 
in Figure 22*. The crimped nickel tubing is protected by an outer monel metal tube. The nickel tube leak is fixed in place through a base support of monel metal.

The sequence of steps used in fabricating this type of leak are:

1. An uncrimped nickel tube is brazed into the monel base. Hydrogen oven braze is recommended in preference to a braze in air due to particle formation.in the latter technique.

2. The tubing is then crimped by means of rollers until the desired leak rate is obtained. The leak rate. can be measured by means of a helium mass spectrometer. The interrelation between the desired leak rate and the pressure drops can be obtained from the formulae of Appendix II, "Extrapolation of Leak Data from Low to High Pressure."

3. An accurate determination of the relation between leak rate and pressure drop is now obtained by measuring the displacement of a liquid from a pipet, whose capacity might range from 0.1 cubic centimeters to 5 cubic centimeters depending on the flow rate. The rate of displacement of the liquid is naturally proportional to leak rate.

4. The leak and base are soft soldered into the monel nickel tubing. Soft solder is used instead of braze in order to minimize the temperature at the leak. High temperatures may cause thermal. stresses which would change the leak calibration.

5. A filter may be placed on the high pressure side. Such filter holders as the Millipore Filter Corporation (Box F, Ashby Road,

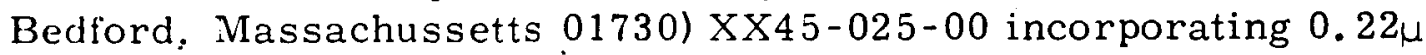
filter paper, which will actually remove particles of lower diameter due to electrostatic attraction, might be employed. Nuclear Products Company(10173 Rush Street, Box 649, El Monte, California 91733) also manufactures compact and convenient inline filters (series $F$ and series FR). They are lightweight and presently available in the $2 u$ size.

The availability of these kinds of leaks as a stock item is somewhat problematical. However, further information can be obtained from: Vacuum Products Business Section, General Electric Company, 1 River Road, Schenectady, New York 12308 and Vecco Instrument Company, Terminal Drive, Plainview, Long Island, New York 11803.

\section{Typical Leak Data}

חlustrative data obtained from leaks which were prepared for Jet Propulsion Laboratory, plotted as flow rate versus pressure drop, are shown

This type of leak has been constructed by K. Herbert Malmstrom Mechanical Technology Laboratory, General Electric Research and Development Center 


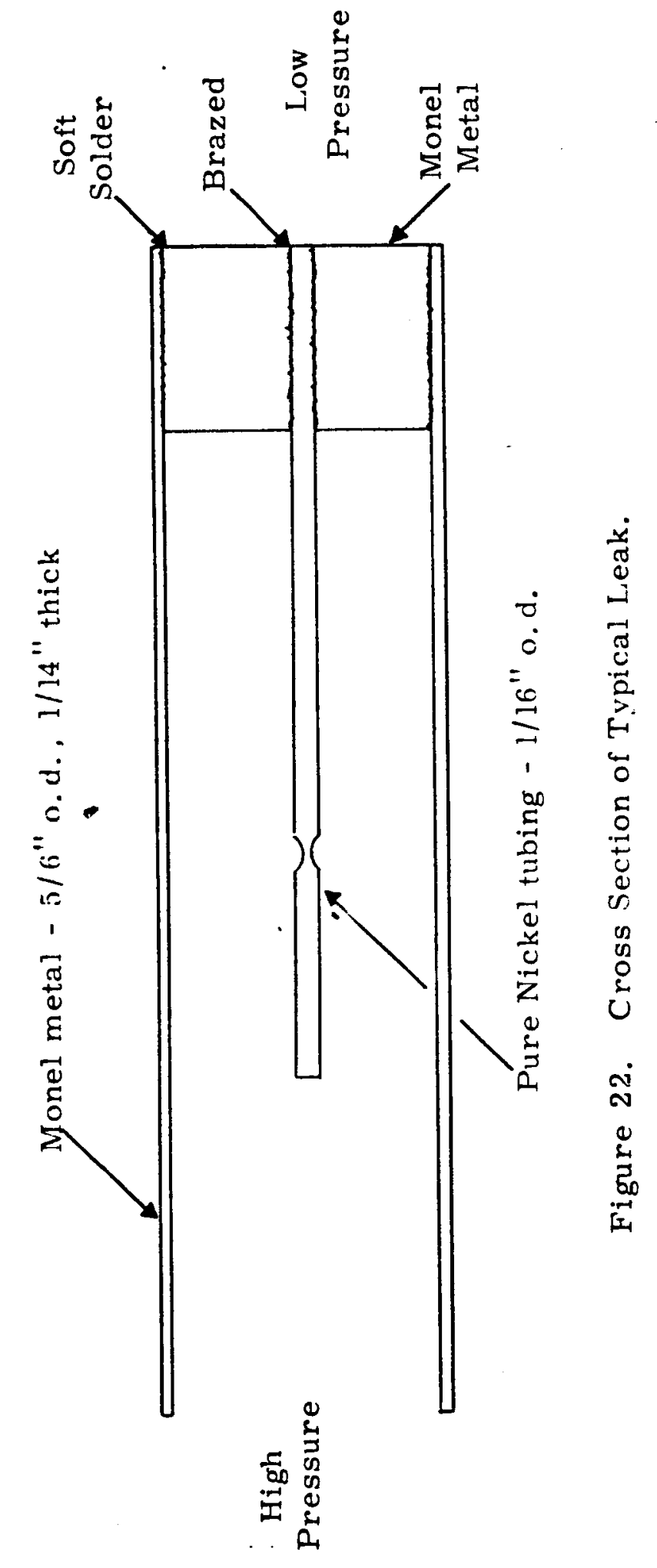


in Figure 23. The leak rate range prescribed was $1.4 \times 10^{-4}$ to $2.8 \times 10^{-2}$ cubic centimeter-atmospheres per second. Since the pressure range was fixed at 50 to 200 pounds per square inch, it was found necessary to employ three leaks. 


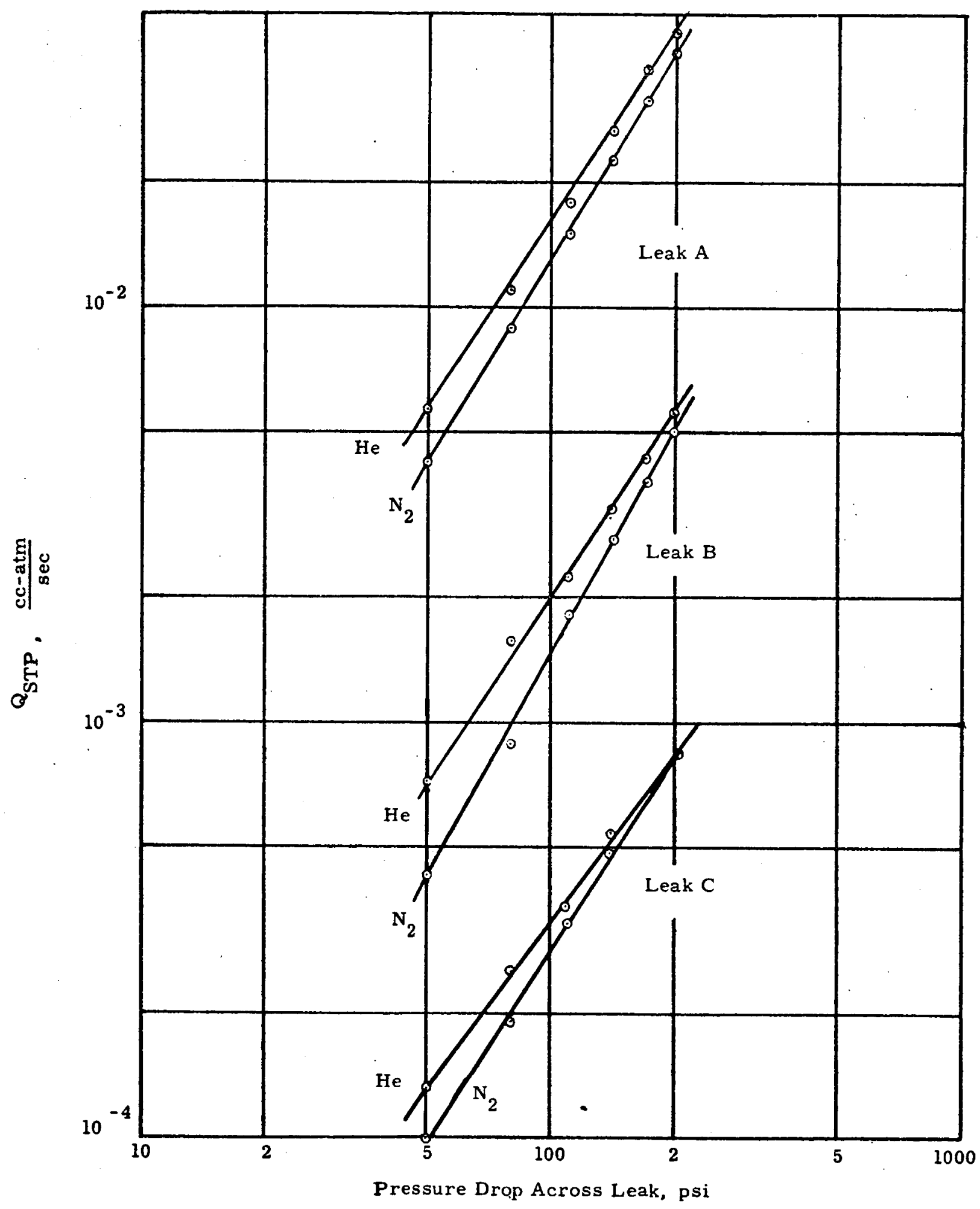

Figure 23. Leak Rate Versus Trace Gas Partial Pressure Drop. 


\section{Section 6}

\section{EXPERIMENTAL PROCEDURE AND SAMPLE RESULTS}

This section describes three testing method:s or determining leak rates by means of a calibrated enclosure technique. 'ire results of experimental tests run using these methods are also reported in this section.

In the calibrated enclosure technique, the.object to be tested is pressurized with helium and the helium leak rate determined. A mixture of helium and another gas may also be used. The test setup is shown in Figure 1. The major steps of rhis procedure are:

1. Pressuring the test object with pure helium or a mixture of helium and another gas (preferabiy the former).

2. Enclosing the object in a bag or tent.

3. Sensing the enclosum content in the and determining the rate of current increase in a mass spectrometer tube.

4. Calibiaing the current incrcase in the mass spectrometer in terms or a helium rate by either 1) comparing to known helium leaks or 2) injecting a known quantity of helium.

Once the helium or helium-mixture leak rate is known, the leak rates of other gases, such as nitrogen, can be estimated. The estimation process is described in Appendix III, "Predicting the Leak Rate of the System Gas From the Leak Rate of Helium or a Mixture of Helium and Another Gas."

The three different testing methods of determining leak: rates using this procedure are:

1. Comparison Method, in which the test leak is directly compared with a calibrated leak.

2. Superposition Method, in which the ratio of the rate of increase for tho: iest leak and the combined calibrated and test leaks is an inaicition of the test leak rate.

3. Injection Method, in which the rate of helium increase in the enclosure is determined, and then the enclosure calibrated by injecting a known amount of beitum.

\section{COMPARISON TESTING METHOD}

The Comparison Testing Method is the most fundamental of the three testing methods; it can be used where application of the others might be 
questionable. This approach hinges on obtaining data for the unknown leak and comparing it with data for known leaks in the same system. Permeability of the enclosure is not a hindrance since it will presumably be the same for the unknown and calibrated leaks. This method requires the greatest time to perform.

Pressurizing the Test System

The system to be leak tested is first pressurized with pure helium or a mixture of helium and another gas. Pressurization with helium is preferred.

The use of a mixture might be preferable if the test volume is large, since a mixture would be less expensive than pure helium. Also it would be difficult to obtain accurate results with pure helium if the leak were large, causing the helium concentration to rise rapidly enough to severely limit the time of the experiment. However, the prediction of the leak rate of nitrogen or other system gas from the leak data of a helium mixture with another gas is not altogether straightforward or precisely accurate. Hence, the use of mixtures for leak testing is not recommended for general use. Appendix III, "Predicting the Leak Rate of the System Gas From the Leak Rate of Helium or a Mixture of Helium and Another Gas, "discusses this further.

The most advisable pressure for the leak testing is that pressure which will actually be used in the operation of the system. Pressurizing to a lower pressure for the leak t $\mathrm{s} l$ and then extrapolating over large ranges is risky as is explained in Appendix II, "Extrapolation of Leak Data from Low to High Pressure." Accuracy can be lost by testing below operating pressure because of the possible existence of a check valve leak which allows flow only above the testing pressure, as explained in Appendix IV, "Leak Rate as a Function of Leak Structure."

\section{Preparing the Enclosure}

Free Volume

The greater the conformity of the enclosure to the shape of the object, the smaller the free volume will be and the more quickly results may be obtained. The volume of "free space" in the enclosure might be reduced through the use of inert volume such as balloons. Enclosure permeability other than gross leaks has been shown, in the discussion of permeation in Section 4, "Derivation of Governing Leak Rate Equations, " to be negligi.ble for most materials of reasonable thickness.

Seals

For most seals, either enclosure bag to bag, or bag to floor, plastic tape should serve well. Suitable enclosure bag materials are listed in Section 5, "Test Equipment." Polyvinyl chloride (20 mil) proved to be 
a durable item and is recommended. The floor should be reasonably smooth and clean in order to form good seals with the tape. If the condition of the floor makes good seals impossible, ia plastic sheet may be placed on the floor. Sealing can then be made from the bag to the plastic floor.

Care should be exercised in forming bag seals. If "sloping-off" of the helium concentration, as read on the helium mass spectrometer leak detector, is observed with time, this should be taken as evidence of poor seals. Although the sloping-off effect may appear at a glance to be small, , it could easily mean a difference of 10 to 15 percent in accuracy. Slopingoff should not be confused with an initially high rate of rise followed by the milder sloping straight line. This behavior appears to be sometimes characteristic of the leak detector.

Air Circulation

One regular office-size fan could be used for most volumes and test objects. However, if the volume is very large, say about 500 cubic feet, or the test object is shaped so that it does not allow adequate circulation, another fan may be desirable. The fan(s) should be positioned to achieve circumferential flow around the inside of the bag.

\section{External Connections}

Probe and calibrated leak connections into the enclosure can be made by means of bulkhead fittings, such as those shown in Figure 24. Certainly simpler connections could be made.

The concentration of helium, it might be anticipated, would be somewhat greater in the upper portion of the enclosure because of the relative densities of helium and air. However, a series of tests was' performed in which the probe and the calibrating leak positions were interchanged, that is, with the calibrated leak lower than the probe.

There was no evidence of a difference in accuracy between tests run with the calibrated leak and the probe in the normal and interchanged positions. The average error with the position interchanged was 9.5 percent, not significantly different from the average erfor for the original positioning. Therefore, provided the enclosure is adequately equipped with fans or blowers there is no effect of probe or leak position.

Provision for power lines into and out of the bag need not be elaborate. Simple duckseal or tape should provide adequate connections.

\section{Selecting Helium Mass Spectrometer Leak Detector Settings}

Adjustment of leak detector sensitivity will depend on a knowledge of the leak range to be expected and also on a familiarity of results obtained with the given enclosure volume and leak detector combination. It is 


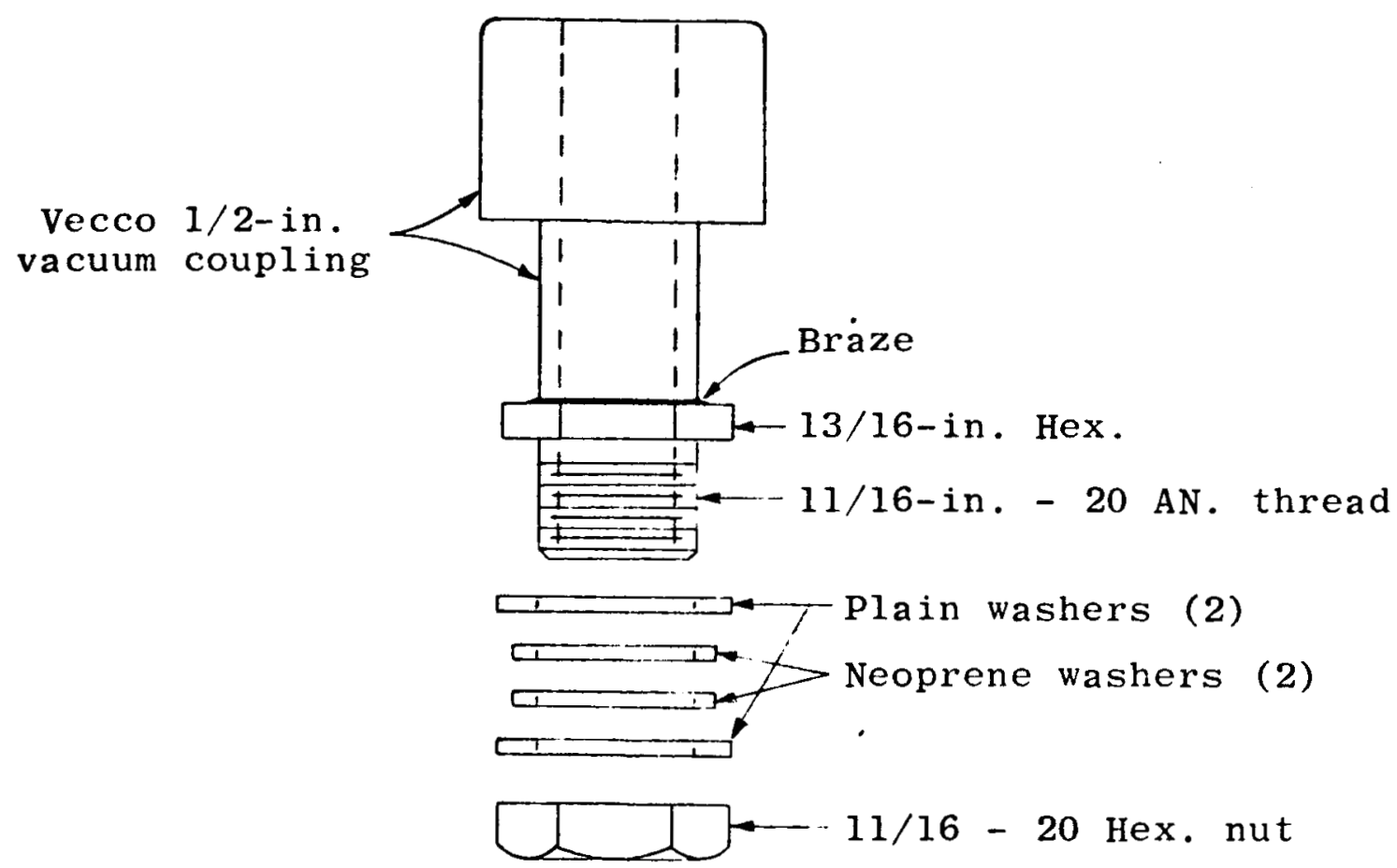

Fittiry For Probe

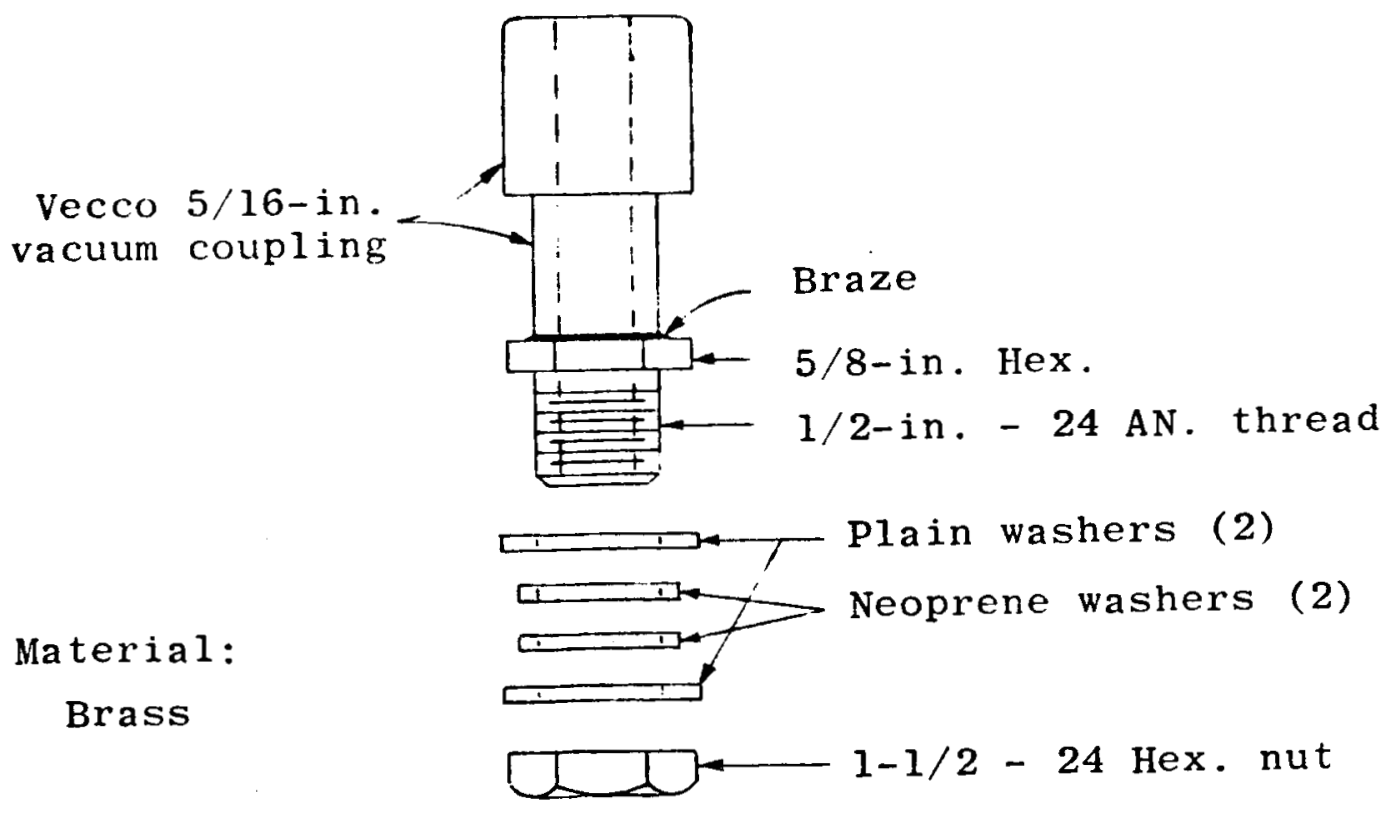

Fitting For Standard Leak

Figure 24. Enclosure Connectors 
advisable, especially if speed is desired, that the test operator have previously carried out several trial runs with the equipment at various leak rates, so that he is familiar with the particular equipments.

In order to facilitate the choice of mass spectrometer settings, several combinations of settings found useful tor the GE LC-20 Helium Leak Detector for a few leak rates are given in Table 3 .

Table 3

SUGGESTED MASS SPECTROMETER SETTINGS (Leaks Into an Enclosure Volume of 231 Cubic Feet)

\begin{tabular}{|c|c|c|c|c|c|c|}
\hline Leak Rate & $\mathrm{P}_{\mu} \mathrm{m}$ & $\begin{array}{l}P_{t} \\
\text { torr } \\
\end{array}$ & Emission & Scale & $\begin{array}{r}\text { M.S. } \\
\text { Reading } \\
\mu \mathrm{a} / \mathrm{hr} \\
\end{array}$ & $\begin{array}{l}\text { Chart } \\
\text { Speed } \\
\text { in/hr } \\
\end{array}$ \\
\hline $10^{-4}$ & 5 to 10 & $4 \times 10^{-5}$ & 1 & $\mathrm{X} 1$ & 0.3 & 1 (or less) \\
\hline $10^{-3}$ & 5 to 10 & $4 \times 10^{-5}$ & 1 & $\mathrm{X} 10$ & 3.0 & 1 to 2 \\
\hline $10^{-2}$ & 5 to 10 & $4 \times 10^{-5}$ & 1 & $\mathrm{X} 10$ & 30 & 2 to 3 \\
\hline
\end{tabular}

The settings given in Table 3 were found useful for a specific set of conditions, enclosure volume, testing times, and a particular mass spectrometer. Other settings might well be more suitable for other circumstances. It $m$ - sometimes be desirable ${ }^{8}$ to attach a sensitive voltmeter to the tube pressure gage in order to maintain close scrutiny of the pressure. The LC-20 exhibited little variation in reading over a period of time (ranging from 63 ta 67 millivolts). The detector reading was linear with helium concentration.

When the mass spectrometer was on the X1 scale, a fair amount of chatter was recorded. Hence, whenever possible the X10 scale should be used. Unfortunately, at the smaller rates the $X 1$ scale may be called for.

The constancy of the pressure at the mass spectrometer tube is of great importance, as is explained in the discussion of the behavior of the tested helium mass spectrometer leak detector contained in Section 5, "Test Equipment." If the inlet valve on the testing detector can not maintain a constant pressure at the tube, modification or replacement will be necessary.

- Experiments in which the leak detector was started up from a shutdown state resulted in noticeable drift. Therefore, it is advisable to leave the detector in a standby condition for a period of at least 12 hours.

The hose connecting the sniffer probe with the leak detector is fairly important. Tygon or flexible stainless steel is recommended. Rubber 
hosing should be avoided because of extensive outgassing.

Detecting Helium Trace Gas Leaks From Test System

The test object is now enclosed in a reasonably tight enclosure. The fan is turned on and the sniffer probe is connected to the helium mass spectrometer leak detector. The calibrated leak is not introduced into the bag at this time, and its connection opening is closed with tape or a rubber stopper.

Figure 25 shows a photograph of an experimental setup. In this particular photograph the enclosure was a cylinder 5.5 feet in diameter by 9.75 feet high. Here the calibrator is shown injecting helium into the bag at a known rate. This would not occur until the next step of the Comparsion and Superposition Testing Methods, that is, not until the actual comparison of the unknown leak rate with the known leak rate.

Helium partial pressure data may be gathered by:

1. continuously monitoring the increase in partial pressure

2. taking discrete samples

For continuous monitoring, the mass spectrometer is zeroed at the beginning of the run by immersing the probe in an atmosphere such as nitrogen or oxygen, free of helium. Oxygen is somewhat more preferable since it usually contains less helium as an impurity. Zeroing supplies a handy reference point from which it is possible to check whether any drift has orcurred.

In the discrete sampling approach, a zero is taken before each clata point is obtained. The data points may be taken at intervals of 30 minutes or so. Thus, the zero must be maintained only over a period of 30 minutes in the discrete sampling approach, while continuous monitoring requires no drift of zero over a period of several hours. However, it has been found that little zero drift does, in fact, occur, as evidenced by the linearity of the pressure rise versus time. Also, a comparison of the accuracies of the two methods reveals negligible difference. Therefore, it is recommended that the continuous sampling approach be employed since it requires less maintenance and use can be made of a chart recorder.

\section{Comparison of Test Leak with Known Leak}

After sufficient data has been obtained, the enclosure is opened or removed and the test object is depressurized of helium. The enclosure is then ventilated to remove residual helium. For best results in this type of test, the initial helium levels for the test and the known runs should be identical. 


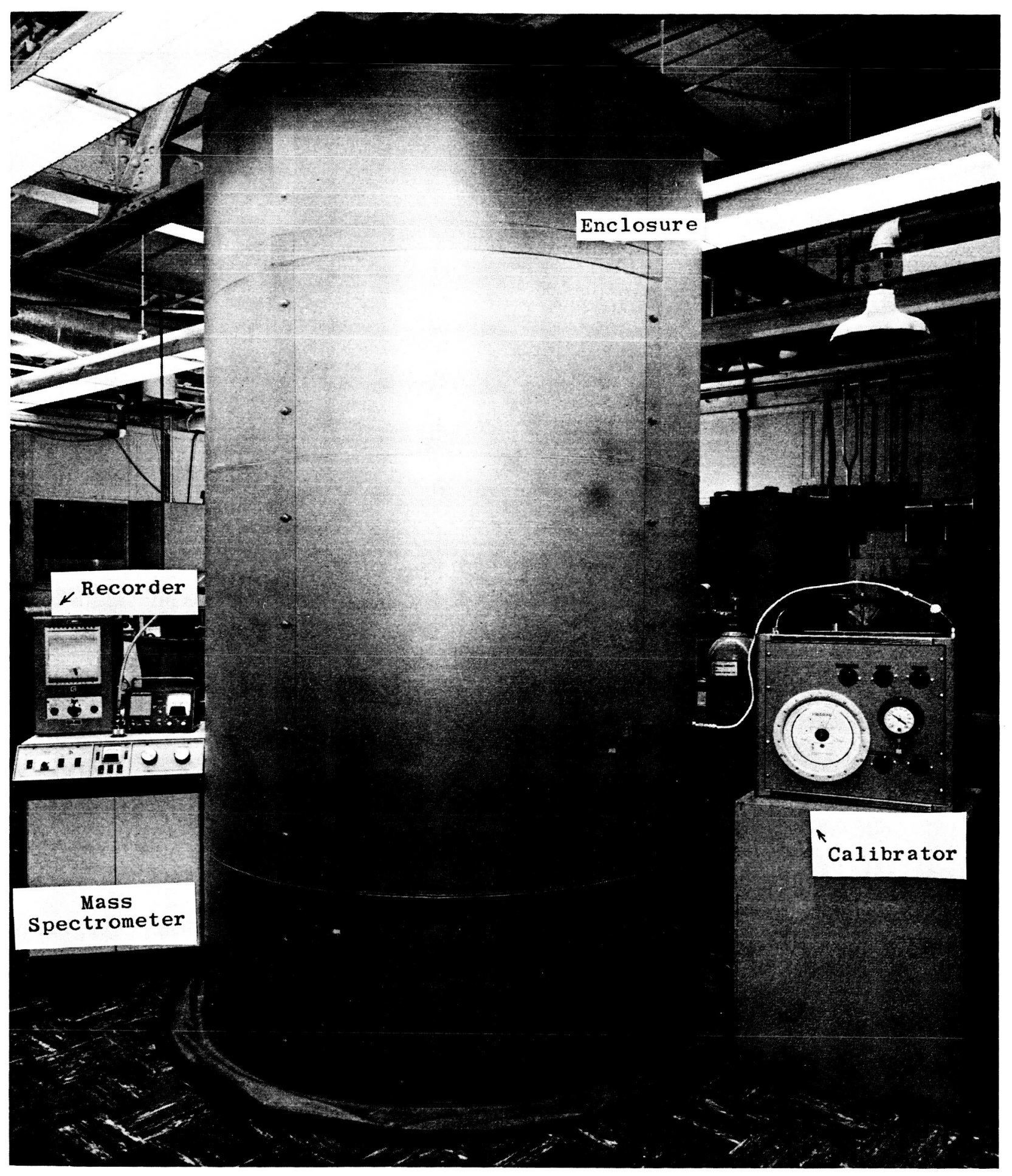

Figure 25. Test Setup. 
The enclosure is then closed or replaced over the test object and helium from the calibrated leak is allowed to flow into the enclosure. The pressure drop across the calibrated leak should be chosen to yield the leak rate, as accurately as may be estimated, of the test object. Until confidence is developed in the ability of the calibrator to maintain a constant pressure drop, the pressure reading should be frequently checked.

A comparison is next made between the test leak and current increases in the mass spectrometer caused by the calibrated leak. Several trials with different known leaks may be required to obtain a good matching of the two curves, or, possibly, experience may be used as a guide in comparing the two leaks.

When the helium leak rate is known, the leak rate of the gas used in the actual operation of the system tested can be determined. The calculations needed for this determination are explained in Appendix III, "Predicting the Leak Rate of the System Gas From the Leak Rate of Helium or a Mixture of Helium and Another Gas."

Data from an experimental test run of the comparison method are given in Figure 26. Both Figures $26 \mathrm{~A}$ and $26 \mathrm{~B}$ show data from a test where the leak rate was 15.8 cubic centimeters per hour. A tracing made of the data from Run A superimposed on the data from Run B would show an almost exact agreement between the data from the two runs. Some very interesting observations may be made from these figures. The following data for the slope was taken directly from the curves:

\begin{tabular}{|c|c|c|}
\hline Run & Range & Slope \\
\hline A & 30 to 40 divisions & 6.14 divisions per hour \\
\hline B & 30 to 40 divisions & 6.00 divisions per hour \\
\hline B & 40 to 50 divisions & 5.34 divisions per hour \\
\hline
\end{tabular}

The slopes of the curves from Runs A and B agree within 2.3 percent in the same range, that is, the 30 to 40 divisions range. However, a comparison of slope $A$ in the 30 to 40 range with slope $B$ in the 40 to 50 range reveals a discrepancy of 11 percent. This might be attributable to permeation at the higher helium concentrations. Permeation here does not necessarily mean permeation through the bag but through seals, say, to the floor.

The Comparison Testing Method is rather lengthy and involved. It may take several runs before matching leak detector readings are obtained. Only under conditions of large permeation of the enclosure or system nonlinearity, for whatever reason, does this method appear appropriate. Either of the other two methods, particularly the Injection Testing Method, is recommended for general use. 


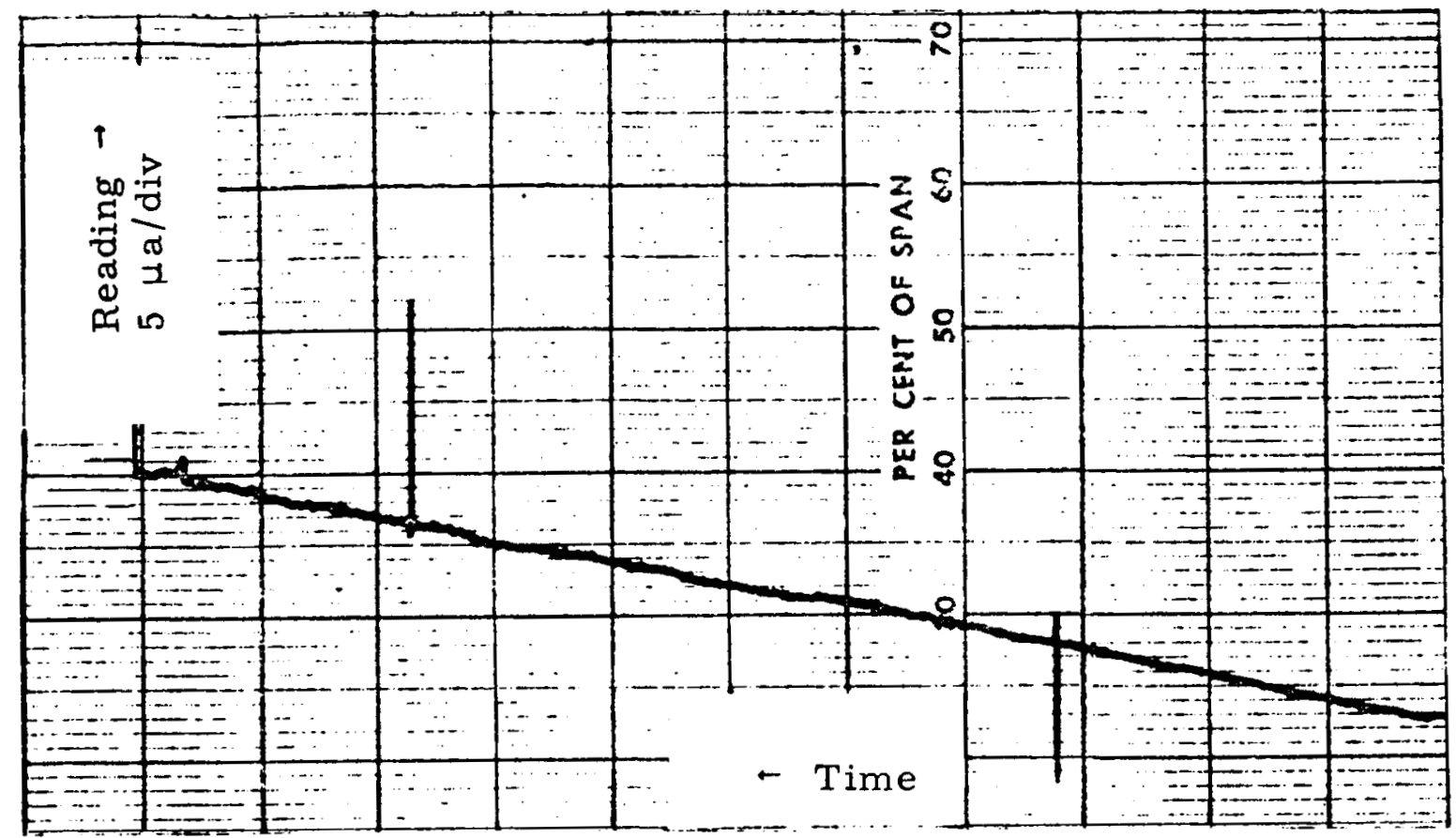

Figure 26A. $\left(Q=15.8 \mathrm{cc} / \mathrm{hr}, 2^{\prime \prime} / \mathrm{hr}\right)$

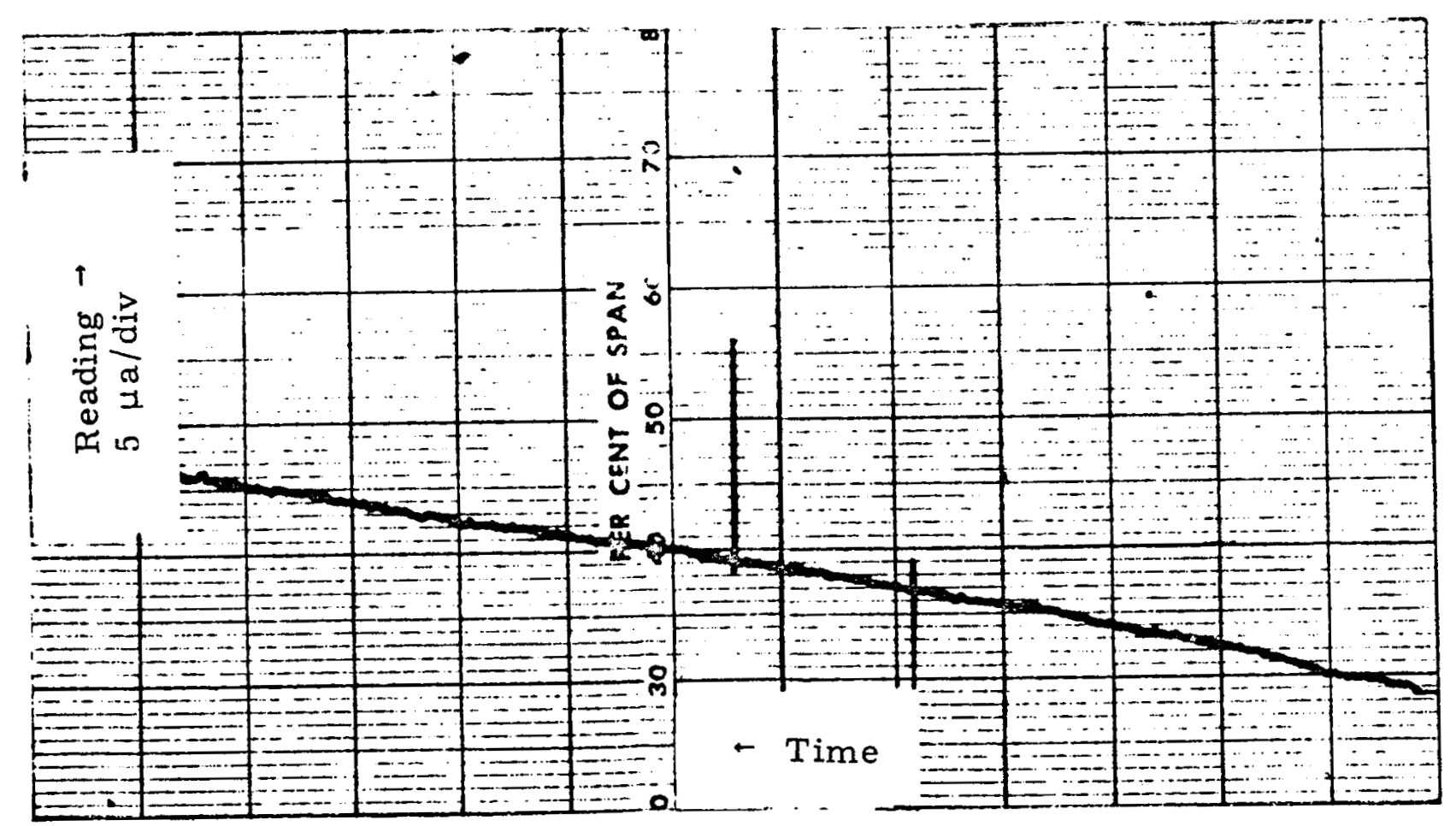

Figure 26B. $\left(Q=15.8 \mathrm{cc} / \mathrm{hr}, 2^{\prime \prime} / \mathrm{hr}\right)$

Figure 26. Comparison Testing Method Data 
In the Superposition Testing Method the unknown is allowed to leak into the enclosure and, after a rate has been established, a calibrated leak is superimposed upon it. Calculation of the unknown leak is possible from the slope of the unknown leak and slope of the sum of the unknown and calibrated leaks.

Pressurizing the Test System

Identical to the Comparison Testing Method.

Preparing the Enclosure

Identical to the Comparison Testing Method.

Selecting Helium Mass Spectrometer Leak Detector Settings

Identical to the Comparison Testing Method.

Detecting Helium Trace Gas Leaks From Test System

Identical to the Comparison Testing Method.

Superpositioning the Calibrated Leak and Test Leak

After the test system has been allowed to leak trace gas into the enclosure for a time periud sufficient to establish a linear relation between mass spectrometer tube reading and time, the calibrated leak may be introduced into the enclosure. Thus, the calibrated leak is superimposed on the unknown leak and the detector senses the sum of the leaks. The pressure drop across the calibrated leak should be chosen so that the resulting leak rate is somewhat higher than the estimated unknown leak. The leak rate can be estimated rom previous data obtained with the enclosure. For instance, if a $10^{-2}$ cubic centimeters-atmosphere per second leak generally causes a 20 microampere per hour reading, then a 2 microampere hour reading irom the test object indicates a $10^{-3}$ rate. Naturally, this argument assumes that the enclosure volume and detector sensitivity are not changed appreciably between runs.

Leak data from an actual run is presented in Figure 27. This data was obtained by allowing the helium leak to flow into a 231 cubic foot enclosure. For pertinent data see the discussion of leak construction and data in Section 5, "Test Equipment." The first line segment was obtained by maintaining a pressure drop of 99.8 pounds per square inch and the second by increasing the pressure to 170.2 pounds per square inch. The leak rates for these two segements correspond to $Q_{1}=1.45 \times 10^{-2}$ and $\mathrm{Q}_{2}=3.4 \times 10^{-2}$ cubic centimeters-atmospheres per second, respectively. Hypothetically, then, unknown and calibrated leaks were:

$$
\begin{aligned}
& Q_{u}=1.50 \times 10^{-2} \mathrm{cc}-\mathrm{atm} / \mathrm{sec} \\
& Q_{c}=1.90 \times 10^{-2} \mathrm{cc}-\mathrm{atm} / \mathrm{sec}
\end{aligned}
$$




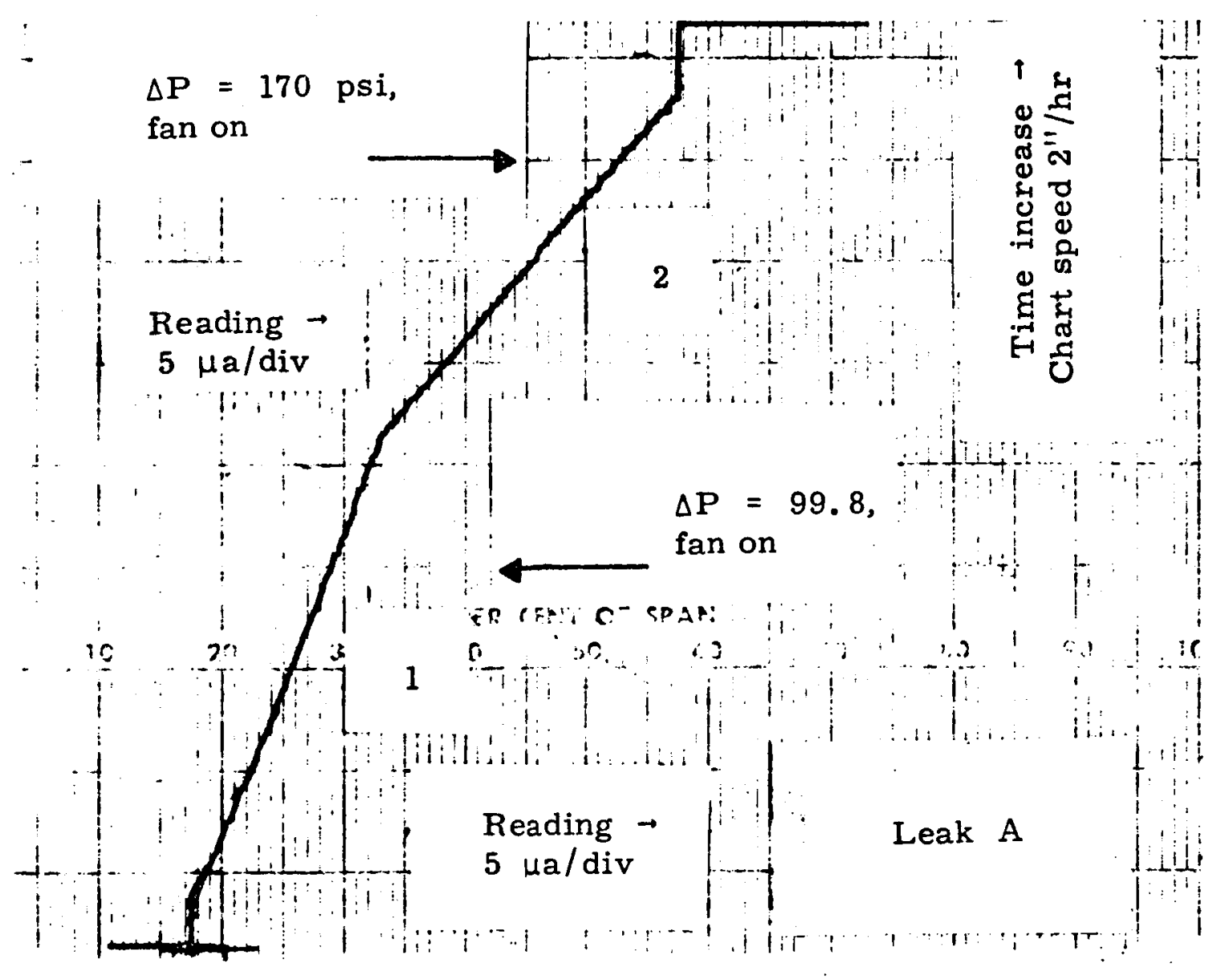

Figure 27. Superposition Testing Method Data. 
Thus the unknown leak equals $Q_{1}$ and the sum of the unknown and calibrated leaks equal $Q_{2}$. From Figure 27 , the slopes of the lines are calculated thus;

$$
\begin{aligned}
& S_{1}=\frac{32.1-18.6}{1}=13.5 \mathrm{div} / 1 \mathrm{n} \\
& S_{2}=\frac{60.0-31.0}{1}=29.0 \mathrm{div} / 1 \mathrm{n}
\end{aligned}
$$

The ratio of the slopes should be equal to the flow rate ratio, therefore:

$$
\mathrm{m}=\frac{\mathrm{S}_{2}}{\mathrm{~S}_{1}}=\frac{\mathrm{Q}_{\mathrm{u}}+\mathrm{Q}_{\mathrm{c}}}{\mathrm{Q}_{\mathrm{u}}}
$$

where $\mathrm{m}$ is the slope ratio. Solving for the unknown flow rate:

$$
\mathrm{Q}_{\mathrm{u}}=\frac{\mathrm{Q}_{\mathrm{c}}}{\mathrm{m}-1}
$$

From the data:

$$
\mathrm{m}=\frac{\mathrm{S}_{2}}{\mathrm{~S}_{1}}=\frac{29.0}{13.5}=2.15
$$

Using Equation 23:

$$
Q_{u}=\frac{1.90 \times 10^{-2}}{2.15-1}=1.65 \times 10^{-2}
$$

which differs from the "actual" $Q_{u}$ of $1.5 \times 10^{-2}$ by ten percent.

If the slope ratio is near unity, a small error in the slope can cause a large error in the flow prediction. For example, if the measured slope ratio was 1.1, but the actual was 1.2, this ten percent error would cause a 100 percent error in $Q_{u}$. For this reason, it is recommended that a $Q_{c}$ greater than the anticipated leak be employed.

Another way of demonstrating the sensitivity of unknown leak rate error to slope ratio error when $m$ is near unity is to use the error expression:

$$
\frac{\Delta \mathrm{Q}_{\mathrm{u}}}{\mathrm{Q}_{\mathrm{u}}}=\frac{\Delta \mathrm{m}}{\mathrm{m}-1}
$$

Therefore, for $\mathrm{m}$ in the neighborhood of 1 , a small $\Delta \mathrm{m}$ will cause a large $\Delta Q_{u} / Q_{u}$. However, Equation 24 predicts that a large $m$ will actually tend 
to reduce the error in $\mathrm{Q}_{\mathrm{u}}$ provided $\Delta \mathrm{m}$ is unaffected by the magnitude of $\mathrm{m}$.

The Superposition Testing Method. is more rapid than the Comparison Testing Method, but slower than the Injection Testing Method. Superposition requires that the leaks be accurately calibrated which might involve a check before each run. The Comparison Testing Method also requires this constant maintanence.

INJECTION TESTING METHOD

After the unknown leak rate has been established on the mass spectrometer in terms of microampere hours, a known quantity of helium is injected into the enclosure. From the injection it is possible to evaluate the sensitivity of the detector to a fixed quantity of helium for the given conditions of volume and helium mass spectrometer leak detector settings. Such a method is simple since it does not require the use of calibrated leaks. It is rapid since time is not required for a calibration run.

Pressurizing the Test System

Identical to the Comparison Testirg Method.

Preparing the Enclosure

Identical to the Comparison Testing Method.

Selecting Helium Mass Spectrometer Leak Detector Settings

Identical to the Comparison Testing Method.

Detecting Helium Trace Gas Leaks From Test System

Identical to the Comparison Testing Method.

Injecting a Known Quantity of Helium

After a suitable line has been established for detector reading versus time, the slope of the line is calibrated. This is done by injecting a known quantity of helium into the enclosure and determining the increment in reading due to the injection. Hence, the output on a chart wecorded will look like the one shown in Figure 28; a straight line with a sudden step where the injection was given.

A hole can be made in the enclosure for injection purposes. It is advisable to locate the injection port diametrically opposite the probe. This will avoid dosing the detector with high helium levels. Duck-seal wax was found a convenient means of repeatedly closing and opening the port.

Injection may be performed with a common laboratory syringe. To assure rapid mixing and to prevent, back diffusion of helium the syringe should be equipped with a needle at least two to three inches in length. 


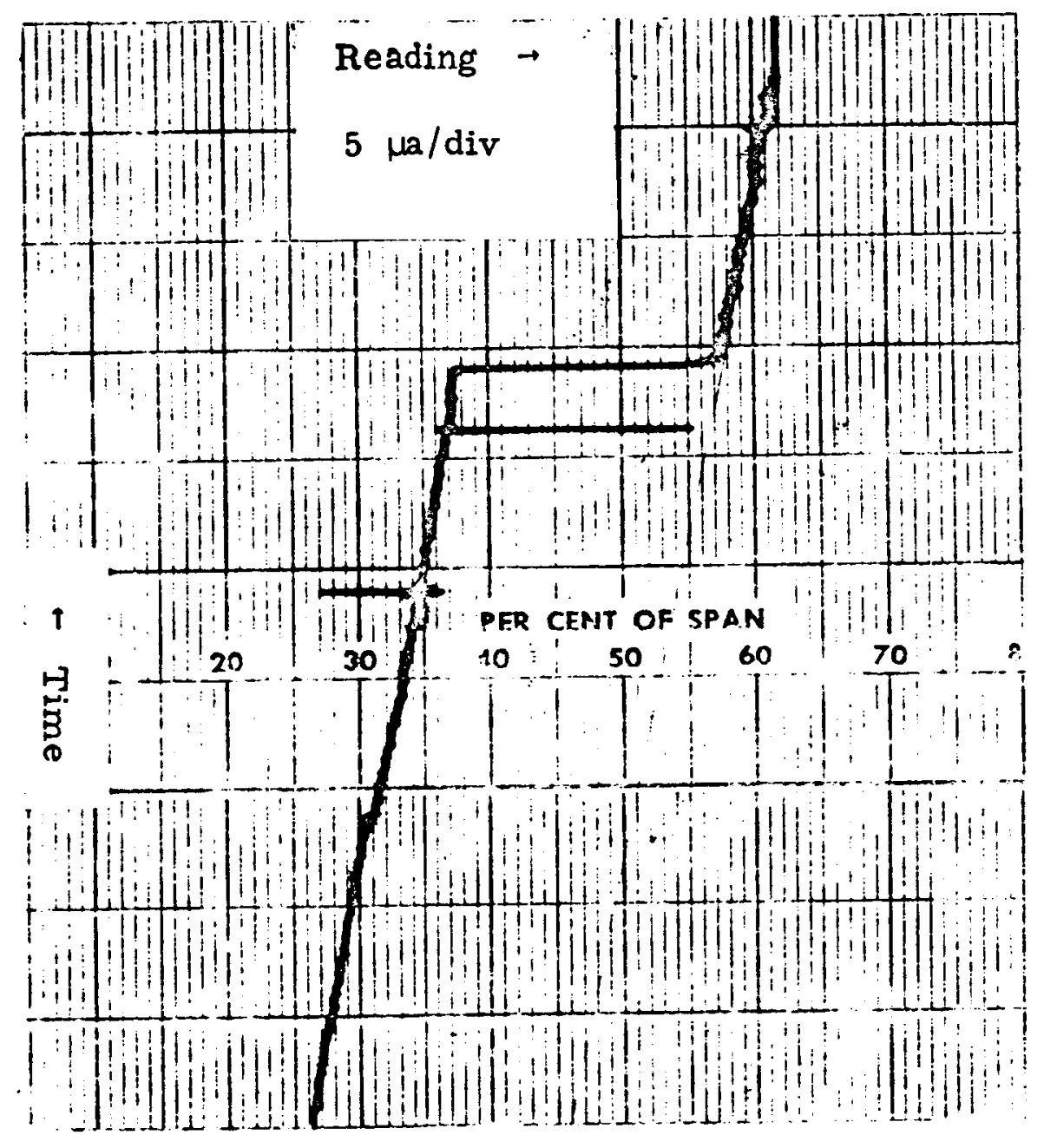

Figure 28. Injection Method Data (2"/hr, 50 cc injected). 
The syringe should also be fitted with a wad of duck seal in the form of a torus about the front part, so that a good seal can be made between the syringe and the enclosure prior to injection: The syringe should be kept in this position for at least one minute after injection in order to avoid helium losses due to high local concentrations.

The quantity of helium injected into the enclosure will depend on:

1. Volume of the enclosure

2. Detector sensitivity

3. Desired increase in reading

In general, to cause a reading increase of $\Delta R$ microamperes, the quantity of helium $\mathrm{V}_{\mathrm{i}}$ cubic centimeters to be injected for a given detector sensitivity of $\mathrm{s}$ microamperes per microatmosphere is calculated from:

$$
\mathrm{V}_{\mathrm{i}}=\frac{\Delta \mathrm{R} \mathrm{V}_{\mathrm{b}}}{\mathrm{s}} \times 10^{-3} \mathrm{cc}
$$

Previous Experiments

Previous experiments with a reading increase of 70 microamperes per microatmosphere on the X10 scale have proved to be within a desirable range. Therefore, in many instances, the volume of helium to be injected can be cal ulated from:

$$
\mathrm{V}_{\mathrm{i}}=7 \times 10^{-3} \mathrm{~V}_{\mathrm{b}}
$$

Thus, 50 cubic centimeters of helium was found to caust a 70 microampere increase in reading, at a detector setting of 5 microns and $4 \times 10^{-5}$ torr for injection into an enclosure $6.53 \times 10^{3}$ liters in volume.

Some practical hints for performing injection runs are:

1. The rate of increase in the mass spectrometer reading is large at the beginning of the run. After about ten minutes this rate decays to a smaller, steady rate. This does not appear to be due to permeation, but rather seems to be a characteristic of the mass spectrometer. However, if "tailing-off" is observed, an inspection should be made of the seals.

2. After the injection is made, the run should be allowed to progress undisturbed until a second slope, displaced in proportion to the amount of injection, is firmly established. This second line is useful in ascertaining the slope. It was found convenient to use two 30-60 triangles aligned to form two parallel lines. The parallel lines of the triangles then are adjusted to match the lines of the data from which the slope may be determined. 
The data for several injection runs are summarized in Table 4. A positive error means that the actual leak (as measured by a calibrating pipet) is greater than the calculated leak rate and conversely for negative errors. The average error for 20 runs, neglecting the -51.5 percent point was 10 percent. There were 12 positive and 8 negative deviations with average errors of 10.8 percent and 9.8 percent respectively. There does not seem to be a systematic error. The average length of time for a run was two to four hours.

Table 4

INJECTION DATA

\section{Leak Rate $(\mathrm{cc}(\mathrm{STP}) / \mathrm{hr})$}

6.125

14.4

15.8

15.8

15.8

16. 2

17. 3

32.7

32.7

33.5

36.0

37.8

45.0

66.7

66.7

67.4

68.5

68.5

99.2

99.2

\section{Percent Error}

$+28.8$

$-11.5$

$-1.4$

$-7.5 *$

$+12.0 *$

$+11.0$

$-12.5 *$

$+3.2$

$+0.5$

$+8.38$

$+10.9 *$

$-51.5$

$-16.3 *$

$+20.0$

$+16.75$

$-13.9$

$+1.6 \%$

$-12.6 *$

$+10.2$

$+5.45$

Figure 28 was obtained from an actual injection run. The slope of the line is:

$$
S=\frac{54.5-47.5}{1}=7.0 \mathrm{div} / \mathrm{hr}
$$

An injection of 50 cubic centimeters of helium resulted in a reading increment of 19.7 divisions. Hence, the detection system may be calibrated as:

$$
\mathrm{j}=19.7 / 50=0.394 \mathrm{div} / \mathrm{cc} \mathrm{He}
$$

* These data were taken with the probe and leak interchanged, i. e. probe. low and leak high. The other data were taken with the normal positioning. 
The flow rate is next easily calculated by dividing the slope by the injection calibition, $\mathrm{j}$, thus:

$$
Q=\frac{S}{j}=\frac{7.0}{0.394}=17.75
$$

or:

$$
Q=0.906 \times 10^{-2} \mathrm{cc} / \mathrm{sec}
$$

and correcting from the conditions of the run to standard temperature and pressure:

$$
\mathrm{Q}=0.917(17.75) \mathrm{cc}-\mathrm{atm} / \mathrm{hr}
$$

or:

$$
(Q)_{\text {calc }}=16.3 \mathrm{cc}(\mathrm{STP}) \mathrm{atm} / \mathrm{hr}
$$

This compares well with the actual leak which was $Q=15.8$ cubic centimeters - amperes per hour The error is about 2.3 percent. The length of the test was about 2.5 hours.:

\section{SUGGESTION FOR INCREASING ACCURACY}

In view of the short testing time required by the injection method it is suggested that several injection runs be performed and the average computed. In this way increased accuracy should be achieved. 


\section{APPENDIX I}

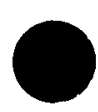




\section{Appendix I}

\section{ERROR ANALYSIS}

This Appendix evaluates the relative importance of variation in such system parameters as volume, leak flow rate, and permeation with regard to error in predicting the leak rate. Since the data generated by the experimental system will be the rate of trace gas partial pressure rise, the error calculations will be based on Equation 8 (Section 4). The rate of partial pressure increase in terms of atmospheres per minute is:

$$
\frac{\Delta \mathrm{p}}{\mathrm{A}}=\frac{2.19 \times 10^{-11} \mathrm{TQ}}{\mathrm{V}_{\mathrm{b}}}-2.41 \times 10^{-8} \frac{\mathrm{kA}}{\mathrm{l}}\left|\frac{\mathrm{T}}{\mathrm{V}_{\mathrm{b}}}\right|^{2} \mathrm{Q} \theta
$$

The only parameters which are considered subject to error are the calibrated leak rate $Q$, the bag volume $\mathrm{V}_{\mathrm{b}}$, and the permeation $\mathrm{KA} / \mathrm{l}$. It is assumed that there is no error in reading the time or the temperature.

ERROR DUE TO PRESSURE SLOPE

The error in the pressure slope is given by the sum of the individual uncertainties:

$$
\therefore\left(\mathrm{p}^{\prime}\right)=\mathrm{E}_{\mathrm{Q}^{\prime}}\left(\mathrm{Q}_{\mathrm{Q}}\right)+\mathrm{E}_{\mathrm{V}_{\mathrm{b}^{\prime}}}\left(\mathrm{V}_{\mathrm{b}}\right)+\mathrm{E}_{\mathrm{K}} \Delta\left|\frac{\mathrm{kA}}{\ell}\right|
$$

where,

$$
\begin{aligned}
& \mathrm{p}^{\prime}=\frac{\dot{\underline{j}} \mathrm{p}}{\dot{\partial}} \\
& \mathrm{E}_{\mathrm{Q}}=\left|\frac{\partial \mathrm{F}^{\prime}}{\partial \mathrm{Q}}\right| \\
& \mathrm{E}_{\mathrm{V}_{\mathrm{b}}}=\left|\frac{\partial \mathrm{p}^{\prime}}{\partial \mathrm{V}_{\mathrm{b}}}\right| \\
& \mathrm{E}_{\mathrm{k}}=\frac{\partial \mathrm{p}^{\prime}}{\frac{\mathrm{kA}}{\ell} \mid}
\end{aligned}
$$

$\Delta(x)$ denotes the error in $x$.

\section{ERROR DUE TO LEAK RATE}

The first term of Equation 28 represents the error due to uncertainties in the leak rate. Such error might be caused by inaccurate pressure 
readings or change in ballast tank pressure by creep in flow regulation. Using Equation 28 and carrying out the indicated differentiation yields:

$$
E_{Q}=\left\langle\frac { \partial p ^ { \top } } { \partial Q } | = | \left[\frac{2.19 \times 10^{-4} \mathrm{~T}}{V_{b}}-2.41 \times 10^{-8}\left|\frac{k A}{\ell}\right|\left|\frac{T}{V_{b}}\right|^{2} \theta||\right.\right.
$$

ERROR DUE TO VOLUME

During the course of the run, the bag volume may fluctuate owing to lack of rigidity of the supporting structure. The error caused by these changes is:

$$
E_{V_{b}}=\left|\frac{\partial p^{i}}{\partial V_{b_{i}}}\right|=\left|-\frac{2.19 \times 10^{-4} \mathrm{TQ}}{V_{b}^{2}}+4.82 \times 10^{-8}\left(\frac{k A}{\ell}\right)\right|\left(\frac{T^{2}}{V_{b}^{3}}\right) Q A \mid
$$

ERROR DUE TO PERMEATION

The possibility exists that the permeation through the bag itself or through seals might have been incorrectly estimated. This is accounted for by:

$$
\left.\mathrm{E}_{\mathrm{k}}=\left|\frac{\partial \mathrm{p}^{\prime}}{\partial\left(\frac{\mathrm{kA}}{\ell}\right)}\right|=2.41 \times 10^{-8} \mid \frac{\mathrm{T}}{\mathrm{V}_{\mathrm{b}}}\right)^{2} \mathrm{Q \theta}
$$

A reasonable value for the permeation factor $\mathrm{kA} / \ell$ is:

$$
\frac{\mathrm{kA}}{\ell}=\frac{\left(10^{-7}\right)\left(10^{5}\right)}{0.5}=2 \times 10^{-2}
$$

Therefore, in the subsequent calculations $\mathrm{kA} / \mathrm{l}$ shall be considered equal to $2 \times 10^{-2}$ and the much less favorable case of 2 cubic centimeters (standard temperature and pressure) per second-atmospheres is also assumed.

Table 5 shows a tabulation of the error coefficients for various bag volumes, leak rates, operating times, and permeation factors. Several generalizations may be drawn from the table. All other factors remaining unchanged:

1. increasing the volume decreases the error

2. increasing running time tends to increase the error

3. larger flow rates tend to result in increased error

4. large permeation factors tend toward increased error. 
Table 5

ERROR COEFFICIENTS

at $\mathrm{T}=298^{\circ} \mathrm{K}$

$\begin{array}{cccc}v_{b} & Q & \quad & k A / \ell\end{array}$

liters cc-atm/sec min $\mathrm{cc} / \mathrm{sec} a \mathrm{tm}$

283

$10^{-4}$

60

0.02

2.00

600

0.02

2.00

$10^{-3}$

0.02

2.00

$\mathrm{E}_{Q} \times 10^{4}$

$E_{V_{b}} \times 10^{10}$

$\underline{E_{k} \times 10^{10}}$

2.310

1.45

1.6

226

1.6

2.300

1.990

21.8

$1.6 \times 10$

2260

$1.6 \times 10$

2.310

2.270

5.88

$1.6 \times 10$

218

$1.6 \times 10$

600

0.02

2.300

2.00

1.990

14.5

$1.6 \times 10^{2}$

$10^{-2}$

0.02

2.310

2257

$1.6 \times 10^{2}$

60

2.00

79.2

$1.6 \times 10^{2}$

2.280

145

$1.6 \times 10^{2}$

600

2.300

2.00

58.8

1.990

2185

$1.6 \times 10_{3}^{3}$

2830

$10^{-4}$

60

0.02

0.230

2.00

0.230

0.0059

$1.6 \times 10^{3}$
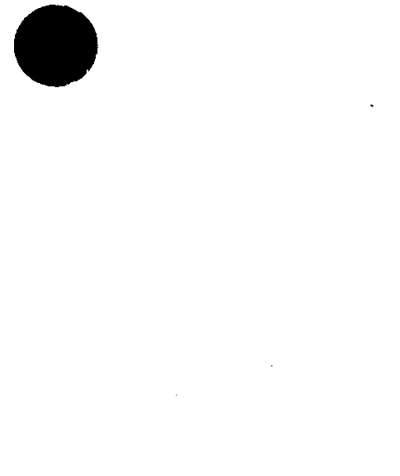

5660

$10^{-3}$

600

0.02

2.00

0.230

0.227

0.218

$1.6 \times 10^{-2}$
$1.6 \times 10^{-2}$

$\begin{array}{ll}0.0145 & 1.6 \times 10^{-1} \\ 2.25 & 1.6 \times 10^{-1}\end{array}$

0.02

0.231

2.00

0.230

0.0793

$1.6 \times 10^{-1}$

600

0.02

2.00

0.231

0.228

$10^{-2}$

0.02

2.00

0.231

0.230

0.145

$1.6 \times 10^{-1}$

$0.0589 \quad 1.6$

2.18

1.6

0.813

1.6

0.589

1.6

600

0.02

0.231

2.00

0.228

0.793

$1.6 \times 10$

1.45

$1.6 \times 10$

$10^{-4}$

0.02

0.115

0.00175

$0.4 \times 10^{-2}$

0.115

0.0263

0.4

0.00079

$0.4 \times 10^{-1}$

0.115

0.281

$0.4 \times 10^{-1}$

$10^{-3}$

2.00

0.115

0.0201

$0.4 \times 10^{-1}$

0.115

0.0079

$0.4 \times 10^{-1}$

0.115

0.115

0.0175

$4.0 \times 10^{-1}$

$10^{-2}$

2.00

0.263

$4.0 \times 10^{-1}$

0.115

0.115

0.203

0.175

$4.0 \times 10^{-1}$

2.00

0.115

600

0.02
2.00

0.201

0.0794

$4.0 \times 10^{-1}$

0.115

$4.0 \times 10^{-1}$

$4.0 \times 10^{-1}$ 
For example, consider the following system values:

$$
\begin{aligned}
Q & =10^{-3} \mathrm{cc}-\mathrm{atm} / \mathrm{sec} \\
\mathrm{V}_{\mathrm{b}} & =200 \mathrm{ft}^{3}=5660 \text { liters } \\
\mathrm{T} & =298^{\circ} \mathrm{K} \\
\mathrm{kA} / \ell & =0.02 \mathrm{cc} / \mathrm{sec}-\mathrm{atm} \\
\theta & =600 \mathrm{~min}
\end{aligned}
$$

For these conditions Equation 27 yields:

$$
\frac{L \mathrm{p}}{\mathrm{A}}=1.152 \times 10^{-8}-8.03 \times 10^{-13}=1.152 \times 10^{-8} \frac{\mathrm{atm}}{\mathrm{min}}
$$

The second term illustrates that the contribution due to permeation, even after 600 minutes, is very small; on the order of $10^{-5}$ less than the major accumulation term.

The error coefficients, computed from Equations 29, 30, and 31 or taken from Table 5, are:

$$
\begin{aligned}
& E_{Q}=0.115 \times 10^{-4} \\
& E_{V_{b}}=0.0175 \times 10^{-10} \\
& E_{k}=4 \times 10^{-11}
\end{aligned}
$$

Five percent inaccuracy is assumed for $Q, V_{b}$, and $k A / \ell$. Thus, the error in each of these variables is found to be:

$$
\begin{aligned}
& \left\llcorner(Q)=0.05\left(10^{-3}\right)=5 \times 10^{-5} \mathrm{cc}-\mathrm{atm} / \mathrm{sec}\right. \\
& \left\llcorner\left(V_{b}\right)=0.05(5660)=283\right. \text { liters } \\
& L(\mathrm{kA} / \ell)=0.05(0.02)=1.0 \times 10^{-3} \mathrm{cc} / \mathrm{sec}-\text { atm }
\end{aligned}
$$

Inserting these values into Equation 28 will give the expected error in the slope:

$$
\dot{L}\left(\mathrm{p}^{\prime}\right)=1.15 \times 10^{-5}\left(5 \times 10^{-5}\right)+1.75 \times 10^{-12}(283)+4 \times 10^{-11}\left(10^{-3}\right)
$$

so that:

$$
\Delta\left(p^{\prime}\right)=5.75 \times 10^{-10}+4.97 \times 10^{-10}+0.0004 \times 10^{-10}=10.72 \times 10^{-10}
$$


The contribution of any error in the permeation is negligible in comparison with the errors resulting from $Q$ or $V_{b}$. The total percent error in the slope is:

$$
\frac{\Delta \mathrm{p}^{\prime}}{\mathrm{p}^{\prime}}=\frac{10.72 \times 10^{-10}}{1.152 \times 10^{-8}}=9.32 \%
$$

The percent error due to the five percent leak rate variation is:

$$
\frac{\Delta\left(p^{\prime}\right) Q}{p^{\prime}}=\frac{5.75 \times 10^{-10}}{1.152 \times 10^{-8}}=4.99 \%
$$

And the percent error due to five percent bag volume variation is:

$$
\frac{\Delta\left(\mathrm{p}^{\prime}\right) \mathrm{V}_{\mathrm{b}}}{\mathrm{p}^{\prime}}=\frac{4.97 \times 10^{-10}}{1.152 \times 10^{-8}}=4.31 \%
$$

For a ten percent error in $Q, V_{b}$, and $k A / \ell$, the total error in the slope p' will be 18.64 percent.

The important conclusion to be drawn from this example is that the error in the permeation factor $\mathrm{kA} / \mathrm{l}$ (within reasonable limits) has little or no effect on the total error. This is a result of the small influence of permeation on $\mathrm{p}^{\prime}$.

As a rule of thumb if:

$$
\begin{aligned}
& \text { Error in } \mathrm{Q}=\mathrm{X} \% \\
& \text { Error in } \mathrm{V}_{\mathrm{b}}=\mathrm{Y} \% \\
& \text { Error in } \mathrm{kA} / \mathrm{l}=\mathrm{Z} \%
\end{aligned}
$$

the total error in the leak rate, at least for the values considered here, will be approximately:

$$
\frac{\hat{n}\left(\mathrm{p}^{\prime}\right)}{\mathrm{p}^{\prime}} \equiv \mathrm{X}+\mathrm{Y}
$$

This can readily be shown to be valid for small contributions of the permeation term. If Equation 27 is rewritten in the form (where $c$ is constant):

$$
p^{\prime}=\frac{c Q}{V_{b}}
$$

Then:

$$
\Delta\left(p^{\prime}\right)=\frac{c}{V_{b}} \Delta(Q)+\frac{c Q}{V_{b}^{2}} \Delta\left(V_{b}\right)
$$


and the percentage error in the slope is:

$$
\frac{\Delta\left(p^{\prime}\right)}{p^{\prime}}=\frac{\Delta(Q)}{Q}+\frac{\Delta\left(X_{b}\right)}{V_{b}}
$$

This is equivalent to Equation 32.

The effect of the error in $Q$ and $V_{b}$ are roughly identical, the uncertainty in $Q$ being perhaps slightly more important.

For example, consider the following system parameters:

$$
\begin{array}{ll}
Q & =10^{-2} \\
\mathrm{~V}_{\mathrm{b}} & =10 \mathrm{ft}^{3}=283 \text { liters } \\
\mathrm{T} & =298^{\circ} \mathrm{K} \\
\mathrm{kA} / \ell & =0.02 \mathrm{cc} / \mathrm{sec}-\mathrm{atm} \\
\theta \quad & =600 \mathrm{~min}
\end{array}
$$

This gives:

$$
\mathrm{p}^{\prime}=2.31 \times 10^{-6} \mathrm{~atm} / \mathrm{min}
$$

The error coefficie for this set of variables are:

$$
\begin{aligned}
& E_{Q}=2.3 \times 10^{-4} \\
& E_{V_{b}}=58.8 \times 10^{-10} \\
& E_{k}=1.6 \times 10^{-7}
\end{aligned}
$$

A five percent error in each of the variables is:

$$
\begin{aligned}
& \Delta(\mathrm{Q})=5 \times 10^{-4} \mathrm{cc} \mathrm{atm} / \mathrm{sec} \\
& \Delta\left(\mathrm{V}_{\mathrm{b}}\right)=14.15 \text { liters } \\
& \Delta(\mathrm{kA} / \mathrm{l})=10^{-3} \mathrm{cc} / \mathrm{sec}-\mathrm{atm}
\end{aligned}
$$

The error in the slope is:

$$
\begin{aligned}
\nabla\left(p^{\prime}\right) & =2.3 \times 10^{-4}\left(5 \times 10^{-4}\right)+58.8 \times 10^{-10}(14.15)+1.6 \times 10^{-7}\left(10^{-3}\right) \\
& =11.5 \times 10^{-8}+8.33 \times 10^{-8}+0.016 \times 10^{-8} \\
& =19.85 \times 10^{-8}
\end{aligned}
$$


Hence:

$$
\frac{\Delta\left(p^{\prime}\right)}{p^{\prime}}=\frac{19.85 \times 10^{8}}{2.31 \times 10^{6}}=8.6 \%
$$


APPENDIX II

5 
Appendix II

EXTRAPOLATION OF LEAK DATA FROM' LOW TO HIGH PRESSURE

It might be convenient in some circumstances to pressurize the test object with trace gas to a pressure lower than that which will actually be used. In this event it will be necessary to predict the leak rate at operating conditions from the data obtained at the lower pressures.

Unfortunately, in leak tests such as the ones which will generally be performed with the calibrated enclosure techniques one never possesses complete knowledge of the type or number of leaks.. Since the form of the equation governing leak rate and pressure drop depends on this kind of information, extrapolation from low to high pressures is, at best, haffardous. Moreover even if the kind of leaks are initially known, they will undoubtedly undergo physical change over a wide pressure range. Since this alteration is far from being predictable, the extrapolation is again rendered questionable. With this in mind, we shall present the theory and compare it to some experimental results.

\section{FLOW REGIME}

- Three different characteristic flow regimes are possible in flow through a leak. They are molecular, viscous, and turbulent flow. The flow through a particular leak may distinctly in one regime or in two or all three. Since the dependence of the leak rate on pressure will be a function of the flow regime, the quantification of these regimes are discussed at sorne length below.

\section{Turbulent Flow}

When the Reynolds number, a dimensionless quantity, is less than 1000 , the flow is predominantly viscous and/or molecular. When this quantity is greater than 1000, the flow is turbulent. This is an oversimplification, since there is a gradual, rather than an abrupt, transition from one flow to the other. For air, oxygen, or nitrogen at $25^{\circ} \mathrm{C}$ it can be shown that the regimes are described by:

$$
\begin{aligned}
& \text { molecular or viscous } Q<4.89 \times 10^{2} \text { a } \frac{c c-a t m}{\mathrm{sec}} \\
& \text { turbulent } \quad Q>4.89 \times 10^{2} \text { a } \frac{c c-a t m}{\mathrm{sec}}
\end{aligned}
$$

where $a$ is the radius of the leak.

For example, if the average radius of a leak is taken as $10^{-4}$ centimeters, then the flow will be predominantly molecular or viscous, provided the leak rate $Q$ is less than $4.89 \times 10^{-2}$ cubic centimeters-atmospheres per second. We shall not consider turbulent flow in detail here. 


\section{Molecular and Viscous Flow}

Molecular flow of a gas through a leak occurs when the mean free path is comparable in magnitude to the characteristic dimensions of the leak. This condition can arise when the pressure is very low or the characteristic dimension of the leak is small. The Knudsen number, which is the dimensionless ratio of the mean free path to the characteristic leak dimension, is the pertinent parameter for these flows. The flow regions can be defined according to the value of the Knudsen number:

$$
\begin{array}{ll}
\text { viscous flow } & \mathrm{Kn}<0.01 \\
\text { molecular flow } & \mathrm{Kn}>1.0 \\
\text { transition range } & 0.01 \leq \mathrm{Kn} \leq 1.0
\end{array}
$$

where

$$
\mathrm{Kn}=\lambda / \mathrm{a}
$$

It may be shown ${ }^{1}$ that for air, oxygen, or nitrogen the flow regimes are representable as:

$$
\begin{array}{ll}
\text { viscous } & \mathrm{aP}>6.6 \times 10^{-4} \mathrm{~cm}-\mathrm{atm} \\
\text { molecular } & \mathrm{aP}<6.6 \times 10^{-5} \mathrm{~cm}-\mathrm{atm} \\
\text { transition } & 6.6 \times 10^{-5} \leq \mathrm{aP} \leq 6.6 \times 10^{-4}
\end{array}
$$

These regions for helium, since its mean free path is 2.8 times that for oxygen or nitrogen are:

$$
\begin{array}{ll}
\text { viscous } & \mathrm{aP}>1.85 \times 10^{-3} \mathrm{~cm} \text {-atm } \\
\text { molecular } & \mathrm{aP}<1.85 \times 10^{-5} \mathrm{~cm} \text {-atm } \\
\text { transition } & 1.85 \times 10^{-5}>\mathrm{aP}>1.85 \times 10^{-3}
\end{array}
$$

Unfortunately one cannot predict the dimensions of a leak in the system under test. However, if an average leak radius of $10^{-4}$ centimeters is taken and the average pressure is assumed to be 10 atmospheres, then the product aP is $10^{-2}$ which would predict predominantly viscous flow. The leak rate in viscous flow should be inversely proportional to the viscosity. Referring to the leak data shown in Figure 22 it is seen tilat the leaks must be predominantly molecular since helium has a higher leak rate than nitrogen, in spite of a higher viscosity. This implies that the leaks whose characteristics are plotted had radii less than $10^{-4}$ centimeters. As the pressure increased, the difference between the leak rates tended to decrease, that is, the leaks became more viscous in nature.

\section{EXTRAPOLATION OF LEAK DATA FOR VISCOUS FLOW}

For viscous flow through a circular cylindrical tube, the flow rate is related to the difference between the squares of the upstream and downstream pressures. Thus: 


$$
Q=\frac{\pi a^{4}}{16 \mu L}\left(P_{2}^{2}-P_{1}^{2}\right)
$$

This expression is derived in many standard texts 9 where $P$ and $P_{2}$ are the pressures downstream and upstream of the leak respectively. Several assumptions are made in this derivation:

1. Fluid motion is laminar

2. No slip condition at the wall

3. The flow is fully developed

4. Incompressible flow

The conditions for laminar and turbulent flow have already been discussed in this Appendix. The no slip or zero velocity condition at the wall is satisfied when the flow is viscous; the criterion for this has also been previously treated. The requirements of fully developed and incompressible flow are dealt with in Reference 7 .

The Langhaar ${ }^{10}$ expression for the entrance length $L_{e}$ is

$$
\mathrm{L}_{\mathrm{e}}=0.227 \mathrm{a} \operatorname{Re}
$$

where $R e$ is the Reynolds number,

$$
\mathrm{Re}=\frac{\rho \mathrm{au}}{\mu}
$$

For air at $25^{\circ} \mathrm{C}$ Equation 36 may be expressed in terms of the leak rate as:

$$
\mathrm{L}_{\mathrm{e}}=0.465 \mathrm{Q} \mathrm{cm}
$$

Thus, for leak rates of $\sigma: 10^{-2}$ cubic centimeter-atmospheres per second, the entrance length will be on the order of $40 \mu$ or less. Most leaks will probably be for fully developed flow.

The condition for incompressible flow of air at $25^{\circ} \mathrm{C}$ is

$$
\mathrm{Q} \cdot 3.7 \times 10^{4} \mathrm{a}^{2} \mathrm{P} \frac{\mathrm{cc}-\mathrm{atm}}{\mathrm{sec}}
$$

Thus, for leak radii on the order of $a=10^{-4}$ centimeters and pressures on the order of 10 atmospheres, the flow rate for incompressible flow must be less than $3.7 \times 10^{-3}$ cubic centimeter-atmospheres per second.

\section{EXTRAPOLATION OF LEAK DATA FOR MOLECULAR FLOW}

Leak rates in the molecular flow regime are dependent on the square root of the gas molecular weight and the pressure drop. Thus for a circular cylindrical tube of length L:

$$
Q=3.05 \times 10^{-4} \frac{a^{3}}{L} \frac{T}{M}{ }^{\frac{1}{2}}\left(P_{2}-P_{1}\right) \frac{c c-a t m}{s e c}
$$


In molecular flow $Q$ is proportional to $P_{2}-P_{1}$ whereas in viscous flow $Q$ is proportional to $\mathrm{P}_{2}^{2}-\mathrm{P}_{1}^{2}$.

In conclusion it is seen that, neglecting complications due to entrance length and compressibility, flow through a leak or leaks may be a combination of molecular, viscous, turbulent, and compressible flow. In the light of this it is not reasonable to expect that one equation alone will be obeyed.

\section{RECOMMENDATION FOR EXTRAPOLATION}

Figure 23 shows that leak rate as a function of trace gas partial pressure drop for an actual leak is fairly linear, although the slope does not correspond either to molecular or viscous flow. An attempt to achieve better correlation of $Q$ with the pressure drop was made by plotting $Q$ versus $P_{\Sigma}^{2}-1$ (Figure 29). The slopes of the plots with standard deviations are given in Table 6 .

From the information provided in $T$ able 6 , it appears somewhat better to use the functionality between $Q$ and $P_{\varepsilon}^{\varepsilon}-1$ than between $Q$ and $P_{\varepsilon}-1$ for these kinds of leaks. Hence, on the basis of this study, which is by no means complete and certainly open to further refinement, it is recommended that the following relations be used

$$
\begin{aligned}
& \text { He leaks, } Q=c\left(P_{z}^{2}-1\right)^{0.74} \\
& N_{2} \text { leaks, } Q^{-}=c\left(P_{z}^{2}-1\right)^{0.807}
\end{aligned}
$$

where $c$ is a constant. Appendix IV: "Leak Rate as a Function of l,eak Structure," gives more information about leak type and pressure functionality.

By means of these formulae a single data point might be extrapolated to higher pressures by either:

1. Determining the value of $c$ from Equations 39 or 40 , and the data for $Q$ and $P_{2}$ and calculating the new $Q$ at the new $P_{2}$

2. Drawing a line through the data point $\left(P_{3}^{2} \ldots 1, Q\right)$ of slope 0.74 or 0.807 on log-log paper.

Extrapolation from a single data point is risky and if time is available, a few points should be obtained and plotted on a $Q$ versus $P_{a}^{2}-1$ graph.

For example, the helium leak rate at 5,000 pounds per square inch gage may be predicted by the following steps.

The data for helium is:

$$
\begin{aligned}
& P_{2}=150 \mathrm{psig} \\
& \mathrm{Q}=10^{-3} \mathrm{cc}-\text { atm } / \mathrm{sec}
\end{aligned}
$$




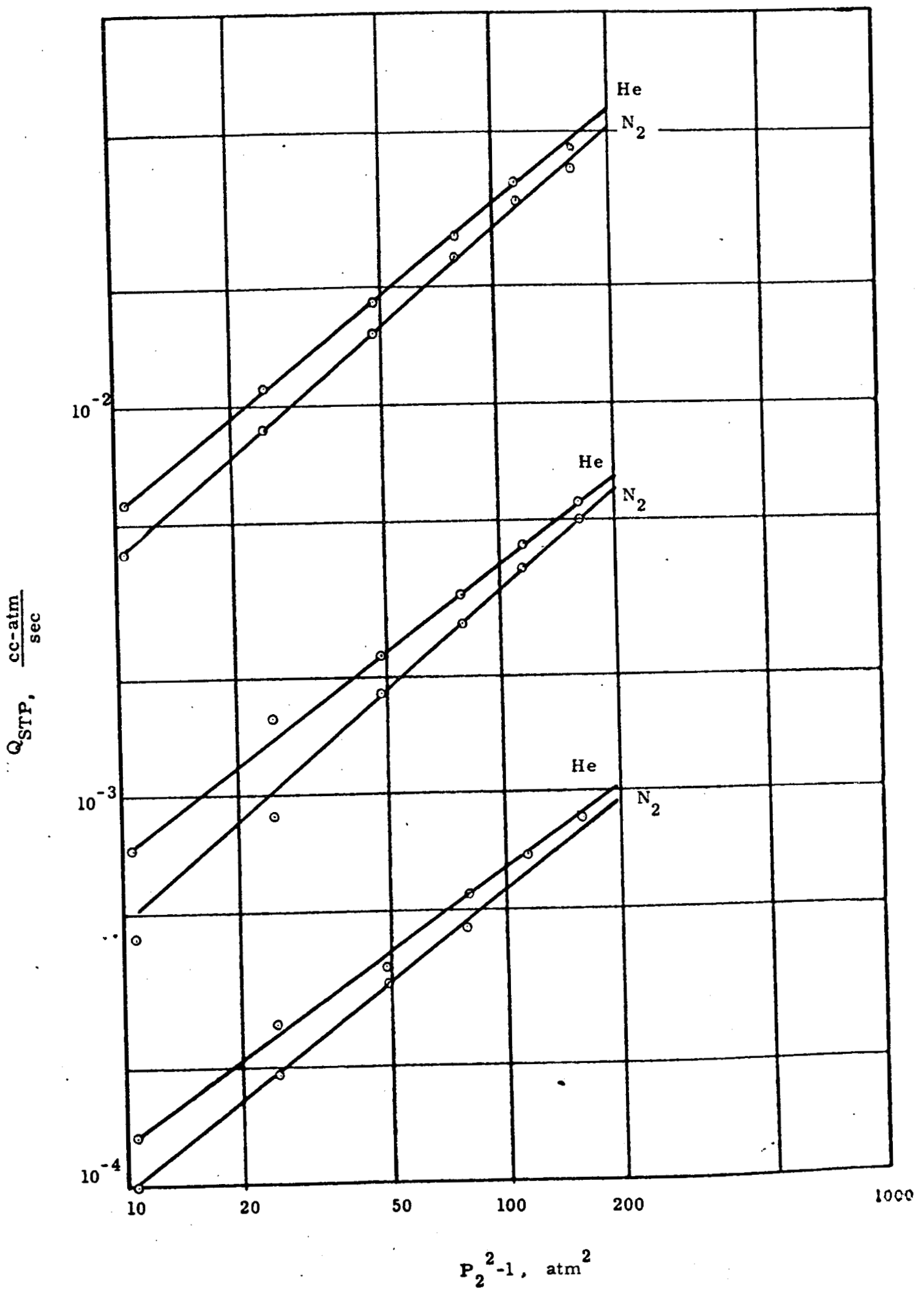

Figure 29. Leak Rate Versus $P_{a}^{2}-1$. 
Table 6

TABULATION OF LEAK SLOPES

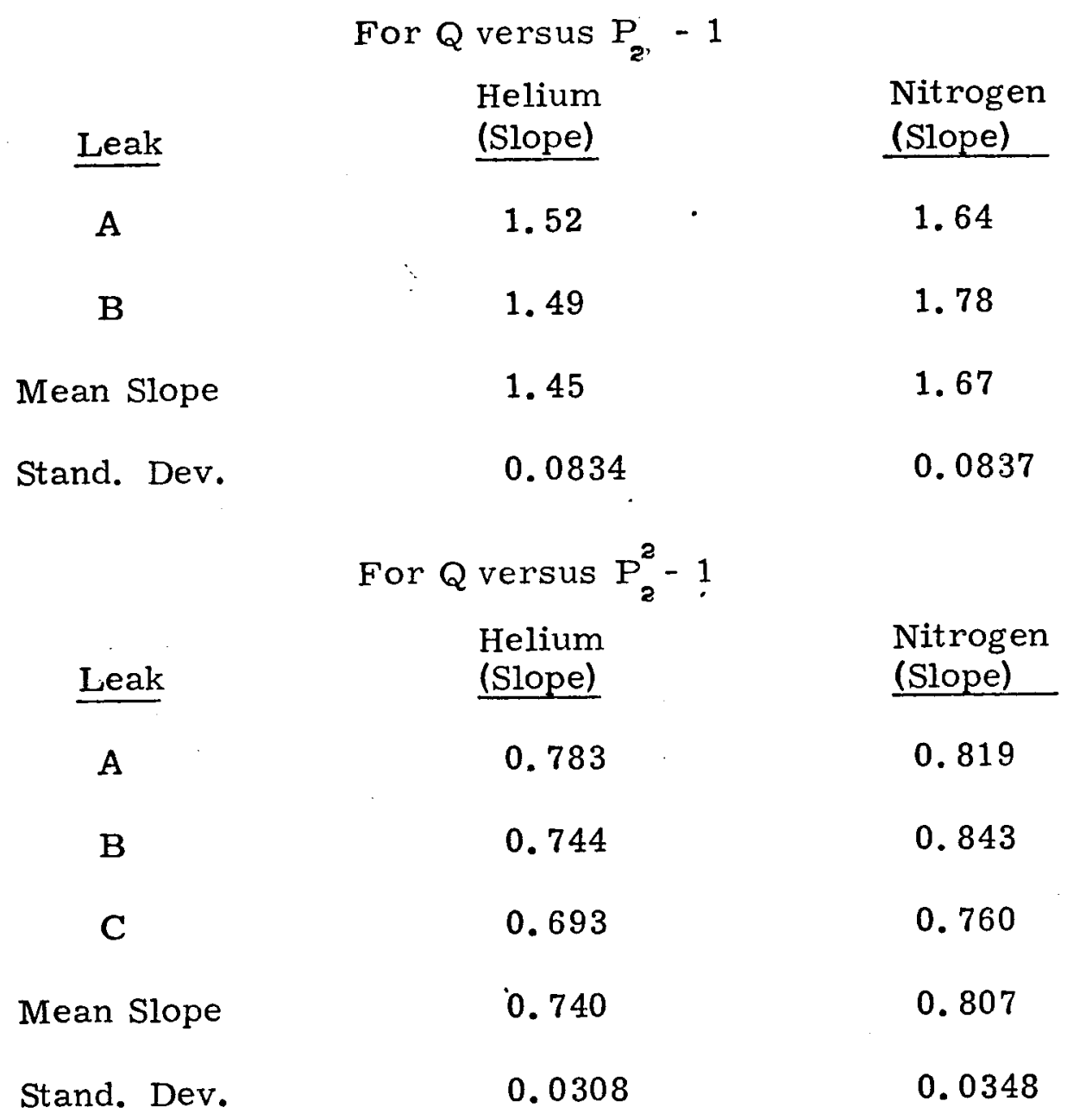


First $P_{2}$ and $P_{2}^{\prime}$ where $P_{2}^{\prime}$ denotes the high upstream pressure are converted to atmospheres and then the values for $P_{2}$ and $Q$ are inserted into Equation 39 to determine c, thus:

$$
\begin{aligned}
& P_{2}=\frac{150}{14.7}=10.2 \mathrm{~atm} \\
& F_{d}^{\prime}=\frac{5000}{14.7}=340 \mathrm{~atm}
\end{aligned}
$$

and:

$$
c=\frac{Q}{\left(P_{2}^{2}-1\right)^{0.74}}=\frac{10^{-3}}{(104-1)^{0.74}}=3.23 \times 10^{-5}
$$

so that:

$$
Q=3.23 \times 10^{-5}\left(P_{2}^{2}-1\right)^{0.74}
$$

therefore:

$$
Q=3.23 \times 10^{-5} \mid\left(3.4 \times 10^{2}\right)^{2}-1 \cdot 0.74
$$

or the leak rate at $\mathrm{P}_{\varepsilon}^{\prime}=5000$ pounds per square inch gage is predicted as

$Q=0.179 \mathrm{cc}-\mathrm{atm} / \mathrm{sec}$ 


\section{APPENDIX III}

13

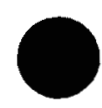


PREDICTING THE LEAK RATE OF THE SYSTEM GAS FROM THE LEAK RATE OF HELIUM OR A MIXTURE OF HELIUM AND ANQTHER GAS

The testing methods described in the Quantitative Leak Test Design Guide are used to determine the leak rate of helium or a mixture of helium and another gas. When these leak rates are known, the leak rate of the gas used in the system which was tested when in normalioperation: can be calculated. This calculating procedure is explained in this Appendix.

The calculations tescribed in this Appendix are, for illustrative purposes, made for a specific case, of the general procedure, that of a heliumnitrogen mixture: . These calculations can be made for mixtures of helium and another gas with the percentage of helium ranging from zero to one hundred percent. Of course, the case of pure helium is the simplest. In order to use these calculations for other mixtures, the viscosity of nitrogen should be replaced with the viscosity of whichever gas is mixed with helium.

It may sometimes be desirable to leak test a system with a mixture of helium and another gas instead of pure helium. For example, in order to conserve helium in the testing of a large object, a mixture might be employed. Also a large leak rate might be determined more accurately if a mixture is used, isince a trace gas of pure helium may cause the helium corrcentration in the enclosure to rise rapidly enough to severely limit the experiment time.

Theoretical predictions are based on a knowledge of whether the leak is molecular, viscous, or turbulent. Appendix II, "Extrapolation of Leak Data from Low to High Pressure," contains a discussion of flow regimes. Unfortunately this information is seldom availabe. However, from several tests it may be possible to ascertain the nature of the leak.

\section{VISCOUS FLOWS}

The total flow rate for an $\mathrm{He}-\mathrm{N}_{2}$ gas mixture in viscous flow is:

$$
Q_{\text {total }}=\frac{\pi a^{4}}{16 \mu_{\text {mix }} L}\left(P_{3}^{2}-P_{1}^{3}\right)
$$

The flow rate of the trace gas is related to its mole fraction in the mixture by:

$$
\mathrm{Q}_{\mathrm{He}}=\mathrm{X}_{\mathrm{He}} \mathrm{Q}_{\text {total }}
$$

Therefore, by combining Equations 41 and 42, and an expression for the nitrogren flow rate we obtain: 


$$
Q_{N_{2}}=\frac{\mu_{\text {mix }}}{\mathrm{X}_{\mathrm{He}} \mu_{N_{2}}} Q_{\mathrm{He}}
$$

In an actual run the helium flow rate would be the measurable quantity and the pure nitrogen leak rate w ould be computed from the above equation.

The viscosity of a mixture of nitrogen and helium may be calculated from a semi-empirical formula from Wilke $11,12_{-}$; which for a two component gas mixture is:

$$
\mu_{\text {mix }}=\frac{X_{1} \mu_{1}}{X_{1} \Phi_{11}+X_{2} \Phi_{12}}+\frac{X_{2} \mu_{2}}{X_{1} \Phi_{21}+X_{2} \Phi_{22}}
$$

where:

$$
\Phi_{i j}=\frac{1}{\sqrt{8}}\left(1+\frac{m_{i}}{m_{j}}\right)^{-1 / 2}\left[1+\left(\frac{\mu_{i}}{\mu_{j}}\right)^{1 / 2}\left(\begin{array}{c}
m_{j} \\
m_{i}
\end{array}\right)^{1 / 4}\right]^{2}
$$

computation of the $\Phi_{i j}$ for this case gives:

$$
\Phi_{11}=1, \Phi_{12}=2.42, \quad \Phi_{21}=0.314, \quad \Phi_{22}=1
$$

with:

$$
\begin{aligned}
& \mu_{1}=196 \text { micropoise at } 25^{\circ} \mathrm{C} \\
& \mu_{2}=177 \text { micropoise at } 25^{\circ} \mathrm{C}
\end{aligned}
$$

The subscripts 1 and 2 enote helium and nitrogen respectively. A plot of the mixture viscosity irsus the helium mole fraction as calculated from Equations 44 and 45 is given in Figure 30 . This procedure for computing viscosity is reputed to give rather good results -- errors of less than one percent being obtainable.

The factor $\mu_{\text {mix }} / \mathrm{X}_{\mathrm{He}} \mathrm{N}_{2}$ required for the calculation of the pure nitrogen leak rate versus the mole fraction of helium in the mixture is plotted in Figure 31.

Possibly the experimental run with the helium-nitrogenimixture might have been performed at a pressure lower than operational. It is then necessary not only to estimate the leak rate of pure nitrogen from the mixture leak rate, but also to predict the nitrogen leak at elevated pressures. This poses no theoretical difficulty since the nitrogen leak at reduced pressure may be estimated with the aid of Equation 43 and subsequently the nitrogen leak at the desired pressure may be calculated from the methods of Appendix II, "Extrapolation of Leak Rates from Low to High Pressure."

Example:

As an example, the $\mathrm{N}_{z}$ leak rate at 1000 pounds per square inch for a viscous flow leak of 20 percent helium and 80 percent nitrogen will be estimated. The leak rate for helium in this mixture known to be $10^{-5}$ cubic centimeter-atmospheres per second at 100 pounds per square inch. 


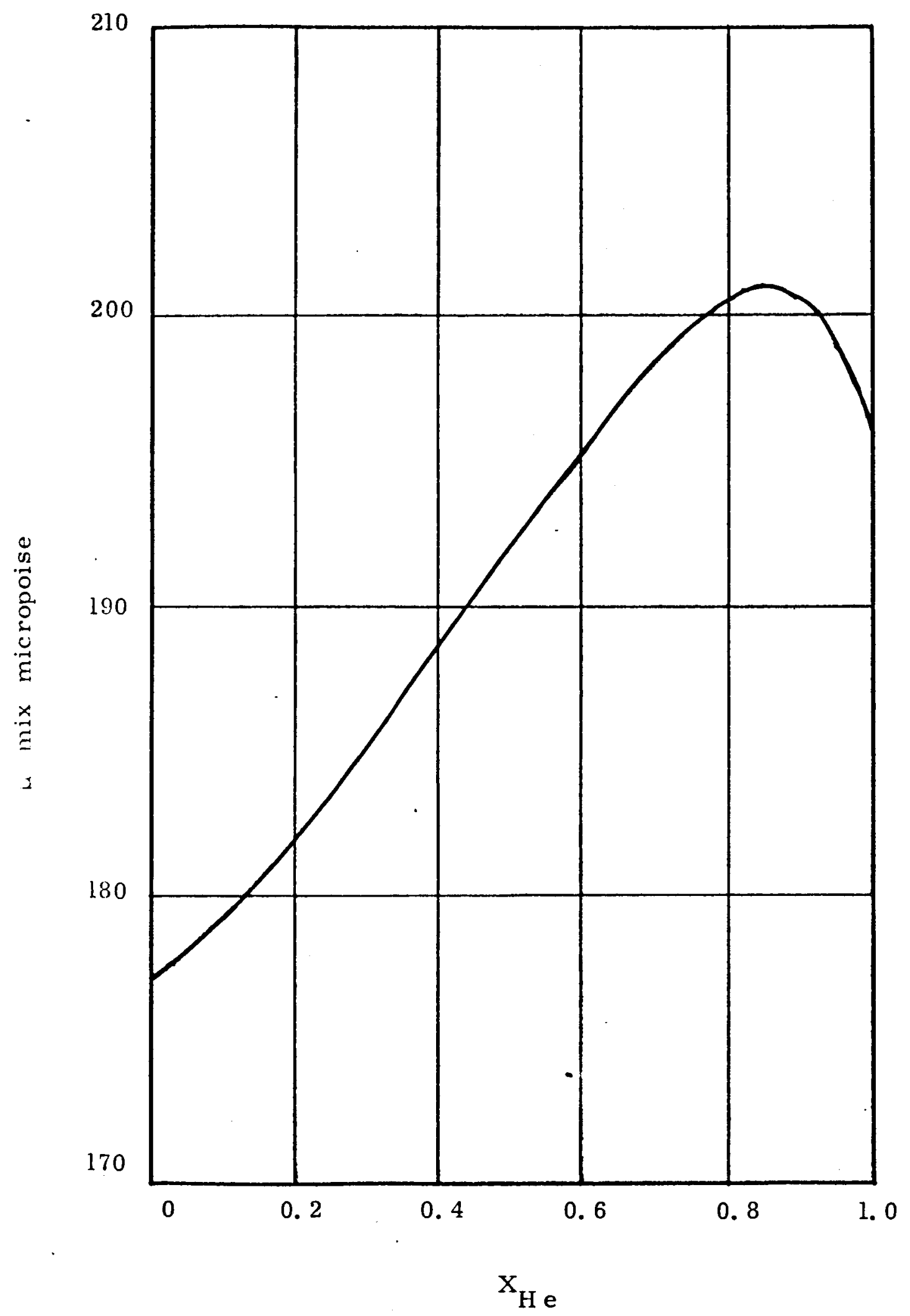

Figure 30. Viscosity of an $\mathrm{He}-\mathrm{N}_{2}$ Mixture Versus Mole Fraction of Helium at $25^{\circ} \mathrm{C}$ and 1 atmosphere. 


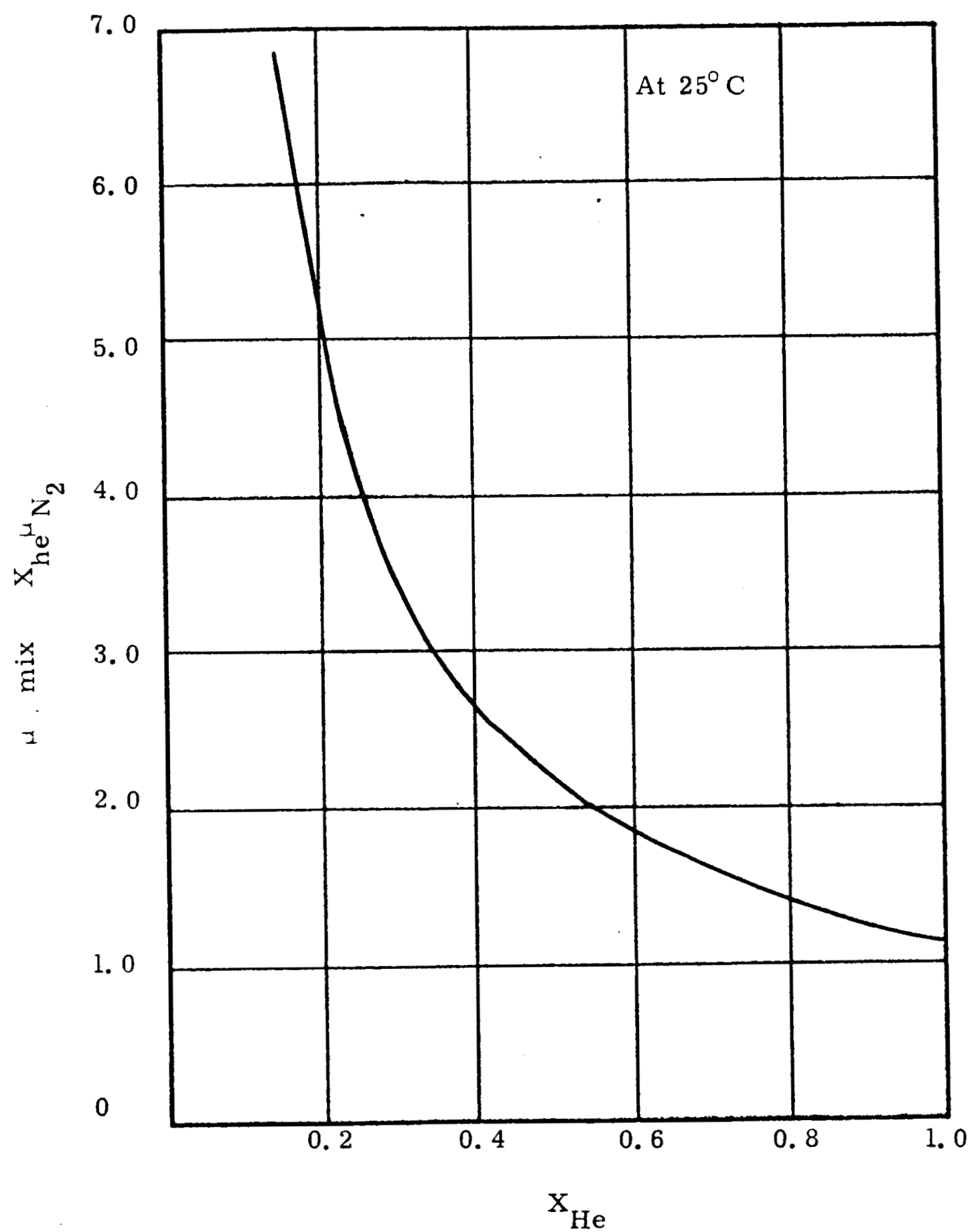

Figure 31. $\mu \mathrm{mix} / \mathrm{x} \mathrm{He} \mu \mathrm{N}_{2}$ Versus Mole Fraction of Helium. 
The helium mass spectrometer leak detector gives us:

$$
\mathrm{Q}_{\mathrm{He}}=10^{-5} \mathrm{cc}-\mathrm{atm} / \mathrm{sec}
$$

From Figure 31 we obtain the factor for a helium mole fraction 0.2 .

$$
\frac{\mu_{\text {mix }}}{\mathrm{x}_{\mathrm{He}} \mu_{\mathrm{N}_{\mathrm{a}}}}=5.35
$$

Equation 43 gives:

$$
Q_{N_{2}}=5.35 \sigma_{\mathrm{He}}=5.35 \times 10^{-5} \mathrm{cc}-\mathrm{atm} / \mathrm{sec}
$$

at a pressure drop of 100 pounds per square inch. Using the methods of Appendix II for extrapolation of leak rates from low to high pressure:

$$
\begin{aligned}
& P_{2}=100 / 14.7=6.8 \mathrm{~atm} \\
& P_{1}=1 \mathrm{~atm} \\
& Q=5.35 \times 10^{-5}=c\left(6.8^{2}-1\right)
\end{aligned}
$$

therefore: $\quad C=1.189 \times 10^{-5}$

Therefore with a pressure drop of 100 pounds per square inch the expected nitrogen flow rate is

$$
\sigma_{\mathrm{N}_{2}}=1.189 \times 10^{-6}\left(6.8^{2}-1\right)=5.5 \times 10^{-3} \mathrm{cc}-\mathrm{atm} / \mathrm{sec}
$$

The above assumes that extrapolation to the higher pressure is valid.

\section{MOLECULAR FLOW}

When flow through the leak is in the molecular regimes the equation governing flow rate is linear with pressure drop and inversely proportional to $\sqrt{M}$ in Equation 36 or in:

$$
Q=c \frac{1}{\sqrt{M}}\left(P_{2}-P_{1}\right)
$$

where $c$ is a constant at a given temperature. In the molecular regime the flow rates of the components will be independent of each other. Therefore, ir the flow of a mixture of helium and nitrogen the ratio of the flows will be:

$$
\frac{Q_{\mathrm{N}_{2}}}{\sigma_{\mathrm{He}}}=\sqrt{\frac{\mathrm{M}_{\mathrm{He}}}{\mathrm{M}_{\mathrm{N}_{2}}}}
$$

or

$$
Q_{\mathrm{N}_{2}}=0.378 Q_{\mathrm{He}}
$$

The ratio of the flow rates of nitrogen and helium will be independent of the mixture composition for molecular flow. 


\section{Example}

As an example the nitrogen leak rate is calculated for molecular flow, given that $Q_{\mathrm{He}}=10^{-4}$ cubic centimeter-atmospheres per second. This is readily computed from Equation 48 :

$$
\mathrm{Q}_{\mathrm{N}_{2}}=3.78 \times 10^{-5} \mathrm{cc}-\mathrm{atm} / \mathrm{sec}
$$


APPENDIX IV

$1^{\circ}$ 
The physical structure of a leak is of great significance in determining its leakage characteristics. Three types of leak structures will be treated here:

1. Check Valve

2. Self-cleaning

3. Porous

The importance of conducting tests at operating pressures will become evident during the course of the discussion.

\section{CHECK VALVE LEAK}

A check valve leak exhibits no flow below a critical pressure; above the critical pressure the flow increases abruptly. Thus, if testing were performed below the critical pressure, leaks which may be major contributors to the total flow at operating pressure would not even be detectable. Figure 32 (taken from Reference 13) illustrates this phenomenon for a damaged. needle valve.

This type of leak in probably characteristic of a valve leak. Of course, other kinds of physical structures may evidence such behavior and conversely a valve may extibit other flow charateristics.

\section{SELF-CLEANING LEAK}

A self-cleaning leak enlarges as system pressure increases, giving rise: to a leak rate versus pressure drop slope greater than two. Rathbun 14 has reported such leaks for gaskets under pressure. Again, this kind of leak is not limited to gaskets and can occur in other connections. Similarly, this is not the only type of leak possible for a gasket.

Since flared tubing fittings have gaskets, a discussion of leakage from this kind of fitting is included here. G. W. Sarney ${ }^{15}$ has reported on a study of flared tubing connectors. His study shows:

A leakage rate of $10^{-4}$ to $10^{-a}$ cubic centimeter-atmospheres per second for the "MC" flared connector at a helium pressure of

- 1500 pounds per square inch. Hence it is recommended that either welds or braze be used whenever possible.

High sealing pressures and consequent deformation of the union are necessary to insure tightness. 


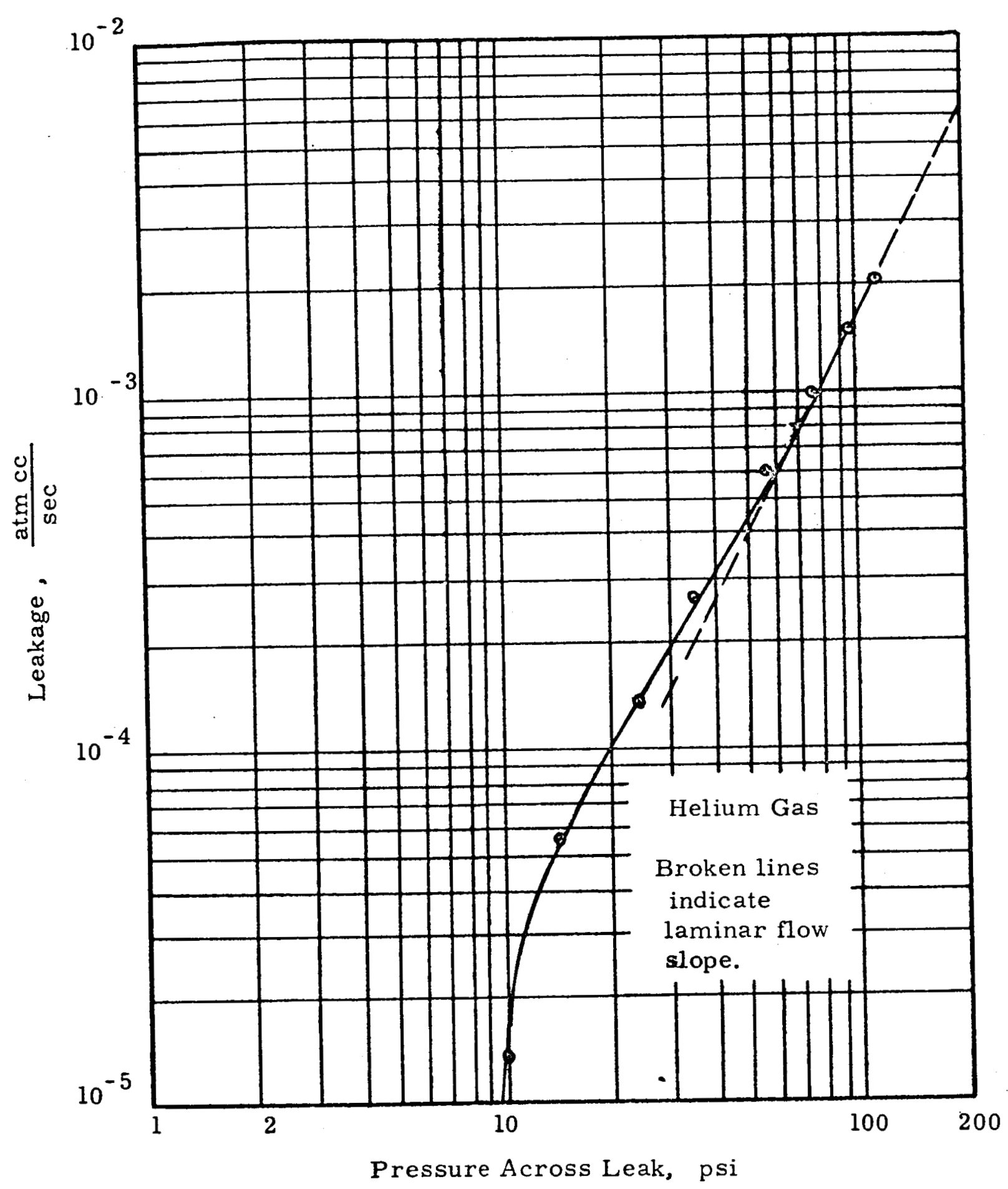

Figure 32. Check Valve Effect in Hardware Leak. 
Leak rate for aluminum fittings increased with connect-disconnect tests. However, the rate from stainless steel fittings was essentially unchanged.

Leak rate versus pressure drop was linear.

The Swagelok connector evidenced good sealing characteristics. POROSITY LEAK

Flow through a porous media is generally described by the equation:

$$
Q=K A \frac{\Delta P}{\ell}
$$

where $\mathrm{K}$ is a constant accounting for porosity. However, there is some evidence ${ }^{16}$ that the flow rate is proportional to $(P \triangle P)^{n}$ where the exponent $\mathrm{n}$ varies between 0.5 and 1 . Braze or weld joints sometimes have leaks of this type.

\section{SUMMARY}

A wide variety of leaks are possible. The nature of the leak with a single data point cannot be ascertained. Because the leak may be a check valve leak which allows flow only above the testing pressure and because of the uncertainty of extrapolation procedures, as explained in Appendix II, "Extrapolation of Leak Data from Low to High Pressure," it is strongly recommended that the testing pressure be cqual to operating pressure. 


\section{APPENDIX V}

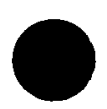




\section{Appendix V}

\section{OPERATING OF THE TESTED STEADY LEAK FLOW BALLAST TANK CA'LIBRATOR}

The calibrator system is designed to supply a steady leak flow of trace gas over a given period of time through the use of a ballast tank. For a discussion of the sizing of the ballast tank the reader is referred to the "Design Guide." A schematic of the calibrator system is shown in Figure 13. The major components of the calibrator are:

Hoke Stainless-steel Cylinder, 8HD1-G

Wallace and Tiernan Differential Fine Pressure Gage, 0 to 300 pounds per square inch FA-234160

Coarse Pressure Gage

Hoke Bellows Brass Seal Valves, No. 284

Bud Cabinet, $14-3 / 4$ by 22 by 19 Inches

The calibrator must also have a high pressure leak gas cylinder of helium to charge the calibrator ballast tank, and a vacuum pump. The vacuum pump is connected to the port labeled "vacuum" and the leak gas cylinder to the port labeled "leak gas. " To the port labeled "leak" is attached the tubing for the calibrated leak.

INSTRUCTIONS FOR $\$$ ART-UP FROM TOTAL SHUTDOWN

The following steps are taken to start the calibrator system from total shutdown:

1. The vacuum pump, leak gas cylinder, and leak are attached to the cylinder. The leak gas cylinder is isolated from the calibrator for this step by attaching a valve and regulator to the leak gas cylinder. The regulator is set to deliver 250 pounds per square inch to the calibrator. The vacuum, ballast tank, leak gas, and fine gage valves are then opened. Opening of the fine gage valve permits evacuation of the Bourdon tube in the fine gage. During the evacuation, the air in the tube leading from the leak gas valve to the valve of the leak gas cylinder is also evacuated. Vacuum causes the fine pressure gage to read approximately -14.7 pounds per square inch. This is not, however, harmful. The coarse pressure gage may also be used in this step as a means of indicating when

- a sufficiently low pressure has been achieved in the system. The system should be evacuated for five minutes after the fine gage indicates -14.7 pounds per square inch. 
2. The vacuum and leak gas valves are closed, and the leak gas cylinder valve is opened. The leak gas valve of the calibrator is opened, admitting helium to a pressure of about 100 pounds per square inch, slowly, so that the precision gage is not surged. Next the valve leading to the leak, which is a copper tubing extension, is opened. The Swagelok fitting holding the appropriate calibrated leak is loosened, in order to purge the leak and its surroundings of any occluded air, and then tightened. In starting from total shutdown steps 1 and 2 may be repeated to completely remove all air.

3. The leak gas pressure, as read on the fine pressure gage, is adjusted to the level which will produce the desired flow rate by means of the vent and/or leak gas valves. About one minute should be allowed for the system to achieve pressure equilibrium. The pressure will tend to overshoot and gradually decay to a steady value. The system should not be pressurized above 200 pounds per square $\ldots$ inch. Pressures greater than 300 pounds per square inch will ruin the fine pressure gage if the protection valve is open.

4. Once the pressure has been adjusted and the valve to the leak opened, the calibrator is ready to deliver a given flow rate.

\section{INSTRUCTIONS FOR PARTIAL SHUTDOWN}

Less time is taken to start the calibrator system from a state of partial shutdown than from one of total shutdown. In a state of partial shutdown the ballast tank remains charged with leak gas. The only parts of the system which see air are the copper tubes running between the ports and valves for the vacuum, the leak gas, and the leak. Partial shutdown is readily achieved by:

1. Maintaining a positive leak gas pressure while closing all valves.

2. Disconnecting the leads to the ports

It may be convenient to ship the calibrator'in this state. INSTRUCTIONS FOR START-UP FROM PARTIAL SHUTDOWN

The following steps are taken to start the calibrator system from partial shutdown:

1. The vacuum pump, leak gas cylinder, and leak are attached to the calibrator.

2. With all valves originally closed, the vacuum and leak gas valves are opened. This evacuates the tubing up to the leak gas cylinder and ballast tank, "whose valves remain closed.

3. The vacuum and leak gas valves are closed. The leak gas cylinder valve is opened. 
4. The ballast tank and pressure gage valves are opened and the pressure is adjusted to desired level in the usual manner.

INSTRUCTIONS FOR TOTAL SHUTDOWN

All contained leak gas is released and the valves are closed. 
APPENDIX VI

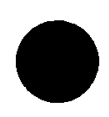

8 


\section{Appendix VI \\ CHARACTERISTICS AND SOURCES OF COMMERCIALLY AVAILABLE LEAK DETECTORS}

The information contained in this appendix is extracted from:

Bialous, A. J., "Characteristics and Sources of Commercially Available Leak Detectors, "General Electric Report No. 5-671013, April 1967.

\section{LIST OF MANUFACTURERS AND ADDRESSES}

Available in United States

Characteristics of the helium mass spectrometer leak detectors manufactured in the United States are given later in this Appendix.

Atlas Mess \& Analysentechnik GMBH

Bremen, Germany

Agents: Heraeus Engelhard Incorporated

Seco Road

Monroeville, Pennsylvania

Consolidated Electrodynamics Corporation

360 Sierra Madre Villa

Pasadena, California 91107

Denton Vacuum, Incorporated

Cherry Hill Industrial Center

Cherry Hill, New Jersy 08034

General Electric Company

Vacuum Products Operation

1 River Road

Schenectady, New York 12305

Norton Company

NRC Equipment Corporation Division

160 Charlemont Street

Cleveland, Ohio 44110

Vacuum Industries, Incorporated

Division of Geophysics Corporation

34 Linden Street

Somerville, Massachusetts 02143 
Vacuum Instrument Corporation

6 Stepar Place

Huntington Station, Long Island; New York 11746

Varian Associates

Vacuum Division/Mikros Plant

7634 S. W. Capitol Highway

Portland, Oregon 97219

Veeco Instruments, Incorporated

Terminal Drive

Plainview, Long Island, New York 11803

Available in Europe

Characteristics of the helium mass spectrometer leak detectors manufactured in Europe are given in:

Bialous, A. J., "Characteristics and Sources of Commercially Available Leak Detectors, "General Electric Report No. 5-671013, April 1967.

"Centronic" Helium Leak Detector, 20th Centruy Electronic Limited

New Addington, Croydon

Surrey, England

"Helitest" Helium Leak Detector

Laboratorie des Basses Pressions.

Argentenil, Seine-et-Oise

France

Compagnie Francaise Thomson-Houston

$173 \mathrm{Bd}$. Haussman

Paris - 8e, France

Atlas Mess \& Analysentechnik GMBH

Bremen, Germany

CHARACTERISTICS OF LEAK DETECTORS AVAILABLE IN UNITED STATES

Characteristics of helium mass spectrometer leak detectors available in the United States are given on the following pages of this Appendix. 
ATLAS MESS \& ANALYSENTECHNIK GMBH

(Haraeus-Engelhard Vacuum, Incorporated, Distributor)

SPECIFICITY:

EXCITATION:

OUTPUT SIGNAL/ IMPEDANCE:

RANGES:

SENSITIVITY:

REPEATABILITY: $\quad \pm 2 \%$

RESPONSE TIME: Less than 0.5 seconds for $50 \%$ of leak when volume of test sample is less than 5 liters

DOES IT FAIL

SAFE:

MAINTENANCE: As needed

PORTABILITY: irt mounted

SIZE:

WEIGHT:

PRICE:

DELIVERY TIME: Stock item

REMARKS:

Helium (other gases can be used, mass 2 to 92 ) $220 \mathrm{~V}, 50 / 60_{\sim}, 600 \mathrm{VA}$

$10 \mathrm{MV}$ or $100 \mathrm{MV}$ full scale deflection

9 sensitivity ranges $(1,3,10,30,100,300,1000$, $3000,10,000)$

Helium $1 \times 10^{-1}$ a std $\mathrm{cc} / \mathrm{sec}$; argon $1 \times 10^{-1}$ a std $\mathrm{cc} / \mathrm{sec}$; freon $5 \times 10^{-10} \mathrm{std} \mathrm{cc} / \mathrm{sec}$

Yes

$515 \mathrm{~mm}$ (20") wide x $555 \mathrm{~mm}$ (22") high x $475 \mathrm{~mm}$ (18 1/2") deep

Approximately $95 \mathrm{~kg}$ (210 lbs)

$\$ 5400$

Many accessories available for use in conjunction with mass spectrometer 
CONSOLIDATED ELECTRODYNAMICS CORPORATION

(Subsidiary of Bell \& Howell Company)

SPECIFICITY:

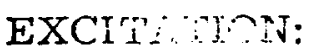

RANGES:

SENSITIVITY:

REPEATABILITY: $\quad \pm 10 \%$

RESPONSE TIME: Less than 1 second to produce $50 \%$ full scale deflection on XI range.

ENVIRONMENT

EFFECTS:

DOES IT FAIL

SAFE:

MAINTENANCE:

LIFE EXPEC-

TANCY:

PORTABILITY:

SIZE:

WEIGHT:

TIME ON MARKET: Approximately 6 years

PRICE:

DELIVERY TIME: Stock item

REMARKS:
Voltage: 105 to $125 \mathrm{~V}$

Temperature: $+40^{\circ} \mathrm{F}$ to $+110^{\circ} \mathrm{F}$ (ambient)

Relative humidity: up to $95 \%$

Yes

Change oil and clean manifold every 6 months

At least 10 years

Is not readily moved unless mounted on a mobile workstand (which is an accessory)

$30^{\prime \prime}$ wide $\times 20^{\prime \prime}$ deep $\times 22^{\prime \prime}$ high

200 lbs (shipping weight - 275 lbs)

$\$ 3375$

Above information is for Model 24-120B; numerous accessories available for user 


\section{DENTON VACUUM, INCORPORATED}

SPECIFICITY:

EXCITATION:

OUTPUT SIGNAL/ IMPEDANCE:

RANGES:

SENSITIVITY:

DOES IT FAIL

SAFE:

MAINTENANCE:

PORTABILITY :

SIZE:

WEIGHT:

REMARKS:
Helium

$115 \mathrm{~V}, 60 \sim 800$ watts

Visual reading on indicating instrument

7 sensitivity ranges $(1,3,10,30,100,300,1000)$

$10^{-1}$ a std $\mathrm{cc} / \mathrm{second}$ if throttled - with longer response time; $10^{-11}$ std $\mathrm{cc} / \mathrm{sec}$ d with produce signal of $2 \%$ of full scale (full pumping speed)

Approximately 1 second dependent on size of connection between leak and leak detector

Yes

As needed

Is mounted on rubber casters

$28^{\prime \prime}$ wide $\times 26^{\prime \prime}$ deep $\times 36^{\prime \prime}$ high

Approximately 300 lbs

Noise level: produces $2 \%$ deflection on output meter

Above information is for Model DLD 1101

Accessories available include audible alarm, helium probe, calibrated helium leak, and sniffer probe. 


\section{GENERAL ELECTRIC COMPANY}

(Vacuum Products Operation)

SPECIFICITY:

Helium

EXCITATION:

115V., 60 15.4 amps for Model LC-20; 7.0 amps for Model LC-10; also available for use at $50_{\sim}$

OUTPUT SIGNAL/

Visual reading on indicating instrument

IMPEDANCE:

RANGES:

4 sensitivity ranges ( $X 1, X 10, X 100, X 1000)$

SENSITIVITY:

$2 \times 10^{-11} \mathrm{std} \mathrm{cc} / \mathrm{sec}$

REPEATABILITY: $\quad \pm 10 \%$

RESPONSE TIME: Less than 1 second

ENVINRONMENT Line voltage between 105 and $125 \mathrm{~V} 60_{\sim}$ for LC 10/20

EFFECTS:

Line voltage between 105 and $125 \mathrm{~V} 50_{\sim}$ for LC 15

DOES IT FAIL

SAFE:

Yes

MAINTENANC:E: $\quad$ aboratory service - approximately annually

'roduction service - from monthly to quarterly

LIFE EXPEC:- Laboratory service - 10 years or more

TANCY:

Production service - up to 10 years

PORTABILITY: $\quad$ Unit mounted on 4 fully swiveling casters

SIZE:

$28^{\prime \prime} \times 25^{\prime \prime} \times 34^{\prime \prime}$ high

W EIGHT:

Model LC-20 345 lbs; Model LC-10 190 lbs

TIME ON MARKET: Since January 1965 - Previous models approximately 10 years $^{\circ}$

PRICE:

$\$ 3850$ to $\$ 5225$ plus accessories

DELIVERY TIME: Stock to 30 days

REMARKS:

Model LC-20 is leak detector with automatic test station

Model LC-10 is leak detector only (accessories available) 
NATIONAL RESEARCH CORPORATION, EQUIPMENT DIVISON

(Subsidiary of Norton Company)

SPECIFICTIY: Helium, also adjustable for hydrogen

EXCITATION: $\quad 115 \mathrm{~V} \mathrm{AC}$, input power: 2200 watts

OUTPUT SIGNAL/ $0-20$ microamperes $/ 2000 \Omega$

IMPEDANCE:

RANGES:

11 ranges $\left(10 \times 10^{-5}\right.$ to $\left.10 \times 10^{-10} \mathrm{std} \mathrm{cc} / \mathrm{sec}\right)$

SENSITIVITY:

$2 \times 10^{-11} \mathrm{std} \mathrm{cc} / \mathrm{sec}$ ( $2 \%$ of most sensitive range)

REPEATABILITY: Good

RESPONSE TIME: Less than 1 second

ENVIRONMENT

Input voltage range: 90 to $125 \mathrm{~V}$ AC

EFF ECTS:

Temperature range: $35^{\circ}$ to $120^{\circ} \mathrm{F}$

DOES IT FAIL Yes

SAFE:

MAINTENANCE: Depends on application; cleaning of cold trap recommended weekly; discharge gauge liner every 2 to 4 weeks

LIFE EXPEC-

Indefinitely long, allowing for replacement of parts

TANCY:

which are subject to wear out or failure

PORTABILITY: $\quad$ Mounted on 4 " pneumatic casters

SIZE:

$40^{\prime \prime}$ wide $\times 25^{\prime \prime}$ deep $\times 351 / 2$ " to work surface $48^{\prime \prime}$ overall height

WEIGHT $600 \mathrm{lbs}$

TIME ON MARKET: 1 year 2 months

PRICE: $\quad \$ 5940$

DELIVERY TIME: 2 weeks

REMARKS:

Above information is for Model 925, which is complete with integral test station.

Various accessories available 
VACUUM INDUSTRIES, INCORPORATED

(Sucsluary of Geophysics Corporation)

SPECIFICITY;

EXCITATION :

SENSITIVITY:

PORTABILITY:

SIZE:

REMARKS:
Helium

$120 \mathrm{~V}, 60 \sim 15 \mathrm{amps}$

$3 \times 10^{-13} \mathrm{std} \mathrm{cc} / \mathrm{sec}$ (Model 1313)

Mounted on 4 swivel casters

$30^{\prime \prime}$ wide $\times 30^{\prime \prime}$ deep $\times 41^{\circ} 1 / 4^{\prime \prime}$ high

Sensing unit is "Inverted Magnetron Cold Cathode Leak Detector"

To obtain maximum sensitivity of $3 \times 10^{-13}$ std cc/sec: A selective pumping system using zeolite and liquid nitrogen trapping is used to reduce the partial pressures of all gases within the system except the critical helium

Unit is completely self contained

Has leak rate meter, output for recorder or remote meter, audible leak monitor, and cold cathode total pressure indicators and all controls required for simple effective operation 
VACUUM INSTRUMENT CORPORATION

$\frac{\text { MODEL NUMBERS }}{\text { MD 100, 100A, 120,120A, } 140 \quad \text { MD190 }}$

\begin{tabular}{|c|c|c|}
\hline SPECIFICITY: & Helium or Argon & Helium \\
\hline EXCITATION: & $115 \mathrm{~V} \mathrm{AC}, 10 \mathrm{amps}$ & $115 \mathrm{~V} \mathrm{AC}, 10$ amps \\
\hline $\begin{array}{l}\text { OUTPUT SIGNAL/ } \\
\text { IMPEDANCE: }\end{array}$ & Panel Meter & Panel Meter \\
\hline RANGES: & Seven & \\
\hline SENSITIVITY: & $\begin{array}{l}1 \times 10^{-4} \mathrm{std} \mathrm{cc} / \mathrm{sec} \text { to } 5 \times 10^{-14} \\
\mathrm{std} \mathrm{cc} / \mathrm{sec}\end{array}$ & $\begin{array}{l}2 \times 10^{-10} \mathrm{std} \mathrm{cc/} \\
\text { sec. }\end{array}$ \\
\hline RESPONSE TIME: & Instantaneous at test port inlet & $\begin{array}{l}\text { Same as other } \\
\text { models }\end{array}$ \\
\hline $\begin{array}{l}\text { ENVIRONMENT } \\
\text { EFFECTS: }\end{array}$ & $\begin{array}{l}\text { Normal factory environment is } \\
\text { recommended; can be used out- } \\
\text { doors in good weather }\end{array}$ & $\begin{array}{l}\text { Same as other } \\
\text { models }\end{array}$ \\
\hline $\begin{array}{l}\text { DOES IT FAIL } \\
\text { SAFE: }\end{array}$ & Yes & \\
\hline $\begin{array}{l}\text { LIFE EXPEC- } \\
\text { TANCY: }\end{array}$ & 10 years & \\
\hline PORTABILITY: & Mounted on rubber casters & $\begin{array}{l}\text { Moveable table } \\
\text { model }\end{array}$ \\
\hline SIZ E: & $34^{\prime \prime}$ wide $\times 24^{\prime \prime}$ deep $\times 30^{\prime \prime}$ high & \\
\hline WEIGHT & Approximately $400 \mathrm{lbs}$ & \\
\hline TIME ON MARKET: & 4 years & New Unit \\
\hline PRICE: & $\$ 4675$ to $\$ 6885$ & $\$ 1975$ \\
\hline DELIVERY TIME: & $2-4$ weeks & \\
\hline REMARKS: & \multicolumn{2}{|c|}{$\begin{array}{l}\text { Accessories available include: Calibra- } \\
\text { ted helium leak, tracer gas sprayer kit, } \\
\text { sampling sniffer probe, audible leak in- } \\
\text { dicator, and test port adapters; units do } \\
\text { not require liquid nitrogen traps; getter } \\
\text { system removes all but noble inert gases }\end{array}$} \\
\hline
\end{tabular}




\section{VARIAN ASSOCIATES \\ (Mikros Division)}

SPECIFIC:ITY:

EXCITATION:

OUTIUTT SIGNAL/

IMPEDANCE:

RANGES:

SFNSITIVITY:

REIPATABILITY:

1)OES IT FAII.

SAFF:

WAINTENANCE:

I.IPF: EXI'EC-

TiNC'Y:

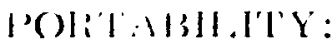

$\therefore 1 / 1 \div:$

W Fil iH':

TIME ON MiliKLY:

PRIC $1:$

IELIVERY TIME: 30 days after receipt of order

REMARKS:

Helium roughing pump system

Meter

$1 \times 10^{-1} \cdots \mathrm{std} \mathrm{cc} / \mathrm{sec}$

Good

No

As needed

Yones

Is mounted on rubber wheels

$16 i^{\prime \prime} \times 27^{\prime \prime}$

$.350 \mathrm{lbs}$

1 year

$\$ 5195$
Approximately 15 amps at $115 \mathrm{~V} 60$ with auxiliary

7 sensitivity ranges $(1,2,5,10,50,100,1000)$

Above information is for Model L,D-100 which includes auxiliary mechanical pump and automatic rough, test and vent valving assemblies

Accessories available 


\section{VEECO INSTRUMENTS, INCORPORATED (Formerly Vacuum Electronics Corporation)}

SPECIFICTIY:

EXCITATION:

RANGES:

SENSITIVITY:

REPEATABILITY

RESPONSE TIME:

ENVIRONMENT EFFECTS:

DOES IT FAIL

SAFE:

MAINTENANCE:

LIFE EXPEC-

TANCY:

PORTABILITY:

SIZ E:

WEIGHT:

PRICE:

REMARKS:
Helium

24 amps at $115 \mathrm{~V}, 60_{\sim}$

7 sensitivity ranges $(1,3,10,30,100,300,1000)$

$1 \times 10^{-10} \mathrm{cc} / \mathrm{sec}$ or 1 part helium in 10 million parts air

Good

Almost instantaneous

Can be used in normal factory environment

Yes; only in automatic operation

Requires frequent tuning of electronics circuitry; piping and vacuum lines cleaned approximately every 2 months to remove out gassing contaminants

No experience in this area

Unit mounted on rubber casters

$41^{\prime \prime}$ wide $\times 273 / 4^{\prime \prime}$ deep x $361 / 2^{\prime \prime}$ high

Approximately 600 lbs

Exact price not known; unit purchased through a rental plan

Above information is for Model MS-9ABC Leak Test and Backfill Station. Accessories available include calibrated leak, helium probe assembly, sniffer kit, reducers, audible alarm, extension cable. 
APPENDIX VII

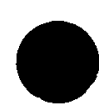

1 
1. Peters, J. L., "Mass Spectrometer Leak Detector With Improved Sensitivity, " Review of Scientific Instruments, 30, 1959, pg. 1093.

2. Daly, N. R, , "High Sensitivity Mass Spectrometer Leak Detector," Review of Scientific Instruments, 31, 1960, pg. 720.

3. Beck, A. H., et al, Handbook of Vacuum Physics, Vol. I, New York, MacMillan, 1964; Chapter by A. H. Turnbull, pp. 153 - 208.

4. Turnbull, A. H., "Leak Detection and Detectors, "Vacuum, 18, 1965, pg. 3.

5. Bialous, A. J., "Characteristics and Sources of Commercially Available Leak Detectors, "General Electric Report No. 5-67-1013, April 1967.

6. Knapp, W. S., Personal Communication, Vacuum Products, General Electric Company, April 1967.

7. Dushman, S., and Laferty, J. M., Scientific Foundations of Vacuum Technique, 2nd Ed., New York, John Wilely and Sons, 1962.

8. Sidwell, L., Personal Communication, Jet Propulsion Laboratory, Pasadena, California, February 1967.

9. Van Atta, C. M., Vacuum Science and Engineering, New York, McGraw Hill, 1965.

10. Langhaar, H. L., "Steady Flow in the Transition Length of a Straight Tube, "Journal of Applied Mechanics, 9, 1942, pg. A-55.

11. Wilke, C. R., "A Viscosity Equation for Gas Mixtures, "Journal of Chemistry and Physics, 18, 1950, pg. 517.

12. Bird, R. B., Stewart, W. E., and Lightfoot, E. M., Transport Phenomena, New York, John Wiley and Sons, 1960.

13. Marr, J. W., and Sherman, J. H., "Application of Leak Testing Theory to Crystal Testing," General Electric TIS Report No. R65-CPD-4, July 1965.

14. Rathbun, F. O., "Design Criteria for Zero-Leakage Connectors for Launch Vehicles, "NAS 8-4012, National Aeronautics and Space Administration George Marshall Space Flight Center, Huntsville, Alabama, December 1963. 
15. Rathbun, F. O., "Design Criteria for Zero Leakage Connectors for Launch Vehicles, "NAS 8-4012, June 1, 1964; Chapter by G. W. Sarney.

16. Creutz, E., "Laminar, Turbulent and Transition Flow in Porous

Media, "Nuclear Science and Engineering, 20, 1964, pg. 28. 